\title{
Groei en productie van fijnspar in Nederland
}

J.J. Jansen ${ }^{1}$, G.M.J. Mohren ${ }^{1}$, A. Oosterbaan ${ }^{2}$ en J. den Ouden ${ }^{1}$

FEM Groei en Productie Rapport 2018 - 2

WAGENINGEN

UNIVERSITY \& RESEARᄃH

1 Forest Ecology and Forest Management group, Wageningen University, Department of Environmental Sciences

2 Nature and Society, Wageningen Environmental Research (WENR) 
Jansen, J.J., G.M.J. Mohren, A. Oosterbaan en J. den Ouden, 2018. Groei en productie van fijnspar in Nederland. FEM Groei en Productie Rapport 2018 - 2, 88 blz.

Synopsis: Van 1951 tot 1989 is in Nederland groei- en productieonderzoek bij de fijnspar uitgevoerd. Dat betreft de studies van Becking en de Dorschkamp/IBN. Tezamen met de permanente steekproeven uit de HOSP zijn 116 proefperken met 388 opnamen beschikbaar. Voor de ontwikkeling van de opperhoogte $h_{\text {top }}$ met de leeftijd $t$ werd het model van Cieszewski gevonden, met site index $h_{50}$ en 3 andere parameters. De diameterontwikkeling tot een opstandhoogte van $7 \mathrm{~m}$ werd het best verklaard met een Gompertz-functie in $h_{\text {top }}$ en het beginstamtal $N_{0}$. Met een powerfunctie werd de grondvlakbijgroei $i_{G}$ verklaard met $h_{\text {top }}$, leeftijd en $S \%$. Voor $S \%>14.7$ daalt de grondvlakbijgroei nietlineair in $S \%$. Het jaar van opname en de site index bleken niet significant.

Het effect van de dunning op de diameter na dunning is gemodelleerd met een gemodificeerd La Bastide-Faber model. Met alle modellen is een stand projection model gemaakt, waarmee de gemeten opstandontwikkeling redelijk voorspeld werd. Er zijn opbrengsttabellen gemaakt met vijf boniteiten en 5 verschillende dunninggraden.

Abstract: From 1951 to 1989 growth and yield research was done on Norway spruce in the Netherlands. This includes studies by Becking and by the Dorschkamp/IBN research institute. Together with the permanent sample plots from the timber prognosis system HOSP, all this comprises a dataset of 116 plots with 388 recordings. For the development of top height $h_{\text {top }}$ with age $t$ Cieszewski's model with site index $h_{50}$ and 3 additional parameters fitted best. The diameter development up to stand height of $7 \mathrm{~m}$ was best described with a Gompertz function based on $h_{\text {top }}$ and initial density $N_{0}$. The basal area increment $i_{G}$ was best described by a power function based on $h_{t o p}$, age and $S \%$. For $S \%>$ 14.7 the basal area increment drops non-linear with S\%. Year of recording and site index were not significant. The effect of thinning on the diameter after thinning was modelled with a modified La Bastide-Faber model. With all models together, a stand projection model was constructed, which describes the measured stand development reasonably well. The model was used to construct yield tables with five site classes and five thinning intensities.

Keywords: Norway spruce, Picea abies, Netherlands, yield tables, thinning intensity, Becking-Hart spacing index, height growth models, power model, basal area increment, Reineke's law, La BastideFaber, stand projection model

Dit rapport is gratis te downloaden op: https://doi.org/10.18174/444089

Dit rapport is gebaseerd op de database: Jansen, J.J., A. Oosterbaan, L.G. Goudzwaard, J.F. Oldenburger, G.M.J. Mohren \& J. den Ouden, 2016. FEM growth and yield data Monocultures - Norway spruce. DANS. http://dx.doi.org/10.17026/dans-ztn-p5uj 


\section{Voorwoord}

Sinds 1951 zijn er in Nederland waarnemingen verricht in permanente proefperken van de fijnspar (Picea abies (L.) H. Karst.). Bartelink et al. (2001) geven een uitgebreid overzicht van de context en publicaties van het groei- en productieonderzoek aan deze en andere boomsoorten in Nederland.

De thans vigerende tabel is die van Jansen en Hildebrand uit 1986. Hierin zijn de data van de Universiteit verwerkt tot ongeveer 1982, dat betreffen maar 8 proefperken met 42 opnamen.

In deze studie is er de beschikking over de gegevens van 128 proefperken en steekproefperken met 439 opnamen, maar niet alle data zijn gebruikt.

In dit rapport wordt de ontwikkeling van opstanden van fijnspar met verschillende dunninggraden geanalyseerd met het doel een groeimodel te maken voor deze ontwikkeling bij een ruim scala aan beheerstrategieën. De studie volgt waar mogelijk dezelfde werkwijze als voor de douglas is gevolgd (Jansen et al., 2016) en in Hoofdstuk 3 wordt de werkwijze zoals gebruik bij de Japanse lariks gevolgd en vaak zijn delen van teksten uit een van beide rapporten gekopieerd en aangepast.

Hans Jansen,

Wageningen, 2018 


\section{Inhoud}

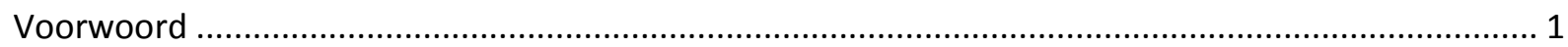

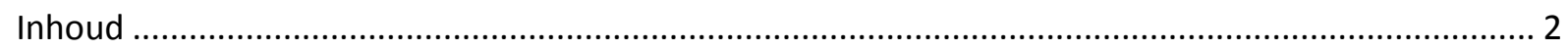

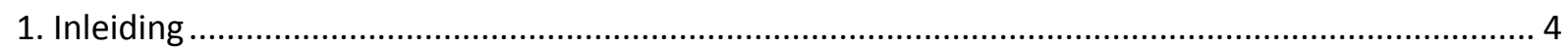

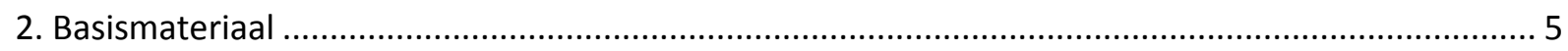

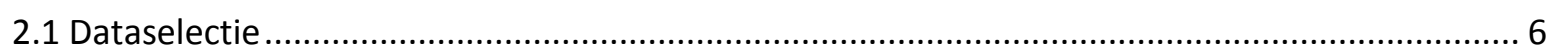

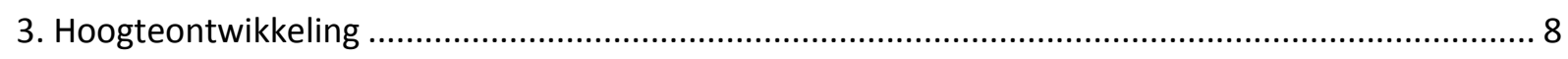

3.1. Modellen voor hoogtegroei ....................................................................................... 8

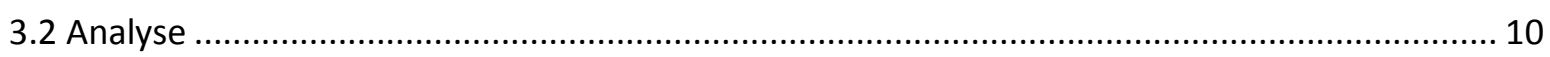

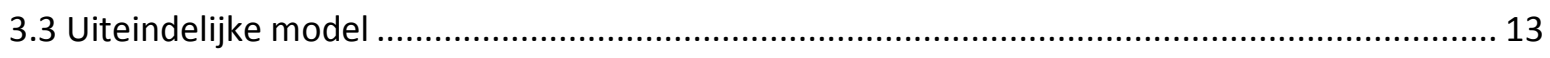

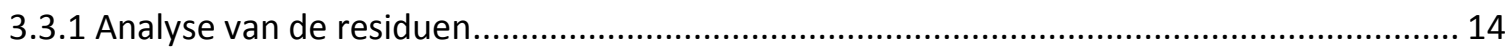

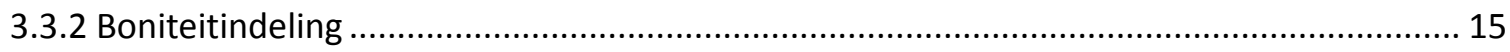

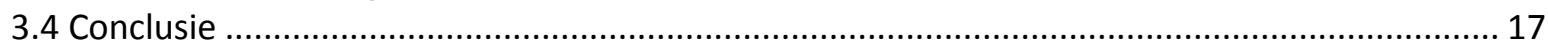

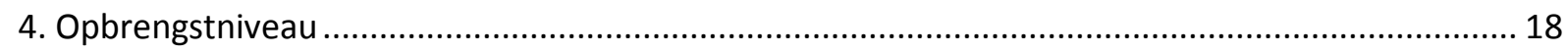

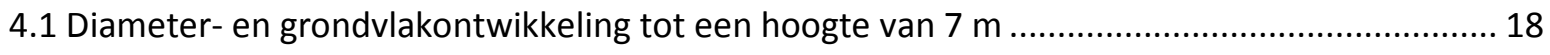

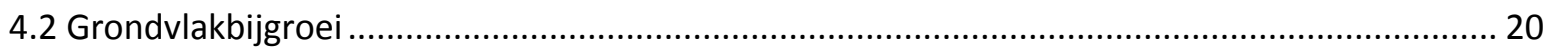

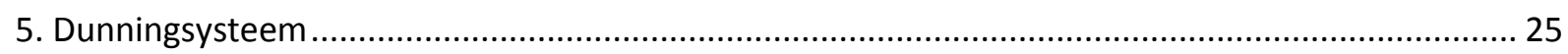

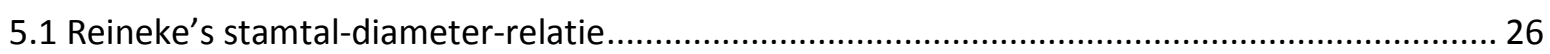

5.2 Model van La Bastide-Faber voor voorspelling diameter na dunning .................................. 27

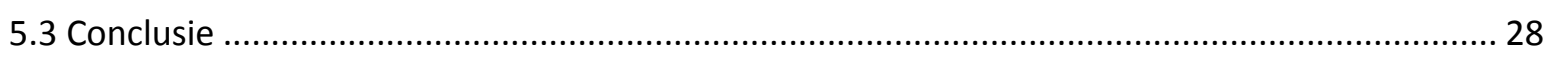

6. Constructie Opbrengsttabellen ................................................................................... 29

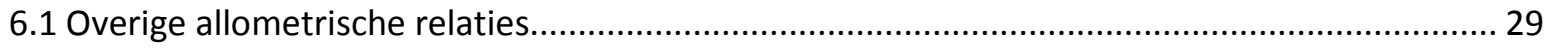

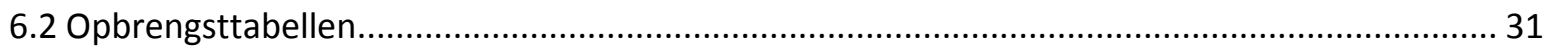

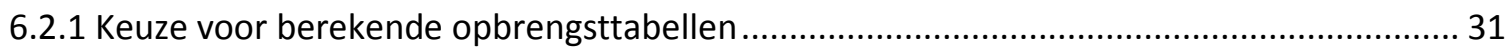

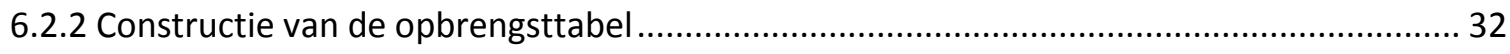

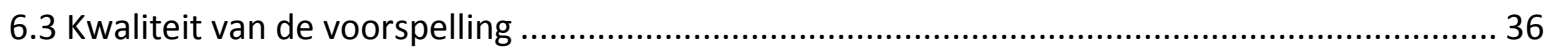

6.4 Vergelijking met andere opbrengsttabellen .............................................................. 37

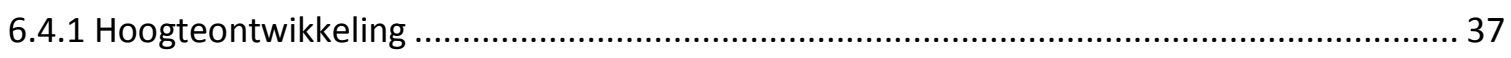

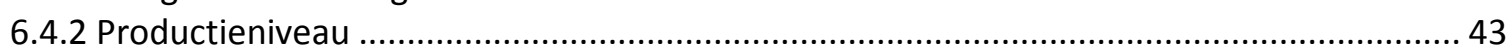

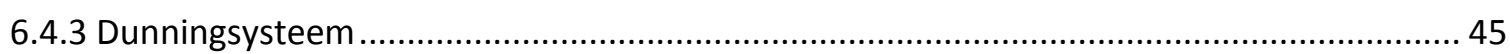

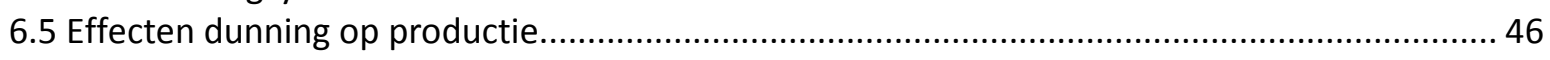

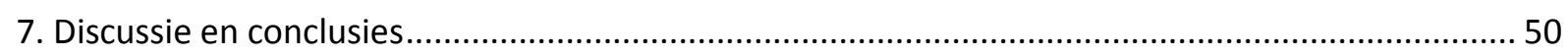

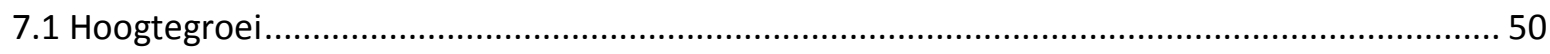

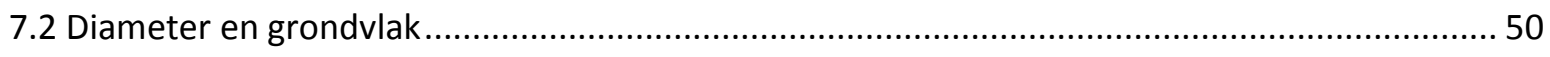

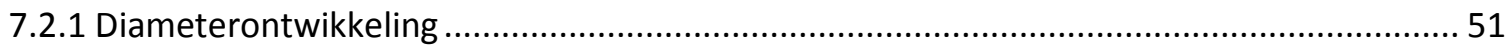

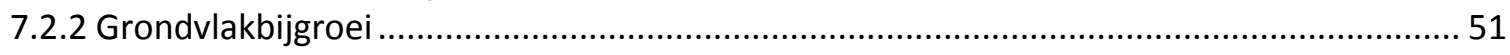

7.3 Variatie in groei tussen verschillende jaren ................................................................. 52 


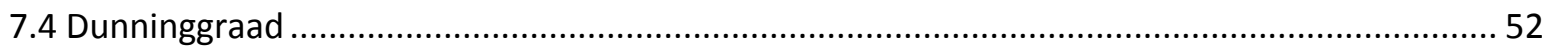

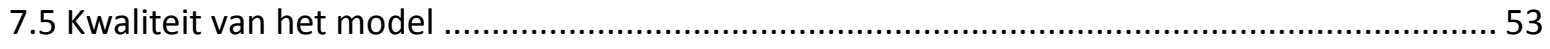

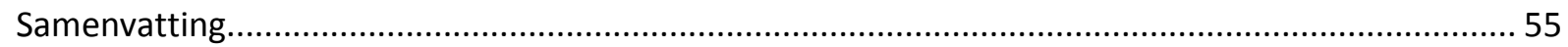

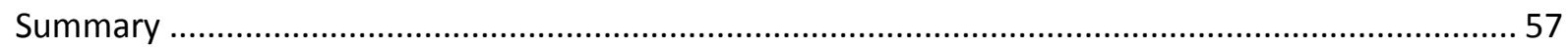

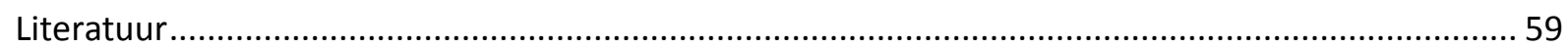

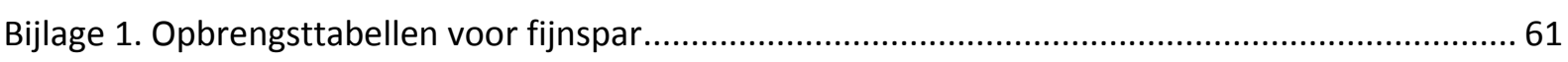

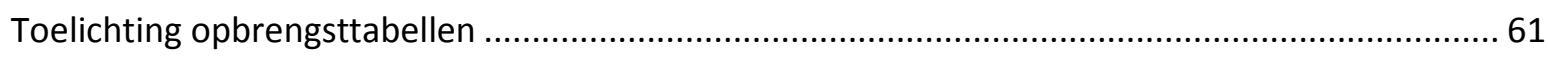

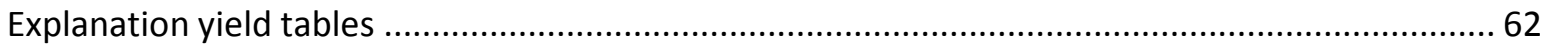

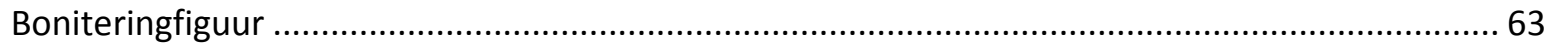

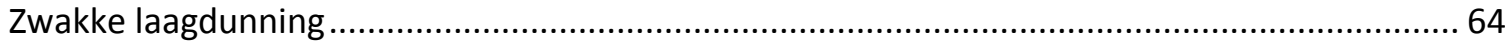

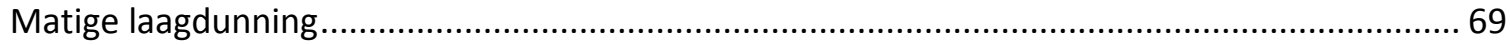

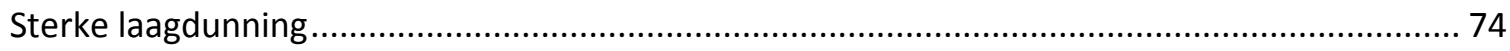

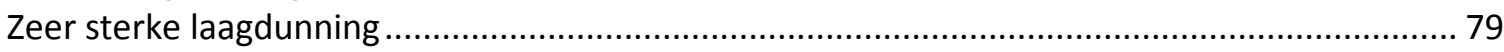

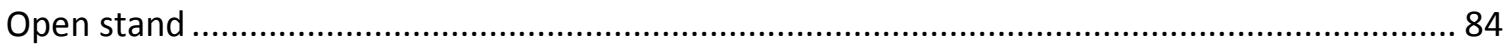




\section{Inleiding}

Tussen 1951 en 1991 zijn er gegevens verzameld over de groei van fijnspar bij verschillende dunninggraden. Met deze gegevens is het mogelijk modellen te maken die de ontwikkeling van fijnsparopstanden bij een variatie aan beheerstrategieën verklaren en mogelijk voorspellen. Eén van de gebruikelijke modellen is een opbrengsttabel. Jansen \& Hildebrand (1986) hebben een opbrengsttabel voor de fijnspar met één dunningregime gemaakt, welk geclassificeerd kan worden als een matige laagdunning. Voor de tabel zelf zie Jansen et al. (1996). Een opbrengsttabel is een model waarmee de opstandontwikkeling in de tijd wordt beschreven en het bestaat meestal uit drie submodellen:

1. Model voor de hoogteontwikkeling, dit wordt In Hoofdstuk 3 besproken;

2. Model voor de grondvlakbijgroei in de tijd of relatief ten opzichte van de hoogte, waarmee het productieniveau van opstanden kan worden voorspeld, dit wordt In Hoofdstuk 4 besproken;

3. Model voor de dunning. Dit model moet een definitie geven van de dunninggraden, daarnaast is het de vraag wat de interactie is met model ad 2 bij verschillende dunninggraden. In Hoofdstuk 5 komen deze vragen aan de orde.

In Hoofdstuk 2 worden de basisgegevens besproken. In Hoofdstuk 6 worden de 3 submodellen geïntegreerd tot een serie opbrengsttabellen. Deze worden vergeleken met andere tabellen en voorspellende kwaliteit van de modellen wordt gekwantificeerd. De tabellen zijn te vinden in Bijlage 1. 


\section{Basismateriaal}

Sinds 1951 is in Nederland onderzoek gedaan naar de ontwikkeling van fijnsparopstanden. In dit onderzoek gaat het om de volgende gebruikte studies:

1. Dunningonderzoek Becking 1951-1982 met 8 fijnspar-proefperken met in totaal 42 opnamen. De behandeling betreft een laagdunning met een vaste dunninggraad, variërend van een zwakke dunning tot een voor die tijd extreem sterke dunning;

2. Groei- en productieonderzoek Dorschkamp/IBN 1959 - 1989 ten behoeve van opbrengsttabellen (La Bastide en Faber, 1972). Er zijn 41 proefperken met 92 opnamen, waarvan 36 met slechts 2 opnamen.

3. Plantafstandproef IBN 1974-1991. Het betreft onderzoek naar groei van bij 3 verschillende plantafstanden 24 proefperken in 3 proefveldcomplexen met in totaal 112 opnamen;

4. HOSP 1984-2000, in beheer bij Probos. Dit zijn ca. 3000 permanente steekproefpunten uit de 4e bosstatistiek. Hieruit zijn 51 monocultures met fijnspar geselecteerd met in totaal 171 opnamen;

7. SBB Drenthe. Series met takkrans posities van gevelde dominante bomen uit 1984. Te zien als 4 proefperken met 22 opnamen van de opperhoogte.

In totaal gaat het om 439 opnamen in 128 proefperken.

De proefvelden van studie 1, 2 en 3 betreffen proefvakken met een vaste oppervlakte. Soms wordt die oppervlakte kleiner door stormschade. De gegevens zijn daarna opnieuw berekend over de kleinste oppervlakte. In studie 4 gaat het om vaste steekproefpunten met een variërende straal zodanig dat er minimaal 25 bomen in de steekproef liggen. Door kap of ingroei kan deze wijzigen. Alleen dat deel wat in alle opnamen aanwezig was is bij het onderzoek betrokken.

Voor het bepalen van de dunninggraad is het S-procent van Hart (1928) (ook bekend als de Hart-Becking Spacing Index) van alle perken en opnamen berekend met formule (1):

$$
S \%=\frac{a_{a t}}{h_{\text {top }}} \cdot 100=\frac{100}{h_{\text {top }}} \cdot \sqrt{\frac{10000}{N_{a t}} \cdot \frac{2}{\sqrt{3}}} \approx \frac{10745.7}{h_{\text {top }} \cdot \sqrt{N_{a t}}}
$$

In deze definitie is de gemiddelde boomafstand na dunning $\left(a_{a t}\right)$ bepaald met een regelmatig driehoekverband. Het symbool $h_{\text {top }}$ staat voor de opperhoogte.

Van alle proefperken zijn basisgegevens als oppervlakte, kiemjaar en ligging bekend. Bij de ligging is onderscheid gemaakt tussen de regio's 1. Noord (Drenthe, Friesland en Groningen, kop van Overijssel), 2. Midden (rest Overijssel, Gelderland, Flevoland, Utrecht en het Gooi), 3. Zuid (Noord-Brabant en Limburg) en 4. West (Flevoland en rest Nederland exclusief de duinen) 5. Kustgebied (Waddeneilanden en duinstrook).

De afzonderlijke metingen en berekeningen aan de bomen in de proefperken vormen de basisgegevens. Deze zijn daarna geaggregeerd tot kenmerken per ha per proefperk van voor, na, en van de dunning. De boomgegevens spelen in deze studie alleen een rol om de opstandkenmerken te genereren. 
Per proefperk en opname zijn de gegevens beschikbaar, zoals vermeld in Tabel 1.

Voor een volledige beschrijving van gemeten en berekende gegevens zie de file "Read me FEM growth and yield data Monocultures - Norway spruce.pdf" in de database FEM growth and yield data Monocultures - Norway spruce (Jansen et al., 2016).

Tabel 1. Basisgegevens per plot en opname.

Table 1. Base information per plot and recording

\begin{tabular}{|l|l|l|}
\hline Naam & Symbool & Betekenis \\
\hline plotnr & & Plotnummer \\
study & & Studienummer \\
region & & Regio \\
area & & Plot oppervlakte in ha \\
yog & Kiemjaar \\
NO & $N_{0}$ & Beginstamtal \\
sperc & $S \%$ & gemiddelde Hart-Becking Spacing Index in plot \\
sperc0 & $S_{0} \%$ & Actuele Hart-Becking Spacing Index in de opname \\
nrec & & Aantal opnamen \\
rec & & Opnamenummer \\
DOR & & Datum van de opname \\
age & $t$ & Leeftijd in jr \\
htop & $h_{t o p}$ & Opperhoogte in $\mathrm{m}$ \\
hdom & $h_{d o m}$ & Dominante hoogte in $\mathrm{m}$ \\
ddom & $d_{d o m}$ & Diameter van de dominante hoogte boom in cm \\
N_bt & $N_{b t}$ & Stamtal per ha voor dunning \\
G_bt & $G_{b t}$ & Grondvlak voor dunning in $\mathrm{m}^{2} /$ ha \\
h_bt & $h_{b t}$ & Hoogte van de grondvlak-middenstam in $\mathrm{m}$ voor dunning \\
dg_bt & $d_{b t}$ & Diameter van de grondvlak-middenstam in $\mathrm{cm}$ voor dunning \\
V_bt & $V_{b t}$ & Volume voor dunning in $\mathrm{m}^{3} / \mathrm{ha}$ \\
N_th & $N_{t h}$ & Stamtal per ha van de dunning \\
G_th & $G_{t h}$ & Grondvlak van de dunning in $\mathrm{m}^{2} /$ ha \\
h_th & $h_{t h}$ & Hoogte van de grondvlak-middenstam in $\mathrm{m}$ van de dunning \\
dg_th & $d_{t h}$ & Diameter van de grondvlak-middenstam in $\mathrm{cm}$ van de dunning \\
V_th & $V_{t h}$ & Volume van de dunning in $\mathrm{m}^{3} /$ ha \\
N_at & $N_{a t}$ & Stamtal per ha na dunning \\
G_at & $G_{a t}$ & Grondvlak na dunning in $\mathrm{m}^{2} /$ ha \\
h_at & $h_{a t}$ & Hoogte van de grondvlak-middenstam in $\mathrm{m}$ na dunning \\
dg_at & $d_{a t}$ & Diameter van de grondvlak-middenstam in $\mathrm{cm}$ na dunning \\
V_at & $V_{a t}$ & Volume na dunning in $\mathrm{m}^{3} / \mathrm{ha}$ \\
& \\
\hline
\end{tabular}

\subsection{Dataselectie}

Een aantal proefperken bevat verdachte gegevens zijn daarom uitgesloten van de analyses, dat betreffen: 
- Plotnummer 22, F102M - Norg. Dit plot heeft op een leeftijd van 15.7 jaar een opperhoogte van $23.6 \mathrm{~m}$, dit is een onwaarschijnlijke waarneming. Vermoedelijk is het kiemjaar fout.

- Plotnummer 79, H0117 - Beetsterzwaag 5. Dit is een plot van 3 are en er zijn dus maar drie opperhoogte-bomen. Van die drie bomen heeft er één onwaarschijnlijke waarnemingen. Namelijk op 35 jaar is de boom 18 m hoog, bij 40 jaar 15 m, bij 44 jaar 21 m en bij 50 jaar $30 \mathrm{~m}$. Het is onduidelijk wat voor fout er is gemaakt.

- Plotnummer 89, H0337 - Smilde 1. In dit plot daalt de opperhoogte van 15.5 m op 12 jaar naar $13.0 \mathrm{~m}$ op 19 jaar ten gevolge van dunning. Onduidelijk is reden hiervan, en past niet in de serie laagdunning. Maar mogelijk gaat het om een twee-etagebos.

- Plotnummer 112, H0799 - Almere 9. In dit plot is de opperhoogte in de $1^{\mathrm{e}}$ opname bij 8 jaar $6 \mathrm{~m}$, in de $2^{\mathrm{e}}$ opname bij 15 jaar $8 \mathrm{~m}$ en in de $3^{\mathrm{e}}$ bij 20 jaar $11 \mathrm{~m}$. Vermoedelijk is hier sprake van een foutief kiemjaar en is de leeftijd 4 à 5 jaar ouder.

- Plotnummer 116, H1264 - Soestdijk. Dit plot heeft op een leeftijd van 135 jaar een opperhoogte van $24 \mathrm{~m}$ en een diameter van $14 \mathrm{~cm}$, dit zijn onwaarschijnlijke waarnemingen. Vermoedelijk is het kiemjaar fout.

- Plotnummer 122, H2406 - Udenoord. In dit plot is de opperhoogte in de $1^{\mathrm{e}}$ opname bij 58 jaar $12.3 \mathrm{~m}$, in de $2^{\mathrm{e}}$ opname bij 65 jaar $13.0 \mathrm{~m}$ en in de $3^{\mathrm{e}}$ bij 70 jaar $16.7 \mathrm{~m}$. Vermoedelijk is er sprake van topsterfte tussen de $1^{\mathrm{e}}$ en $2^{\mathrm{e}}$ opname, maar zo'n sterk herstel is uiterst onwaarschijnlijk voor een plot met een $\mathrm{V}^{\mathrm{e}}$ of lagere boniteit op die leeftijd.

- Plotnummer 123, H2420 - Groesbeek 1. In dit plot is de opperhoogte in de $1^{\mathrm{e}}$ opname bij 94 jaar $21.6 \mathrm{~m}$, in de $2^{\mathrm{e}}$ opname bij 97 jaar $19.9 \mathrm{~m}$ en in de $3^{\mathrm{e}}$ bij 103 jaar $25 \mathrm{~m}$. Vermoedelijk is er sprake van topsterfte tussen de $1^{\mathrm{e}}$ en $2^{\mathrm{e}}$ opname, maar zo'n sterk herstel is uiterst onwaarschijnlijk voor een plot met een $V^{e}$ boniteit op die leeftijd.

- Plotnummer 124, H2920 - Weert 5. In dit plot is de opperhoogte in de $1^{\mathrm{e}}$ opname bij 19 jaar $17.0 \mathrm{~m}$, in de $2^{\mathrm{e}}$ opname bij 31 jaar $15.0 \mathrm{~m}$, in de $3^{\mathrm{e}}$ bij 36 jaar $25 \mathrm{~m}$ en in de $4^{\mathrm{e}}$ opname bij 41 jaar 20.0. Vermoedelijk is er sprake van foutieve waarnemingen.

- Plotnummer 125, FB001 - Smilde 5. Hier is sprake van een plot waar het zeer lang duurde voor een opperhoogte van $7 \mathrm{~m}$ werd bereikt onder normale groeiomstandigheden werd die in de Boswachterij Smilde op een leeftijd van ongeveer 15 bereikt, hier is dat 43 jaar. Hier is de boniteithistorische leeftijd erg afwijkend van de echte leeftijd. Dit is een bekend fenomeen, Jansen et al. (1996) geven aan hoe hiermee om te gaan in de praktijk, maar het plot is ongeschikt voor het maken van opbrengsttabellen.

- Plotnummer 126, FB002 - Smilde 6. Hier is sprake van een plot waar het lang duurde voor een opperhoogte van $7 \mathrm{~m}$ werd bereikt onder normale groeiomstandigheden werd die in de Boswachterij Smilde op een leeftijd van ongeveer 15 bereikt, hier is dat 24 jaar, met dezelfde conclusie als bij plot 125 .

- Plotnummer 127, FB003 - Smilde 7, alleen de hoogte is bekend.

- Plotnummer 128, FB004 - Smilde 8, alleen de hoogte is bekend.

Er resteren 116 plots met 388 waarnemingen. In de plantafstandproef F400 Gieten bestaat uit drie behandelingen met zes herhalingen. Voor de analyse van de hoogteontwikkeling zijn in Hoofdstuk 3 in plaats van de 6 herhalingen de som per behandeling als één 'nieuw' plot gebruikt. Er zijn dan 116-18+3=101 plots met in totaal 310 opnamen voor de analyses. 


\section{Hoogteontwikkeling}

In de studie voor de Japanse lariks en douglas zijn de HOSP-plots als controle gebruik. Van de 101 proefperken met 310 opnamen zijn er echter 47 \% HOSP-plots. Om voldoende dekking te krijgen over het totale spectrum, zijn bij de fijnspar de HOSP-plots ook voor de analyse gebruikt. In Figuur 1a is de hoogte ontwikkeling per plot weergegeven. Daarnaast is er beschikking over de hoogtegegevens van 7760 fijnsparrenopstanden uit de $4^{\mathrm{e}}$ Bosstatistiek (CBS, 1985), zie Figuur $1 \mathrm{~b}$.
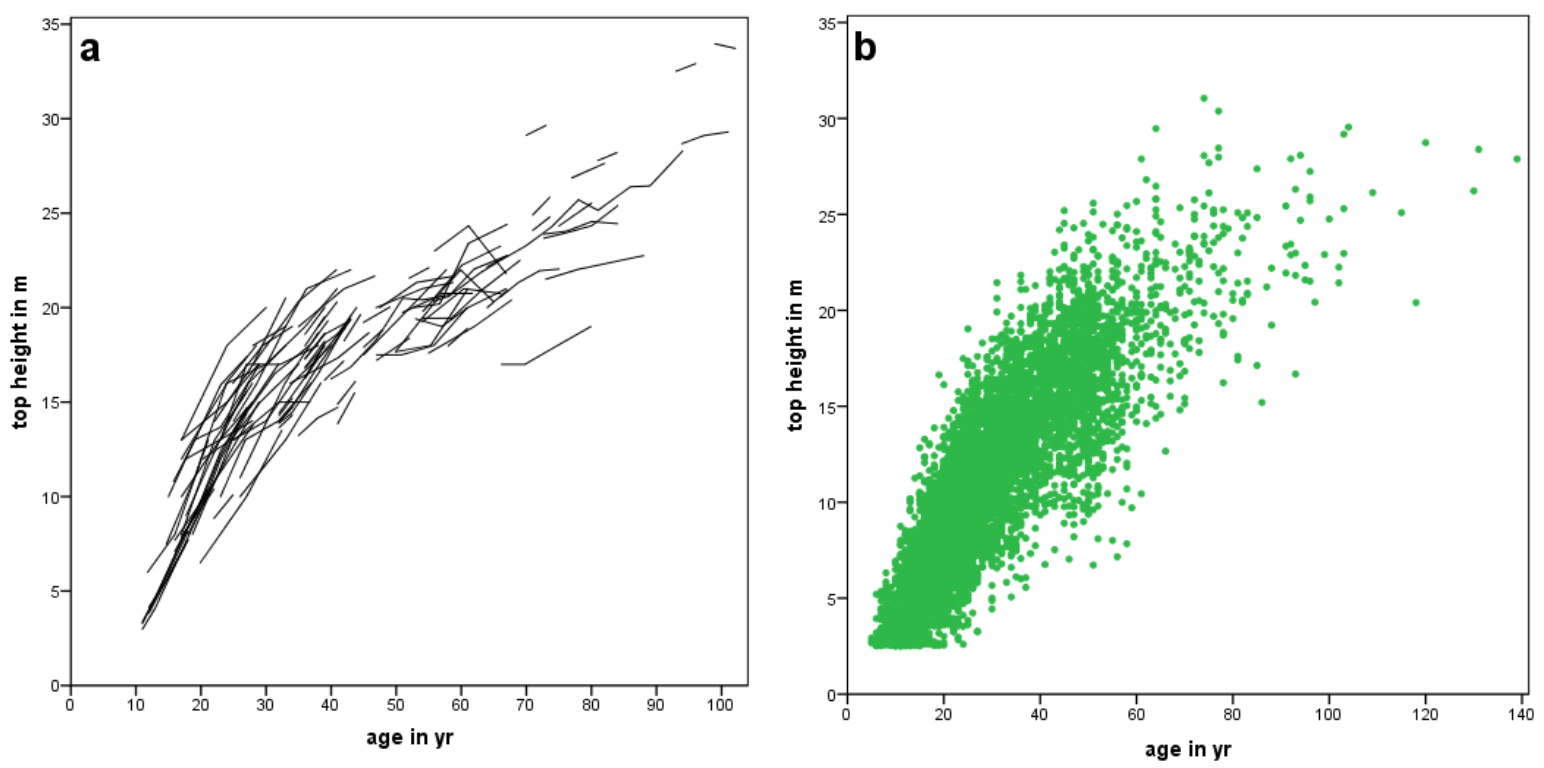

Figuur 1 . Hoogteontwikkeling in de geselecteerde fijnsparproefperken (a) en hoogte en leeftijd bij opstanden in $4^{e}$ Bosstatistiek (b).

Figure 1. Development of tree height in the selected Norway spruce plots (a) and height and age of stands in Fourth National Forest Inventory (b).

Bij enkele perken is er sprake van een lagere hoogte bij een volgende opname. Dit gaat meestal om echte fenomenen en geen fouten in de waarnemingen. Er is sprake van topsterven door incidentele ziekten of plagen of omdat de opstand een hoogte bereikt heeft waarop er een soort evenwicht ontstaat tussen de groei van nieuwe topscheuten en de afbraak ervan. Er is sprake van een afplattingshoogte. Aangezien er ieder jaar weer een nieuwe topscheut wordt gemaakt, is (zolang de bomen leven) er dus geen maximale "gesommeerde hoogtegroei" maar wel een maximale opstandhoogte (als resultante van de groei in de top en van het topsterven). Bij de modelvorming moeten we daar dus rekening mee houden.

\subsection{Modellen voor hoogtegroei}

In de opbrengsttabellen tot ongeveer 1970 is de hoogteontwikkeling meestal handmatig gefit. Vanaf 1970 worden over het algemeen niet-lineaire groeifuncties gebruikt om de hoogteontwikkeling te fitten. In de huidige Nederlandse opbrengsttabel voor de fijnspar is een variant van Chapman-Richards model gebruikt (Jansen \& Hildebrand, 1986):

$$
h_{\text {top }}=S \cdot\left(1-e^{-a \cdot t}\right)^{\left(b_{0}+b_{1} \cdot S\right)}
$$


De te onderzoeken modellen hebben dus een asymptoot, waarvoor hier het symbool $S$ wordt gebruikt, dit is een maat voor de boniteit, daarnaast wordt ook de hoogte bij een vaste leeftijd als maat voor de boniteit gebruikt. Voor de fijnspar zal de $h_{50}$ worden gebruikt.

In Formule (2) is $S$ de zogenaamde "S-waarde" de proefperkspecifieke constante en de asymptoot in het model. Deze $S$ kan gezien worden als de afplattingshoogte en het is tevens een maat voor de boniteit, in dit geval een absolute hoogteboniteit.

Jansen et al. (2018) testten 8 modellen voor de Japanse lariks, drie daarvan scoorden zo laag dat deze niet meer onderzocht zullen worden. De te onderzoeken modellen zijn naast het model van Formule (2), Chapman-Richards, Burkhart-Tennent, Jansen et al. 2016 en Cieszewski.

Jansen et al. (2018) ontwikkelde een selectiemethode voor een model in twee stappen. Als eerste een werd een MCA (Multi criteria-analyse) gebruik met 7 criteria. Daarna een visuele test met de data van de $4^{\mathrm{e}}$ bosstatistiek. De 7 criteria betreffen:

1. De algemene maat voor de verklaring, hiervoor is $R^{2}$ adj gebruikt;

2. De kwaliteit van de schatter van boniteit-parameters door naar de variatiecoëfficiënt $C V$ ervan te kijken. Indien het model voor alle proefperken geschikt is, zal het $95 \%$ betrouwbaarheidsinterval van $C V$ klein zijn;

3. De $h_{50}$ met de gemiddelde waarde en een $95 \%$ betrouwbaarheidsinterval, volgens Figuur 1 a moet dat ongeveer $21 \mathrm{~m}$ zijn en tussen de 14 en $27 \mathrm{~m}$ liggen, maar volgens Figuur $1 \mathrm{~b}$ tussen 10 en $25 \mathrm{~m}$, dus erg nauwkeurig is dit niet te bepalen;

4. De model parameter $S$ en een $95 \%$ betrouwbaarheidsinterval ervan, en getoetst of deze overeenkomt met de te verwachten maximale afplattingshoogte. De hoogst gemeten opperhoogte bleek $34.0 \mathrm{~m}$ bij een leeftijd van $100 \mathrm{jr}$. Bij de opname voor de 4e bosstatistiek (CBS, 1985) is de opperhoogte per opstand geschat. De hoogste waarde voor fijnspar bedroeg $31 \mathrm{~m}$. De hoogste fijnsparren in opstandverband bevinden zich in een menging met douglas op Het Loo en bedragen bij een leeftijd van ruim 150 jaar tussen 39 tot $43 \mathrm{~m}$, zie https://www.monumentaltrees.com/nl/hoogterecords/nld/ (geraadpleegd op 11-2-

2018). De maximale S-waarde voor de beste boniteit voor monoculturen van fijnspar zal daarom 35 à $37 \mathrm{~m}$ mogen bedragen;

5. De leeftijd waarop de borsthoogte wordt bereikt. Op het tijdstip 0 moet de hoogte ook 0 zijn, daarna moet de groei in de jeugd langzaam op gang komen. Een gemiddelde boniteit doet er ongeveer 6 jaar over om borsthoogte te bereiken met een range van 4 tot 10 jaar, maar het kan onder extreme omstandigheden ook veel langer duren. De mate waarin de door het model voorspelde waarde $t_{130}$ en een $95 \%$ betrouwbaarheidsinterval ervan, overeenkomt met deze verwachting;

6. De groei versnelt tot de hoogte ongeveer $8 \mathrm{~m}$, dat moet dus het buigpunt van de curve zijn, zie Figuur 2. De mate waarin de door het model voorspelde waarde voor de hoogte van het buigpunt $h_{\text {if }}$ en een 95\% betrouwbaarheidsinterval ervan overeenkomt met die uit Figuur 2, dus ongeveer bij 8.2 jaar;

7. Het al dan significant zijn van alle parameterschattingen. 


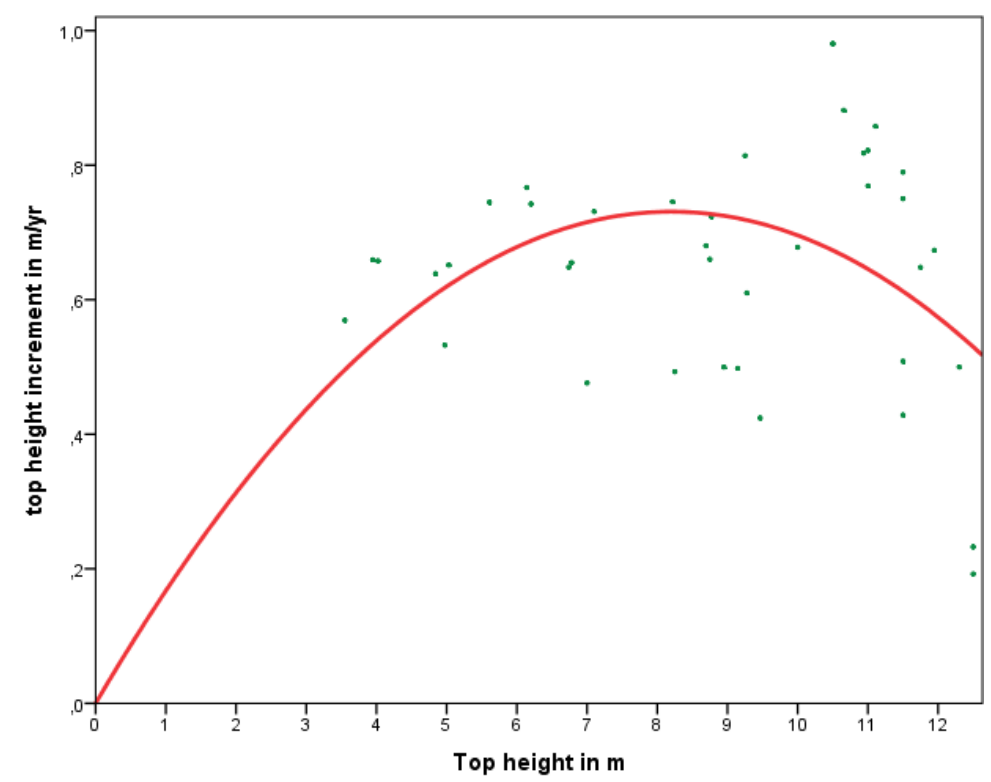

Figuur 2 . Hoogtebijgroei als functie van opperhoogte voor $h_{\text {top }} \leq 13 \mathrm{~m}$. Met rode lijn is de kwadratische fit door de puntenwolk en door de oorsprong, een buigpunt bij 8.2 m.

Figure 2. Height increment as a function of the height for $h_{\text {top }} \leq 13 \mathrm{~m}$. The red line shows the quadratic fit through the measured points and through the origin, an inflection point at $8.2 \mathrm{~m}$.

\subsection{Analyse}

De volgende zes modellen zijn onderzocht.

1. Chapman-Richards (zie Pienaar \& Turnbull, 1973):

$$
h_{\text {top }}=S \cdot\left(1-e^{-a \cdot t}\right)^{b}
$$

2. Burkhart \& Tennent (1977) paste het Chapman-Richard model aan door de parameter $a$ als functie van $S$ uit te drukken waardoor een heteromorf model ontstaat:

$$
h_{\text {top }}=S \cdot\left(1-e^{-\left(a_{0}+a_{1} \cdot S\right) \cdot t}\right)^{b}
$$

3. Jansen \& Hildebrand (1986), zie Formule (2)

4. Jansen et al. (2016) paste dit model aan door een jeugdgroei-component toe te voegen gebaseerd op het model van Korf:

$$
\begin{aligned}
h_{\text {top }}= \begin{cases}f_{1}(t)=x \cdot \frac{e^{-a_{k} \cdot t^{-c}}}{e^{-a_{k} \cdot t_{x}^{c}}} & \text { for } t \leq t_{x} \\
f_{2}(t)=S \cdot\left(1-e^{-a \cdot t}\right)^{\left(b_{0}-b_{1} \cdot s\right)} & \text { for } t>t_{x}\end{cases} \\
\text { where } t_{x}=-\frac{\ln \left(1-(x / s)^{1 / b}\right)}{a} \text { for } h_{\text {top }}=x \text { and } a_{k}=\frac{a \cdot b}{c \cdot t_{x}^{-c-1} \cdot\left(e^{a \cdot t_{x}}-1\right)}
\end{aligned}
$$

Voor de grenswaarde voor de jeugdgroei gebruikten ze $x=7 \mathrm{~m}$. 
5. Het Cieszewski model (2001) gebruikt een referentieleeftijd, voor 50 jaar luidt het:

$$
h_{\text {top }}=h_{50} \cdot \frac{t^{a} \cdot\left(50^{a} \cdot R+b\right)}{50^{a} \cdot\left(t^{a} \cdot R+b\right)}, \text { where } R=Z+\sqrt{Z^{2}+\frac{2 \cdot b \cdot h_{50}}{50^{a}}} \text { and } Z=h_{50}-c
$$

Dit heteromorfe model heeft wel een asymptoot, maar de oplossing moet gevonden worden met formule (6).

Een probleem bij het schatten van de parameters van de modellen is dat naast de 1, 2 of 3 parameters van het model ook de boniteit (de 101 proefperkparameters $S$ of $h_{50}$ ) moeten worden geschat. "Zo wordt bijvoorbeeld het Chapman-Richards model (3) herschreven tot

$$
h_{\text {top }, i j}=\left(\sum_{i=1}^{101} S_{i} \cdot x_{i}\right) \cdot\left(1-e^{-a \cdot t_{i j}}\right)^{b} \text { for the } j^{\text {th }} \text { recording in the } i^{\text {th }} \text { plot }
$$

Hierin is $x_{i}$ een variabele die 1 is in het $i^{\text {de }}$ perk en 0 elders.

Om dit probleem te vermijden geven La Bastide en Faber (1972) een oplossing, door niet $h_{\text {top }}$ te schatten maar de relatieve groei ervan:

$$
y=\frac{d h_{\text {top }}}{d t} \cdot \frac{1}{h_{\text {top }}}=\frac{\left(h_{\text {top } 2}-h_{\text {top } 1}\right)}{\left(t_{2}-t_{1}\right) \cdot\left(h_{t o p 1}+h_{t o p 2}\right) / 2}
$$

Met de huidige rekencapaciteit is dat niet meer nodig, maar hiermee kunnen wel goede beginschatters voor de modelparameters worden gevonden. In Figuur 3 is deze relatieve groei tegen de leeftijd uitgezet, met de hier getoonde grote variatie zal een duidelijk beste model niet eenduidig te bepalen zijn. Juist de moeilijk te bepalen jeugdgroei is bepalend. 


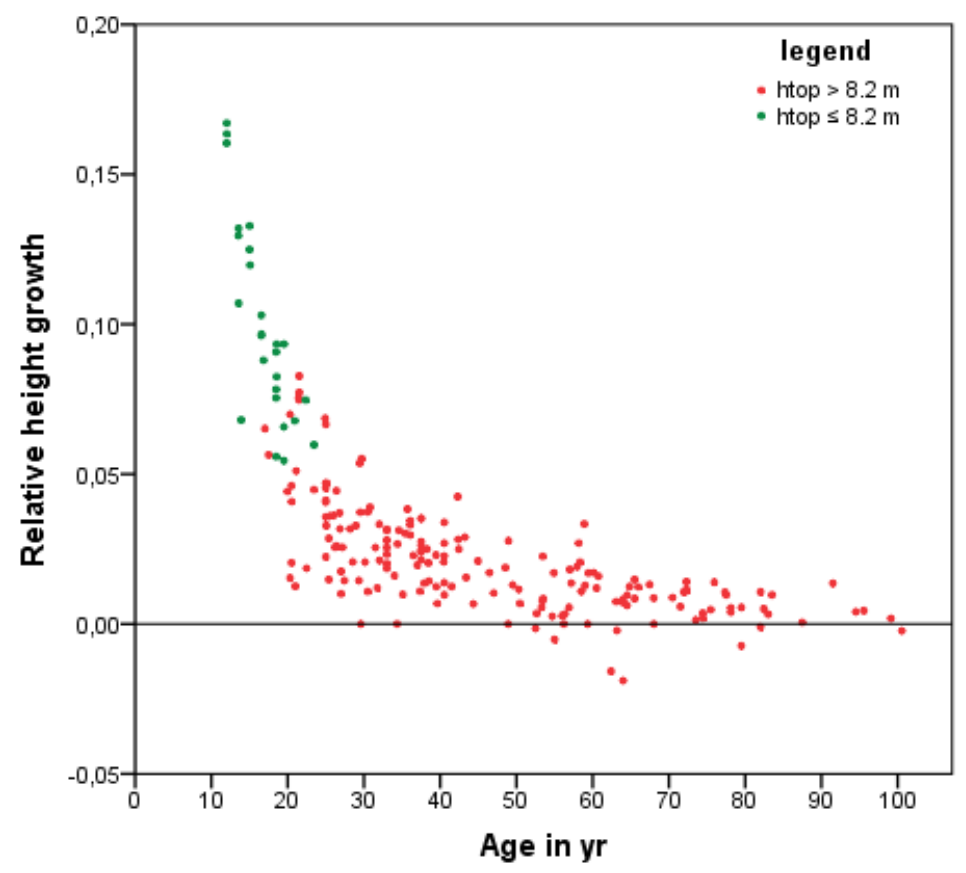

Figuur 3. Relatieve hoogtegroei als functie van de leeftijd. Negatieve waarden duiden op topsterfte (uiteraard kan er in een lang meetinterval ook bij een positieve relatieve hoogtegroei sprake van topsterven zijn geweest).

Figure 3. Relative height increment as a function of age. Negative values indicate dieback (over a long time interval, dieback may have also occurred, despite an overall positive relative height increment).

Met een Multi criteria-analyse (MCA) met de 7 criteria van Pagina 9 met gelijk gewicht zijn de resultaten beoordeeld. In tabel 2 zijn de resultaten weergegeven van de regressieanalyse van de opperhoogte met de besproken modellen. In de bovenste helft van de Tabel 2 de absolute waarde voor de criteria opgenomen. In het onderste deel van de tabel is de volgorde van resultaat (beste $=1$ en slechtste is 5 ) gegeven ( 2.5 betekent gedeelde $2^{\mathrm{e}}$ en $3^{\mathrm{e}}$ plaats). Daarmee is de keuze gevallen op het model van Cieszewski.

Tabel 2. Resultaten van niet-lineaire regressie met de geselecteerde modellen in MCA. Table 2. Results of nonlinear regression for the selected models in MCA.

\begin{tabular}{|c|c|c|c|c|c|c|c|c|c|c|}
\hline & model & $n_{\text {par }}{ }^{*}$ & $R^{2}$ adj & $C V_{-} S$ & $h_{50}$ & $S$ & $t_{130}$ & $\boldsymbol{h}_{\text {if }}$ & s/ns & result \\
\hline \multirow{5}{*}{$\frac{\mathscr{J}}{\frac{\partial}{\sigma}}$} & Chapman-Richards & 2 & 0.977 & $6\{3 ; 9\}$ & $21\{14 ; 32\}$ & $33\{22 ; 49\}$ & $4\{3 ; 5\}$ & $6\{4 ; 8\}$ & $\mathrm{s}$ & 4 \\
\hline & Burkhart \& Tennent & 3 & 0.979 & $6\{2 ; 10\}$ & $21\{14 ; 30\}$ & $30\{23 ; 37\}$ & $5\{3 ; 6\}$ & $6\{5 ; 7\}$ & ns & 2 \\
\hline & Jansen \& Hildebrand & 3 & 0.982 & $3\{2 ; 4\}$ & $21\{12 ; 38\}$ & $28\{23 ; 33\}$ & - & - & ns & 5 \\
\hline & Jansen et al. & 4 & 0.982 & $4\{2 ; 5\}$ & $21\{12 ; 33\}$ & $29\{23 ; 34\}$ & $10\{3 ; 17\}$ & $1\{0 ; 11\}$ & ns & 3 \\
\hline & Cieszewski & 3 & 0.982 & $3\{1 ; 5\}$ & $21\{13 ; 30\}$ & $31\{30 ; 35\}$ & $4\{4 ; 8\}$ & $9\{8 ; 9\}$ & ns & 1 \\
\hline \multirow{6}{*}{ 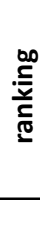 } & Chapman-Richards & 2 & 5 & 4 & 3 & 5 & 3 & 2 & 1 & 23 \\
\hline & Burkhart \& Tennent & 3 & 4 & 5 & 1 & 1 & 2 & 3 & 3.5 & 19.5 \\
\hline & Jansen \& Hildebrand & 3 & 2 & 1 & 5 & 4 & 5 & 5 & 3.5 & 25.5 \\
\hline & Jansen et al. & 4 & 1 & 3 & 4 & 3 & 4 & 4 & 3.5 & 22.5 \\
\hline & Cieszewski & 3 & 3 & 2 & 2 & 2 & 1 & 1 & 3.5 & 14.5 \\
\hline & best score & & $\max$ & $\min$ & $21\{14 ; 27\}$ & $\leq 37$ & $6\{4 ; 10\}$ & 8.2 & $\mathrm{~s}$ & \\
\hline
\end{tabular}

${ }^{*} n_{\text {par }}=$ aantal model parameters exclusief de 101 parameters voor de boniteit.

In Figuur 4 zijn de data van de lijnen behorend bij de beste en slechtste boniteit tezamen met de waarnemingen van de $4^{\mathrm{e}}$ Bosstatistiek getekend. 


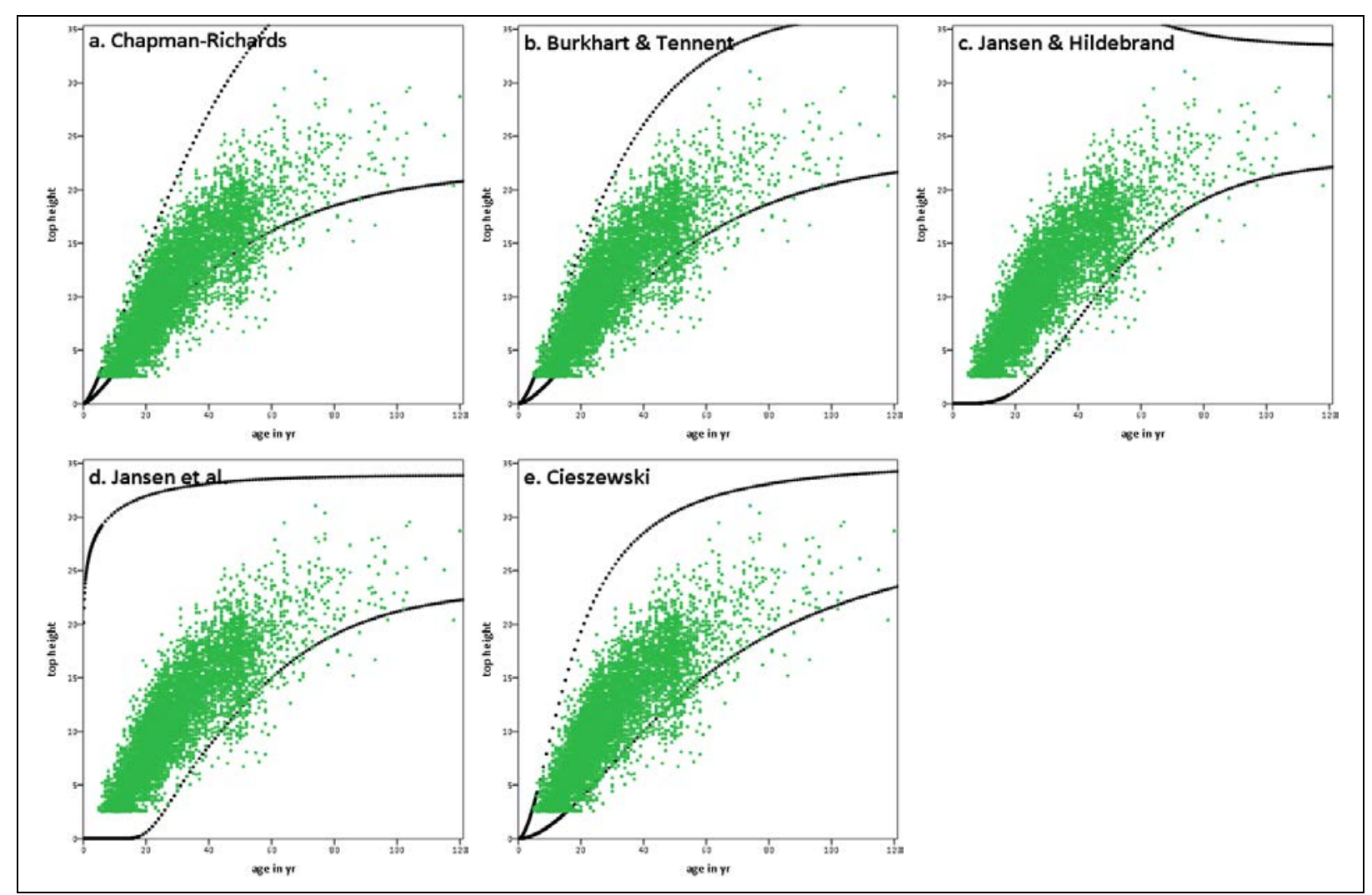

Figuur 4. Hoogtewaarnemingen $4^{e}$ Bosstatistiek en curven van de laagste en hoogste boniteit per model.

Figure 4. Top height observations in $4^{\text {th }}$ Dutch Forest Inventory with lowest and highest site curves per model.

In Figuur 4 is te zien dat zowel het model van Jansen \& Hildebrand als dat van Jansen et al. een onmogelijke combinaties van $b_{0}$ en $b_{1}$ opleveren voor de extremen. Bij Jansen \& Hildebrand ontstond zelfs een negatieve $b$. De ondergrens van het model van Cieszewski sluit redelijk aan bij de data van de $4^{\mathrm{e}}$ Bosstatistiek, dat geldt niet voor de bovengrens.

In een voorstudie zijn met gewogen gemiddelden de data van de $4^{\mathrm{e}}$ Bosstatistiek in 4 groepen ingedeeld en de modellen getest op de wijze zoals dat bij de beuk is gebeurd. Ook hier bleek het model van Cieszewski het best. Er bleek echter een zeer groot verschil tussen de $b$ parameters uit Formule (6) in beide datasets, voor de proefperken net iets meer als 0 en niet significant en voor de $4^{\mathrm{e}}$ Bosstatistiek was dat 2181.7777 en wel significant. $\mathrm{Er}$ is daarom besloten model (6) te fitten met als voorwaarde $b>2181.7777$. De $R^{2}$ adj bleef afgerond gelijk, namelijk 0.982.

\subsection{Uiteindelijke model}

In formule (9) en alle volgende vergelijkingen die een onderdeel van het opbrengstmodel vormen worden de parameters genummerd als $c_{1}, c_{2}, c_{3}$ enzovoorts. Het model van Cieszewski (2002) luidt dan:

$$
h_{\text {top }}=h_{50} \cdot \frac{t^{c_{1}} \cdot\left(50^{c_{1}} \cdot R+c_{2}\right)}{50^{c_{1}} \cdot\left(t^{c_{1}} \cdot R+c_{2}\right)} \text {, where } R=Z+\sqrt{Z^{2}+\frac{2 \cdot c_{2} \cdot h_{50}}{50^{c_{1}}}} \text { and } Z=h_{50}-c_{3}
$$


In Tabel 3 zijn de parameters en enige andere modeleigenschappen weergegeven

Tabel 3. Parameters en andere eigenschappen voor hoogteontwikkeling met Model (9)

Table 3. Parameters and other characteristics for height development with Model (9).

\begin{tabular}{|c|c|c|c|c|c|c|c|c|c|}
\hline & & & \multicolumn{3}{|c|}{ Parameter Estimates } & \multirow[b]{2}{*}{$s$} & \multirow[b]{2}{*}{$h_{50}$} & \multirow[b]{2}{*}{$t_{130}$} & \multirow[b]{2}{*}{$h_{\text {if }}$} \\
\hline$R^{2}$ & $R^{2}$ adj & RMSE & Parameter & Estimate & Std. Error & & & & \\
\hline \multirow{3}{*}{0.988} & & & $c_{1}$ & 1.7859 & 0.089 & & & & \\
\hline & 0.982 & 0.77 & $c_{2}$ & 2181.7777 & 2704.007 & $33.5\{30.0 ; 35.4\}$ & $21.2\{12.8 ; 30.5\}$ & $5.8\{2.9 ; 10.4\}$ & $8.5\{8.1 ; 9.6\}$ \\
\hline & & & $c_{3}$ & 29.2173 & 2.631 & & & & \\
\hline
\end{tabular}

In Figuur 5 is de met Formule (9) voorspelde opperhoogte uitgezet tegen de gemeten opperhoogte, er blijkt enige onzuiverheid bij lage waarden tot ongeveer $10 \mathrm{~m}$. Bij bijvoorbeeld $7 \mathrm{~m}$ is er een overschatting met $20 \mathrm{~cm}$.

\subsubsection{Analyse van de residuen}

Bij lineaire regressie is het gebruikelijk naar uitbijters te kijken om fouten op te sporen. De residuen van de CNLR met Formule (9) zijn uitgezet tegen de systeemvariabelen leeftijd en $h_{50}$ (Figuur 6).

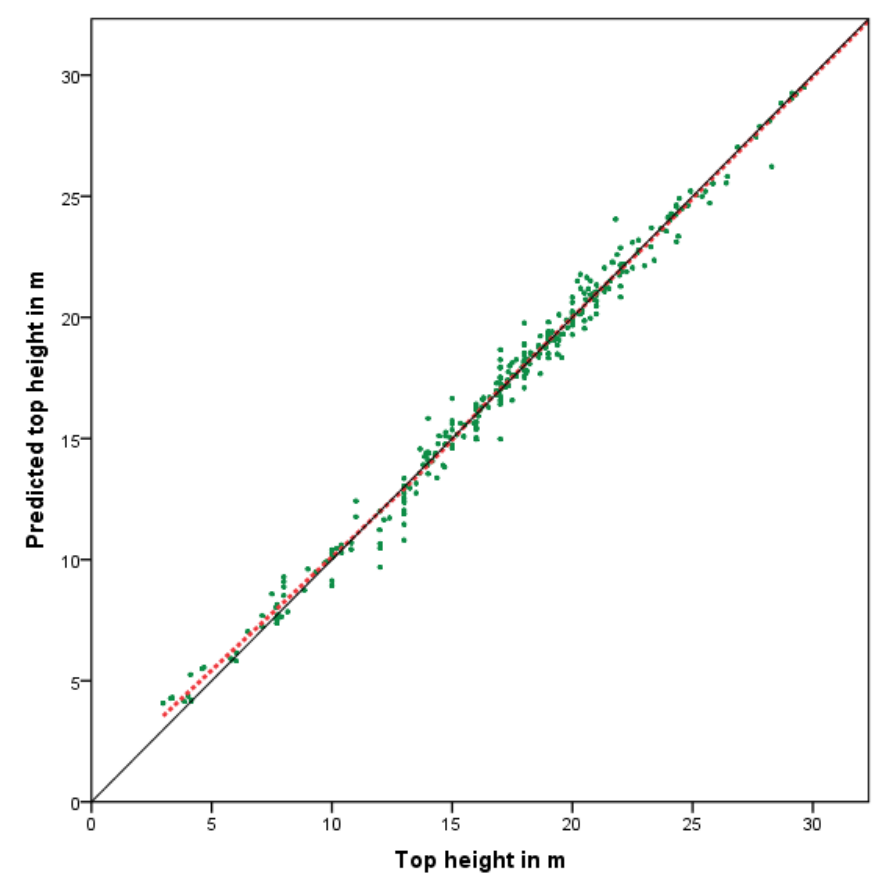

Figuur 5. Voorspelde opperhoogte met Formule (9) in relatie met gemeten opperhoogte op tijdstip van de waarneming. De rode lijn geeft het voortschrijdend gemiddelde weer, de zwarte lijn geeft de perfecte fit met een hoek van $45^{\circ}$ weer.

Figure 5. $\quad$ Predicted top height with model (13) in relation with observed top height at recording time. The red line represents the moving average, the black line the perfect fit with an angle of $45^{\circ}$. 

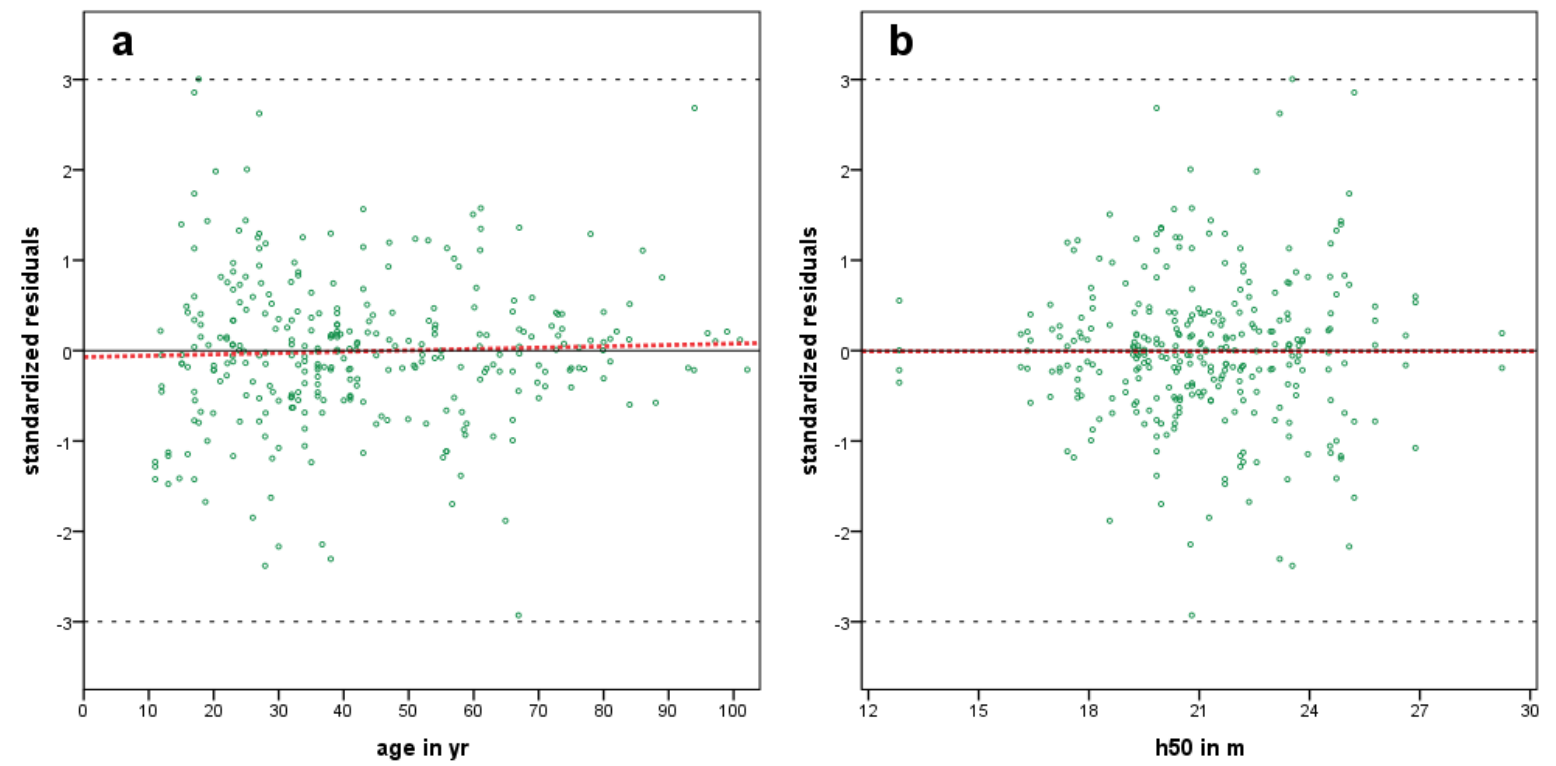

Figuur 6. Residuen in relatie tot leeftijd (a) en $h_{50}(b)$, de rode lijn geeft de lineaire fit weer.

Figure 6. Residuals in relation to top height (a) and $h_{50}(b)$, the red line is the linear fit.

In Figuur 6a is te zien dat er een geringe onzuiverheid is in het model ten opzichte van de leeftijd, deze is echter niet significant. Er zijn ook geen uitbijters aanwezig.

\subsubsection{Boniteitindeling}

Met de gegevens van de $4^{\mathrm{e}}$ bosstatistiek (CBS, 1985) is van 7760 monocultures met fijnspar de $h_{50}$ bepaald volgens de methode van Jansen et al. (2016). Dit leidt tot de verdeling over de $h_{50}$ zoals weergegeven in Figuur 7.

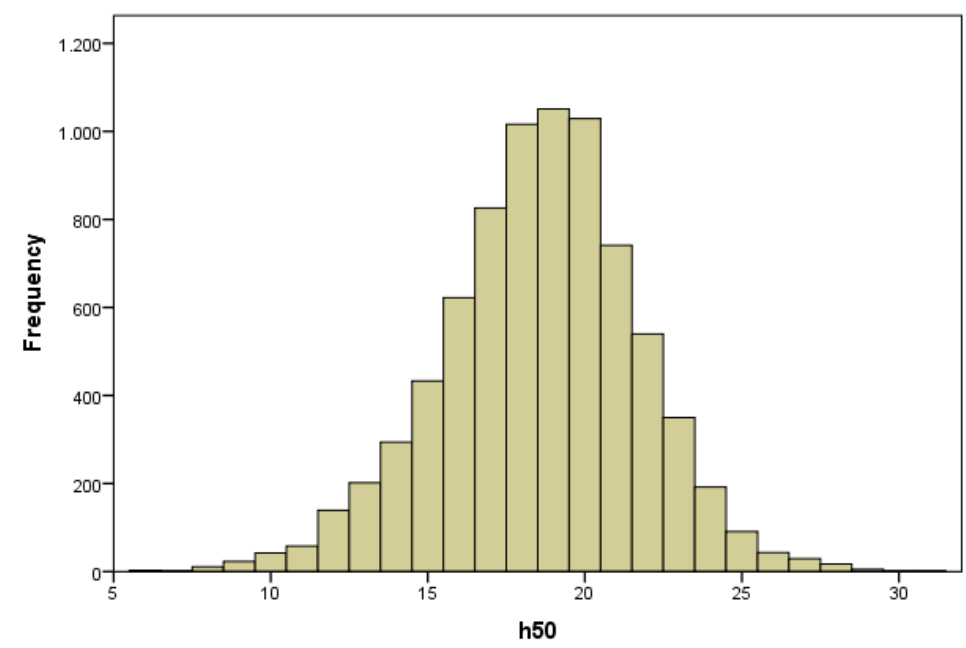

Figuur 7. Frequentiehistogram van $h_{50}$ in $4^{e}$ Bosstatistiek.

Figure 7. Frequency histogram of $h_{50}$ in the $4^{\text {th }}$ National Forest Inventory.

Het frequentiehistogram van Figuur 7 is redelijk normaal verdeeld. De gemiddelde $h_{50}$ bedraagt 19.6 en ligt tussen 6.0 en $31.4 \mathrm{~m}$. In de plotdata was dat $21.2\{12.8 ; 30.5\}$, dus vooral 
aan de onderkant is de marge veel groter in de data van de $4^{\mathrm{e}}$ Bosstatistiek. Er is gekozen om het deel tussen 10.7 en $25.7 \mathrm{~m}$ in 5 boniteiten in te delen. Zie Tabel 4 voor het resultaat. Met deze indeling heeft $1.0 \%$ van alle opstanden van de fijnspar een betere boniteit dan de $\mathrm{I}^{\mathrm{e}}$ en $1.2 \%$ heeft een slechtere boniteit dan de $\mathrm{V}$.

Tabel 4. Indeling in boniteiten gebaseerd op de $\boldsymbol{h}_{50}$.

Table 4. Classification in site classes based on the $h_{50}$.

\begin{tabular}{|c|c|c|r|r|}
\hline $\begin{array}{c}\text { Boniteit } \\
\text { site class }\end{array}$ & $\begin{array}{c}\boldsymbol{h}_{\mathbf{5 0}} \\
\boldsymbol{h}_{50}\end{array}$ & $\begin{array}{c}\text { Bereik } \boldsymbol{h}_{\mathbf{5 0}} \\
\text { range } h_{50}\end{array}$ & $\begin{array}{r}\text { \% in dataset } \\
\text { \% in data set }\end{array}$ & $\begin{array}{r}\text { \% in 4 } \\
\text { \% in 4th forest inventory }\end{array}$ \\
\hline$<$ I & & $>25.7$ & 4.2 & 1.0 \\
I & 24.2 & $(22.7-25.7)$ & 21.6 & 7.3 \\
II & 21.2 & $(19.7-22.7)$ & 45.2 & 28.2 \\
III & 18.2 & $(16.7-19.7)$ & 25.2 & 38.1 \\
IV & 15.2 & $(13.7-16.7)$ & 2.6 & 18.5 \\
V & 12.2 & $(10.7-13.7)$ & 1.3 & 5.6 \\
$>$ V & & $<10.7$ & & 1.2 \\
\hline
\end{tabular}

In de dataset blijken de betere boniteiten oververtegenwoordigd, wat ook bij de eerder geanalyseerde datasets het geval was.

De verdeling over de leeftijdsklassen binnen de boniteiten is niet homogeen, hetgeen ook wel zonder toets van aanpassing te zien is, zie Tabel 5. Er van uitgaande dat in de echte situatie in het Nederlandse bos wel sprake is van een homogene verdeling, dan blijkt jong bos met de nieuwe parametercombinatie te hoog te worden geboniteerd en oud bos te laag. In Figuur 8 a is de hoogteontwikkeling per boniteit samen met die van de proefperken en in Figuur $8 \mathrm{~b}$ samen met de gegevens van de $4^{\mathrm{e}}$ Bosstatistiek weergegeven. Opstanden met leeftijden boven 120 jaar zijn in Figuur 8b weggelaten.

Tabel 5. Aantal opstanden per leeftijdsklassen en boniteit in $4^{\mathrm{e}}$ Bosstatistiek.

Table 5. Age classes per site class in $4^{\text {th }}$ National Forest Inventory (number of stands).

\begin{tabular}{|c|rrrrr|r|}
\hline leeftijdsklasse & $\mathbf{S}$ I & II & III & IV & $\mathbf{\geq ~ V}$ & totaal \\
\hline $0-10$ & 128 & 73 & 13 & & & 214 \\
$10-20$ & 300 & 761 & 771 & 271 & 53 & 2156 \\
$20-30$ & 147 & 808 & 1097 & 419 & 102 & 2573 \\
$30-40$ & 28 & 343 & 487 & 271 & 86 & 1215 \\
$40-50$ & 21 & 140 & 399 & 267 & 130 & 957 \\
$50-60$ & 7 & 42 & 126 & 138 & 102 & 415 \\
$60-70$ & 6 & 9 & 28 & 39 & 30 & 112 \\
$70-80$ & 6 & 8 & 24 & 15 & 10 & 63 \\
$80-90$ & & 1 & 7 & 7 & 6 & 21 \\
$90-100$ & & 4 & 4 & 8 & 5 & 21 \\
$>100$ & 2 & 2 & 3 & 3 & 3 & 13 \\
\hline Totaal & 645 & 2191 & 2959 & 1438 & 527 & 7760 \\
\hline
\end{tabular}

In Figuur 8 a is juist te zien dat de boniteit van veel jong bos in de loop van de tijd een betere boniteit krijgt. Er is dus een discrepantie tussen de conclusie bij Tabel 5 en Figuur 8. Dit komt omdat de bij Model (9) gevonden parameters van Tabel 3 een compromis betreft tussen 
groei in de permanente proefperken en de gemiddelde situatie uit de $4^{\mathrm{e}}$ Bosstatistiek. Het compromis betrof de voorwaarde voor een zeker minimum voor $c_{2}$ bij de oplossing in Formule (9), gebaseerd op de data uit de $4^{\mathrm{e}}$ Bosstatistiek.
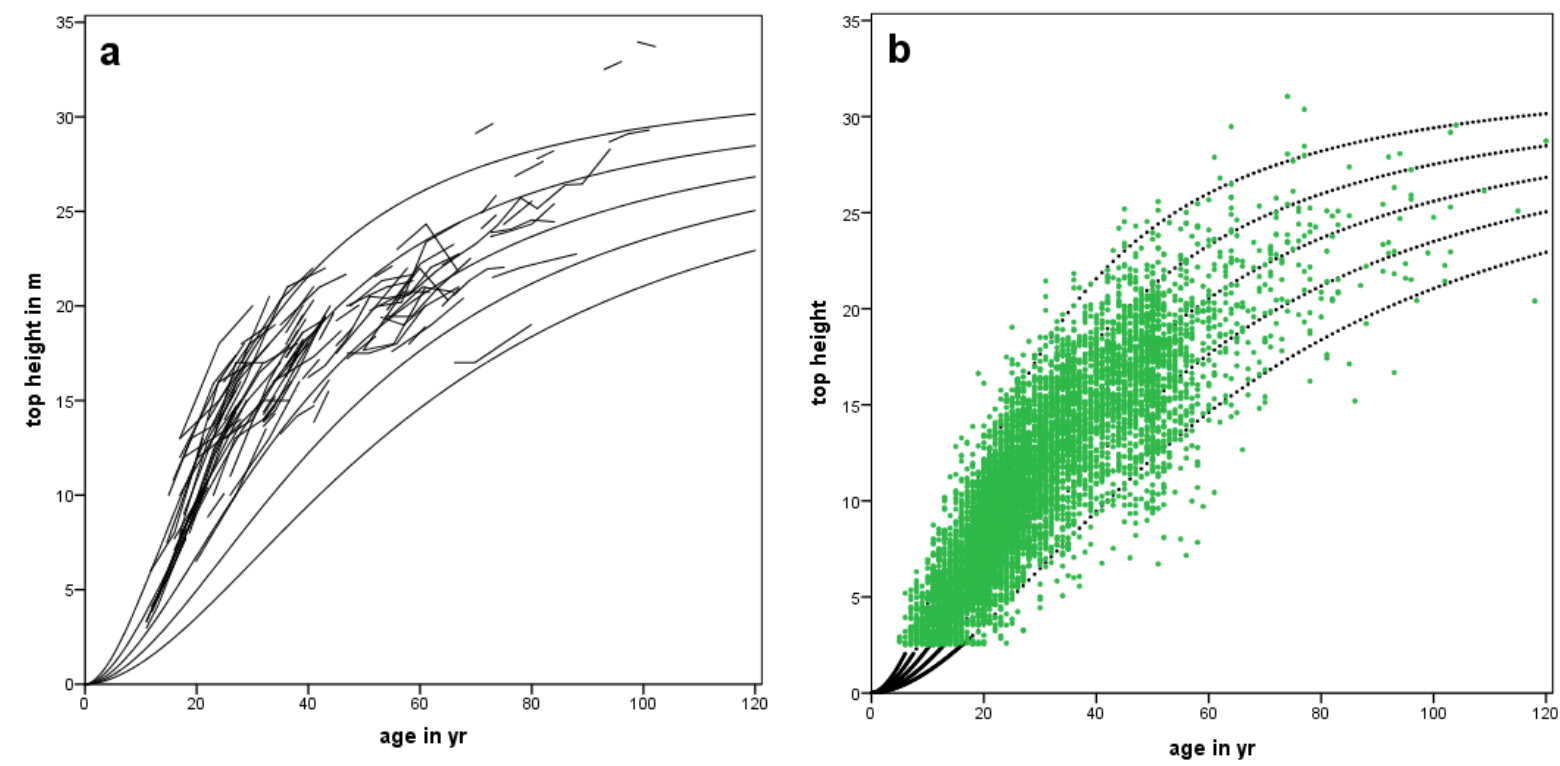

Figuur 8. Boniteitcurven voor de fijnspar in Nederland met de hoogteontwikkeling van de proefperken(a) en met de waarnemingen van de $4^{e}$ Bosstatistiek (b).

Figure 8. Top height development of the plots (a) and data $4^{\text {th }}$ National Forest Inventory (b) both with site curves.

\subsection{Conclusie}

Geen enkel model voldeed voldoende aan de uitgangscriteria. Het model van Cieszewski benaderde dit het best, hiermee is een indeling in 5 boniteiten gemaakt. Ongeveer $1 \%$ van de fijnsparbossen in Nederland heeft een betere boniteit dan de hier gepresenteerde boniteit I, en eveneens $1 \%$ heeft een lagere boniteit dan boniteit V. Een tekortkoming van het model is dat de verklaring van de hoogteontwikkeling tot $10 \mathrm{~m}$ tegenstrijdig is tussen die in proefperken en in $4^{\mathrm{e}}$ Bosstatistiek. 


\section{Opbrengstniveau}

Naast de hoogtegroei vindt ook diktegroei plaats. Dit resulteert in diameterbijgroei $i_{d}=\left(d_{2}-d_{1}\right) /\left(t_{2}-t_{1}\right)$ en grondvlakbijgroei $i_{G}=\left(G_{2}-G_{1}\right) /\left(t_{2}-t_{1}\right)$. Hoogtegroei en diktegroei tezamen resulteren in een volumebijgroei. In opbrengsttabellen is een belangrijk doel juist de volumebijgroei te bepalen. Aangezien het boomvolume in de dataset een afgeleide, berekende variabele is en niet berust op een primaire waarneming, zal ook de volumebijgroei indirect worden berekend. Diameter en het totale grondvlak zullen in de loop van de tijd toenemen, maar gelijktijdig neemt ook de hoogte toe.

Jansen et al. (2016) onderzochten voor douglas een aantal groeimodellen en vonden dat de opstandontwikkeling tot een opstandhoogte van $7 \mathrm{~m}$ het best verklaard werd met een voorspelling van de diameter voor dunning. Vanaf een hoogte van $7 \mathrm{~m}$ werd de opstandontwikkeling beter verklaard door de grondvlakbijgroei. In Paragraaf 4.1 zal de diameterontwikkeling en daaraan gekoppeld de grondvlakontwikkeling worden geanalyseerd en gemodelleerd. In Paragraaf 4.2 zal de grondvlakbijgroei vanaf een hoogte van $7 \mathrm{~m}$ worden geanalyseerd en gemodelleerd.

\subsection{Diameter- en grondvlakontwikkeling tot een hoogte van $7 \mathrm{~m}$}

Als maat voor de diameter is gekozen voor de "gemiddelde" diameter van de opstand voor dunning $\left(d_{b t}\right)$. Onder "gemiddelde" wordt hier verstaan het kwadratische gemiddelde. Het gaat dus om de $d_{g}$, maar de toevoeging $g$ (van gemiddelde grondvlak) is weggelaten. Uit Figuur 9 blijkt dat de diameter voor dunning zowel met behulp van de leeftijd als de opperhoogte is te voorspellen. De eerste stap het selecteren van een goed groeimodel.
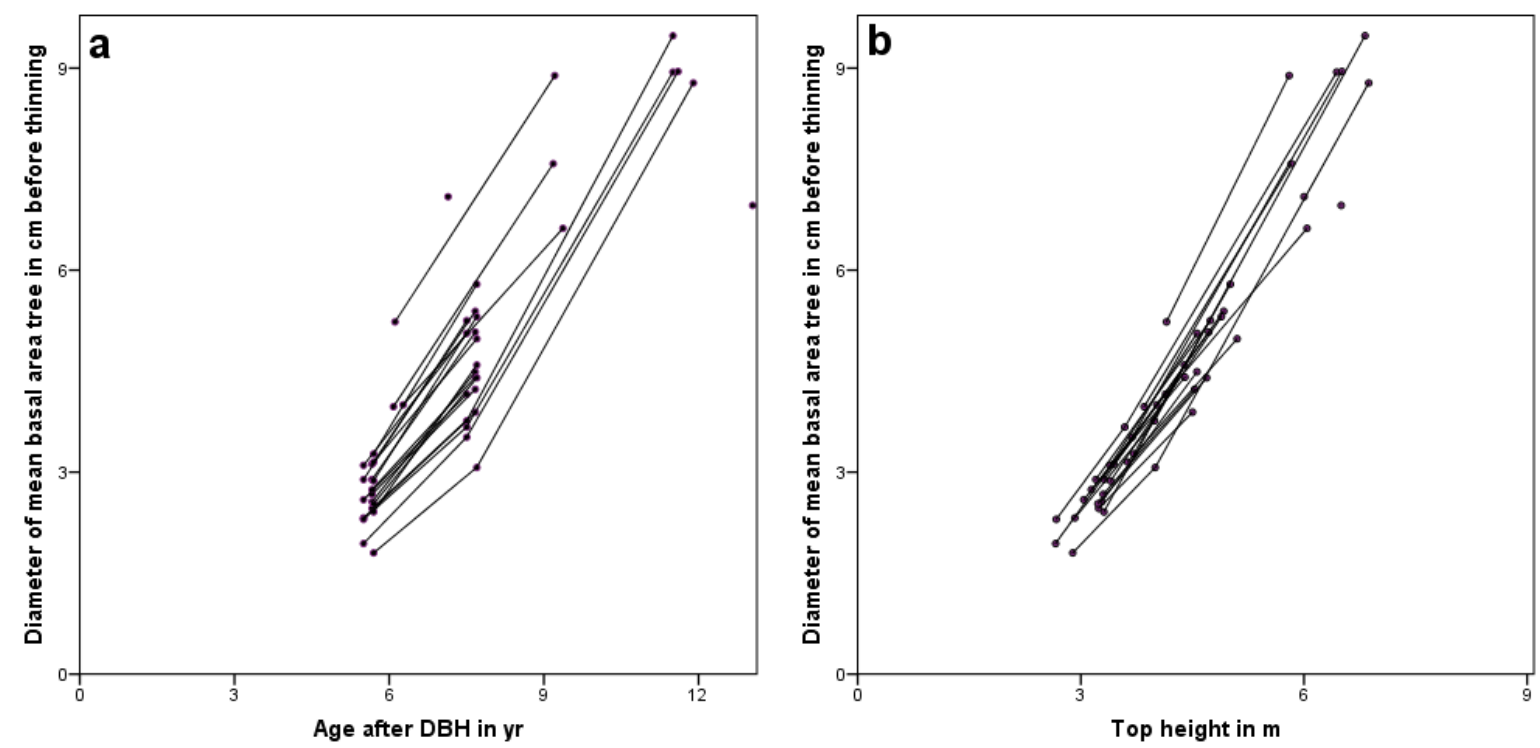

Figuur 9. Verloop diameterontwikkeling als functie van leeftijd (a) en opperhoogte (b).

Figure 9. Course of the diameter development as a function of age (a) and top height (b). 
Stap 1. Het bepalen van een groeimodel

Het model, dat Jansen et al. (2016) voor de diameterontwikkeling van douglas gebruikten, bestaat uit een component voor de jeugdgroei tot een hoogte van $7 \mathrm{~m}$ zonder dunning, en een component voor de ontwikkeling daarna, met een Gompertz-functie voor jeugdgroei en een powerfunctie daarna. Jansen et al. (2018) vereenvoudigde het model voor de Japanse lariks en transformeerde het naar een schatter voor het gemiddelde boomgrondvlak voor dunning:

$$
\begin{gathered}
g_{b t}=\pi \cdot\left(\frac{d_{b t}}{200}\right)^{2}=\pi \cdot\left(\frac{d_{7}}{200}\right)^{2} \cdot\left\{\frac{\exp \left(-c_{4} \cdot e^{-c_{5} \cdot\left(h_{\text {top }}-1.30\right)}\right)}{\exp \left(-c_{4} \cdot e^{-c_{5} \cdot(7-1.30)}\right)}\right\}^{2} \text { for } h_{\text {top }} \leq 7 \mathrm{~m} \\
\text { where } d_{7}=c_{6}+c_{7} / \sqrt{N_{0}}
\end{gathered}
$$

Met 48 waarnemingen en een $R^{2}$ adj van 0.976 de oplossing van Tabel 6 gevonden.

Tabel 6. Parameters voor Model (10).

Table 6. Parameters for Model (10).

\begin{tabular}{|l|r|r|r|r|}
\hline \multirow{2}{*}{ Parameter } & & & \multicolumn{2}{|c|}{ 95\% Confidence Interval } \\
\cline { 4 - 5 } & Estimate & Std. Error & Lower Bound & Upper Bound \\
\hline$c_{4}$ & 3.8455 & 0.597 & 2.643 & 5.048 \\
$c_{5}$ & 0.1486 & 0.056 & 0.036 & 0.261 \\
$c_{6}$ & 7.2517 & 0.221 & 6.806 & 7.697 \\
$c_{7}$ & 120.4953 & 10.968 & 98.390 & 142.601 \\
\hline
\end{tabular}

In Tabel 7 is het effect van het beginstamtal op de ontwikkeling van de diameter gegeven, indien er tot een opperhoogte van $7 \mathrm{~m}$ niet gedund wordt.

Tabel 7. Diameter voor dunning bij $\boldsymbol{h}_{\text {top }}=\mathbf{7} \mathrm{m}$ en HD-ratio per beginstamtal.

Table 7. Diameter before thinning at $h_{\text {top }}=7 \mathrm{~m}$ and HD-ratio per initial density.

\begin{tabular}{|rrr|}
\hline $\boldsymbol{N}_{\mathbf{0}}$ & $\boldsymbol{d}_{\mathbf{7}}$ & $\boldsymbol{H D}$-ratio \\
\hline 1250 & 10.7 & 66 \\
2500 & 9.7 & 72 \\
5000 & 9.0 & 78 \\
10000 & 8.5 & 83 \\
\hline
\end{tabular}

In de regressiediagnose werden geen aandachtspunten gevonden.

\section{Conclusie}

Het model dat Jansen et al. (2018) voor de Japanse lariks vonden bleek toepasbaar voor de fijnspar. 
Er is een nauwkeurige schatter voor de $d_{7}$ (de diameter bij een opperhoogte van $7 \mathrm{~m}$ ) gevonden. En ook de ontwikkeling van die diameter tot $d_{7}$ kan voorspeld worden.

\subsection{Grondvlakbijgroei}

In Figuur 10 is te zien dat de grondvlakbijgroei een nogal chaotisch verloop vertoond. Het lijkt erop of er sprake is van een eerst stijgende functie zowel naar leeftijd als hoogte en daarna een monotoon dalende functie. Als grens is een hoogte van $7 \mathrm{~m}$ aangehouden, ontwikkeling van het grondvlak tot $7 \mathrm{~m}$ is in Paragraaf 4.1 al besproken. Hier wordt de groei vanaf een hoogte van $7 \mathrm{~m}$ behandeld.
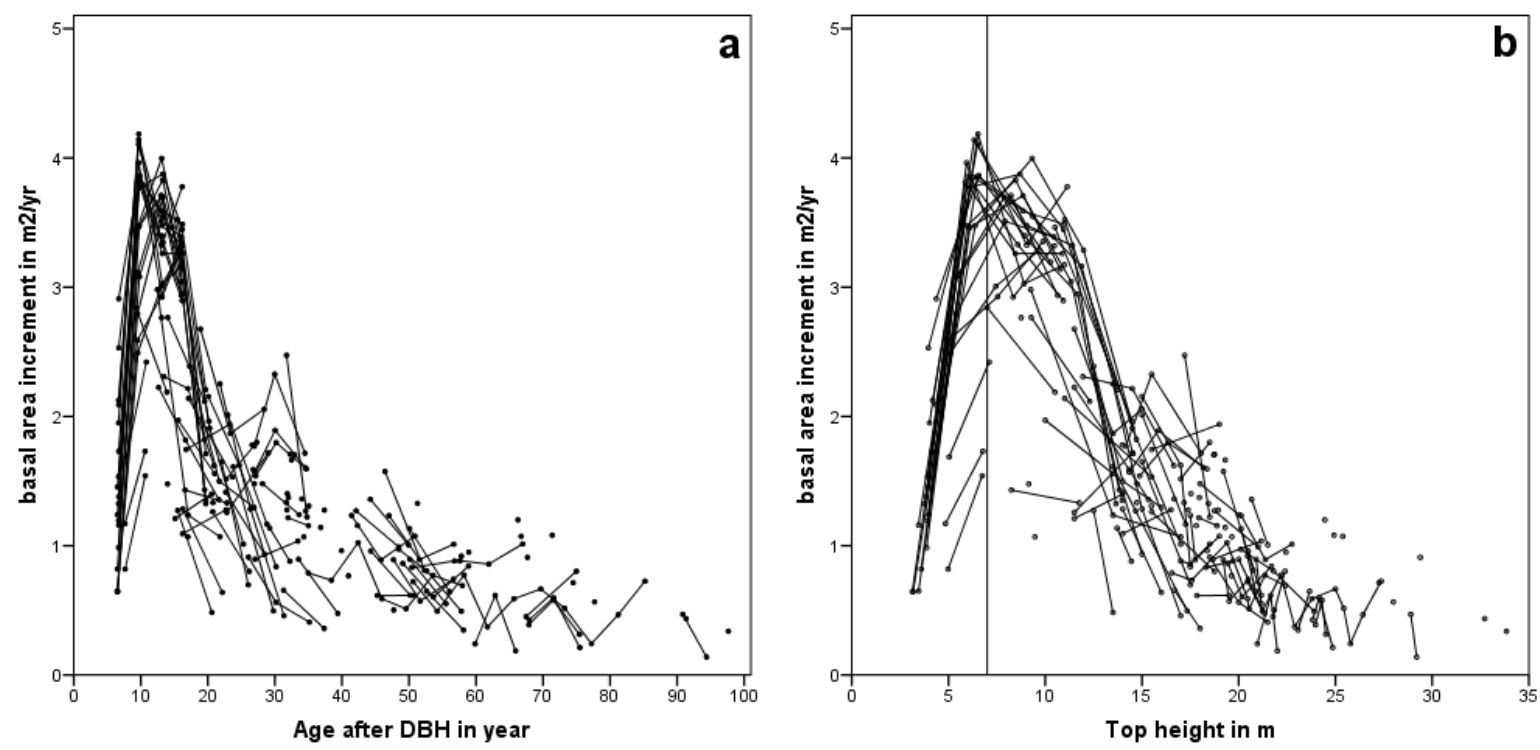

Figuur 10. Grondvlakbijgroei als functie van leeftijd (a) en opperhoogte (b). De zwarte lijnen geven het verloop binnen één plot aan.

Figure 10 The basal area increment as a function of age (a) and top height (b). The black line represents the course within one plot.

De grondvlakbijgroei betreft een berekende waarneming tussen 2 opnamen, de leeftijd en opperhoogte betreffen dan het gemiddelde tussen beide opnamen.

Uit Figuur 10b blijkt dat de keuze voor een ondergrens bij een opperhoogte van $7 \mathrm{~m}$ voor de dat bij de analyse in deze Paragraaf redelijk is, maar zeker niet voor alle plots een geschikt moment is. In verband daarmee zijn de data van de proefperken 19 (F16), 39 (F809), 97 (H0401) en 119 (H1794) uitgesloten van navolgende analyse.

Stap 1. Bijgroeimodel voor grondvlak bepalen.

Jansen et al. (2016) ontwikkelden voor de grondvlakbijgroei van douglas het volgende model:

$$
i_{G, i j k}=Y I_{j} \cdot P L_{k} \cdot f_{1}(\text { Tgr }) \cdot f_{2}(\text { boniteit }) \cdot \frac{F_{3}\left(t_{2}, h_{2}\right)-F_{3}\left(t_{1}, h_{1}\right)}{t_{2}-t_{1}}
$$

Voor de douglas bleek $f_{2}$ geen significante bijdrage te leveren.

Hierin is $F_{3}$ een power-functie, een simpel groeimodel (power-functie) luidt: 


$$
f_{3}=a \cdot h_{m 0}^{b} \quad \text { where } h_{m 0}=\left(h_{\text {top } 1}+h_{\text {top } 2}\right) / 2-1.30
$$

Hierin is $f_{3}$ niet langer het verschilmodel $F_{3}$ uit formule (11), maar het afgeleide model ervan. Dit model is gefit, in Figuur $11 \mathrm{a}$ is beste fit met $I_{G}=f_{3}$ gegeven. Ook het jaar van aanleg $Y I$ lijkt veel variantie te verklaren (Figuur 11b), maar voorzichtigheid is geboden omdat de toppen bij 1982, 1983 en 1986 juist de hoogste waarden in figuur 11a vertegenwoordigen tussen de 7 en $12 \mathrm{~m}$.

Geconstateerd kan worden dat een powermodel zoals Jansen et al. (2016) gebruiken geschikt is om de grondvlakbijgroei te verklaren.
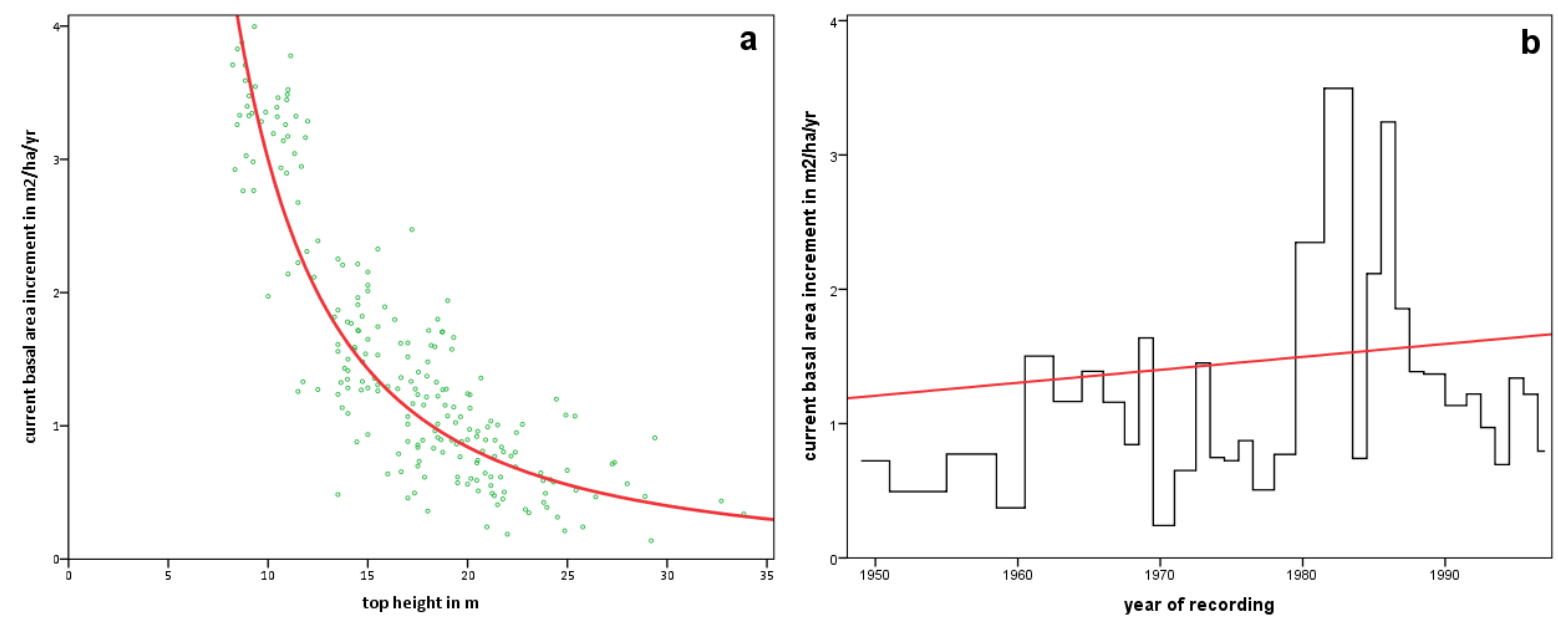

Figuur 11. Lopende grondvlakbijgroei als functie van de opperhoogte met in rood de beste fit voor een power-model (a) en de gemiddelde lopende grondvlakbijgroei als functie van het jaar van opname met in rood de lineaire fit (b).

Figure 11. Current Basal area increment as a function of the top height with in red the best fitting power function (a), and with the year of recording with in red the linear fit (b).

Stap 2. Verschilmodel voor grondvlakbijgroei.

Bij het fitten van Model (11) kan de jaarindex $Y I$ voor het $j^{e}$ kalender niet worden meegenomen wel bleek deze bij de douglas te kunnen worden vervangen door een correctiefactor $c f_{80}$ met een waarde voor opname voor en na 1980 . De functie $f_{2}$ bleek voor douglas geen significante bijdrage te leveren. $F_{3}$ is de functie voor de totale grondvlakproductie, hier voldeed een powerfunctie die zowel naar de hoogte als de leeftijd kan worden gemodelleerd. Voor de douglas bleek de toevoeging van de leeftijd geen extra verklaring te geven.

Ook voor de fijnspar bleek het model toepasbaar, en $f_{2}$ bleek net als bij douglas geen rol te spelen. De $c f_{80}$ factor bleek niet significant, en de leeftijd was wel van belang. Het aangepaste model luidt: 


$$
\begin{aligned}
& i_{G}=\operatorname{cor}_{5 \%} \cdot c_{8} \cdot\left\{c_{14} \cdot \operatorname{Term}_{h}+\left(1-c_{14}\right) \cdot \operatorname{Term}_{t}\right\} \quad \text { for } h_{2}>7 \\
& \text { where } \operatorname{Term}_{h}=\frac{\left(h_{2 c}-1.30\right)^{b}-\left(h_{1}-1.30\right)^{b}}{d t} \text { and } \operatorname{Term}_{t}=\frac{\left(t_{2}-t_{130}\right)^{b}-\left(t_{1}-t_{130}\right)^{b}}{d t} \\
& b= \begin{cases}c_{11} & \text { for } h_{\text {top }}>c_{13} \\
c_{11}+c_{12} \cdot \sqrt{c_{13}-h_{\text {top }}} & \text { for } h_{\text {top }} \leq c_{13}\end{cases} \\
& \operatorname{cor}_{5 \%}= \begin{cases}1 & \text { for } S \% \leq c_{10} \\
1-c_{9} \cdot \sqrt{S \%-c_{10}} & \text { for } S \%>c_{10}\end{cases} \\
& h_{1} \text { and } h_{2} \text { are the top heights at time } t_{1} \text { and } t_{2} \\
& h_{2 c}= \begin{cases}h_{2} & \text { for } h_{2}>h_{1} \\
h_{1}+\hat{h}_{2}-\hat{h}_{1} & \text { for } h_{2} \leq h_{1}\end{cases}
\end{aligned}
$$

Met een $R^{2}$ adj $=0.857$ en standaarddeviatie $0.37 \mathrm{~m}^{2} \mathrm{jr}^{-1} \mathrm{ha}^{-1}$ werden volgende parameters gevonden (zie Tabel 8).

Tabel 8. Parameterschatting met Model (13)

Table 8. Parameter estimation with Model (13).

\begin{tabular}{|l|rrrr|}
\hline & & \multicolumn{3}{|c|}{ 95\% Confidence Interval } \\
Parameter & \multicolumn{1}{|c|}{ Estimate } & Std. Error & Lower Bound & Upper Bound \\
\hline$c_{8}$ & 40.4054 & 17.021 & 6.854 & 73.957 \\
$c_{9}$ & 0.0936 & 0.017 & 0.060 & 0.127 \\
$c_{10}$ & 14.2874 & 3.622 & 7.147 & 21.428 \\
$c_{11}$ & 0.3885 & 0.071 & 0.249 & 0.528 \\
$c_{12}$ & 0.0537 & 0.012 & 0.030 & 0.078 \\
$c_{13}$ & 10.9979 & 0.306 & 10.395 & 11.601 \\
$c_{14}$ & 0.4254 & 0.059 & 0.309 & 0.542 \\
\hline
\end{tabular}

Stap 3. Kwaliteit van het model

In Figuur 12 is te zien is dat het model lage waarden van de grondvlakbijgroei overschat en de hoge waarden onderschat. Dit heeft te maken met het ontbreken van een verfijnde jaarindex. In Figuur 13 is te zien dat er 1 uitbijter is die meer dan $3 \sigma$ afwijken. Een verklaring werd niet gevonden.

In Figuur 13 is te zien dat het model voor de beide directe modelvariabelen opperhoogte (Figuur 13a) en S\% (Figuur 13b) een nagenoeg zuivere schatter geeft. Dat geldt ook voor de modelvariabele leeftijd (hier niet getekend). Maar de hellingshoek van de lineaire fit door de puntenwolk bij de niet-modelvariabele boniteit $h_{50}$ in de Figuur 14 a blijkt net niet significant. Er werd geen oplossing gevonden voor een aanpassing van model (13). Figuur $14 \mathrm{~b}$ laat met een voortschrijdend gemiddelde zien dat zo'n oplossing niet voor de hand ligt. 


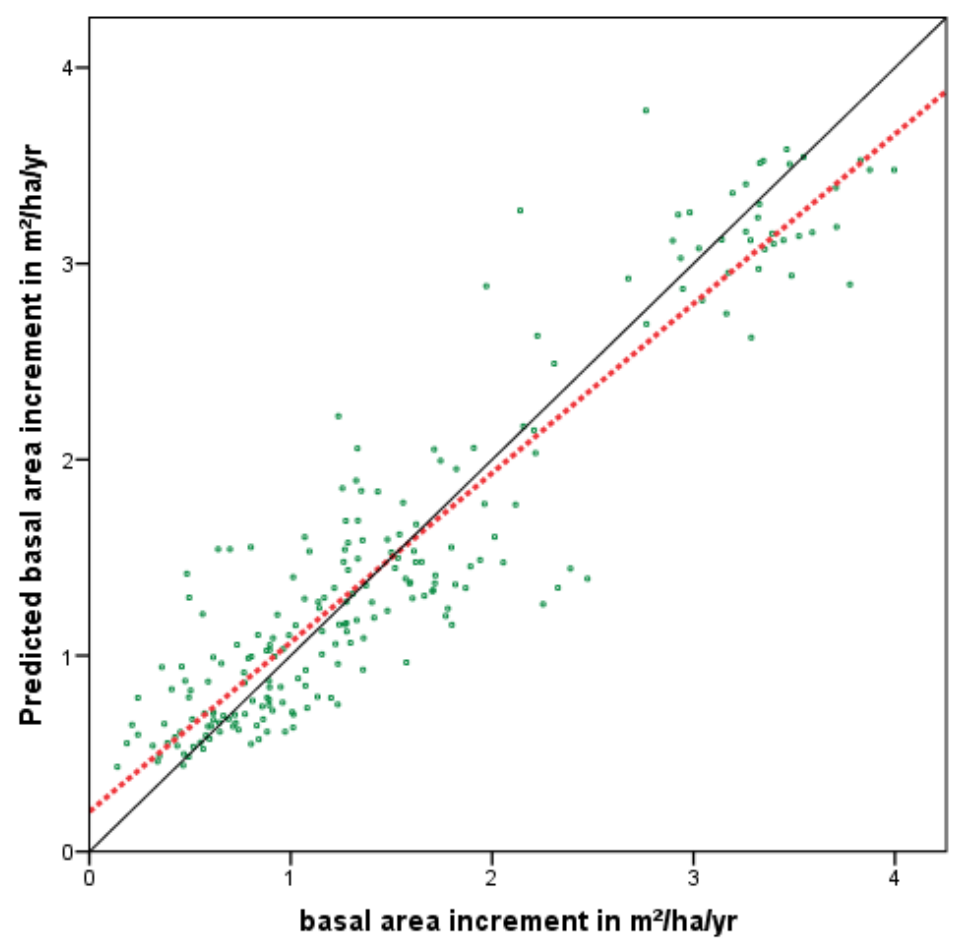

Figuur 12. Voorspelde grondvlakbijgroei als functie van de gemeten grondvlakbijgroei. De zwarte lijn geeft een 1 op 1 verhouding aan; de rode lijn is de lineaire fit door de puntenwolk.

Figure 12. Predicted basal area increment as a function of the measured basal area increment. The black line represents a 1 to 1 relation; the red line is the linear fit through the point cloud.
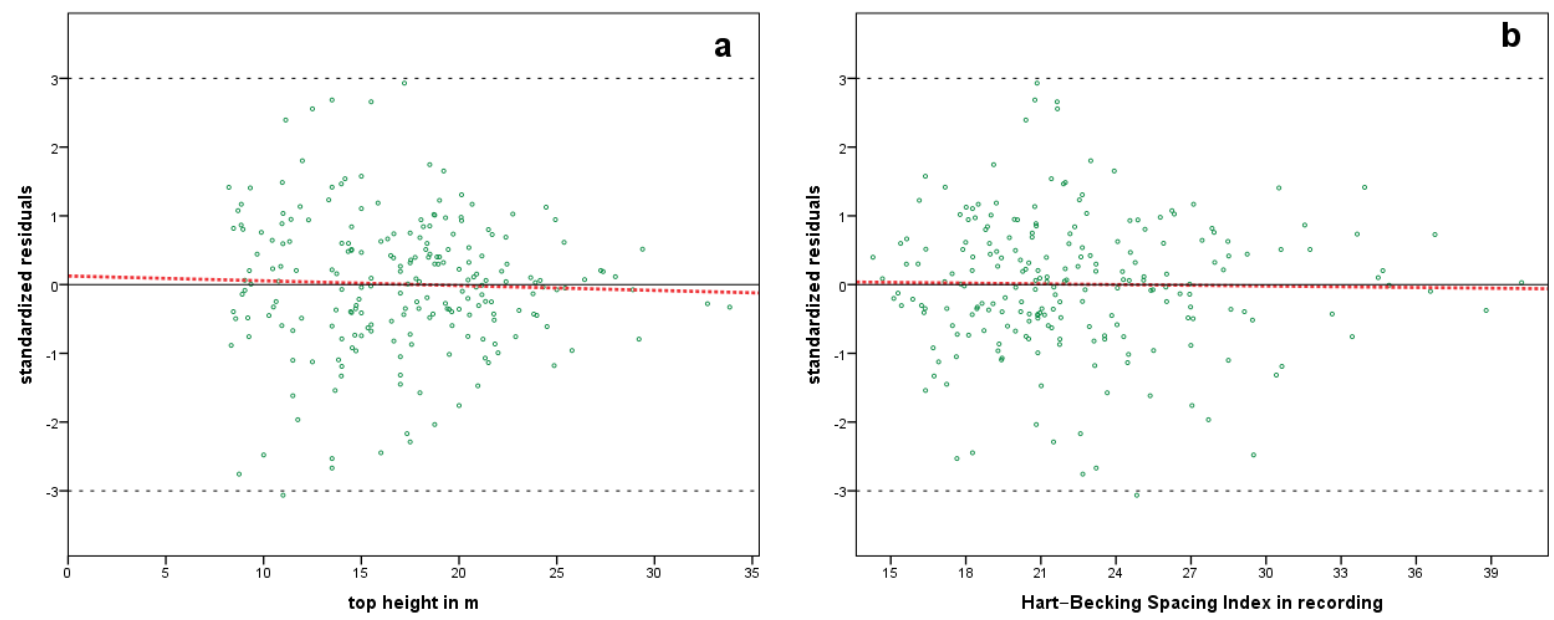

Figuur 13. Gestandaardiseerde residuen van Model (13) in relatie tot de modelvariabelen opperhoogte(a) en S\% (b). De rode lijn geeft de lineaire regressielijn weer door de residuen.

Figure 13. Standardized residuals of Model (13) in relation to the model variables top height (a) and HartBecking Spacing Index (b). The red line shows the linear regression line through the residuals. 

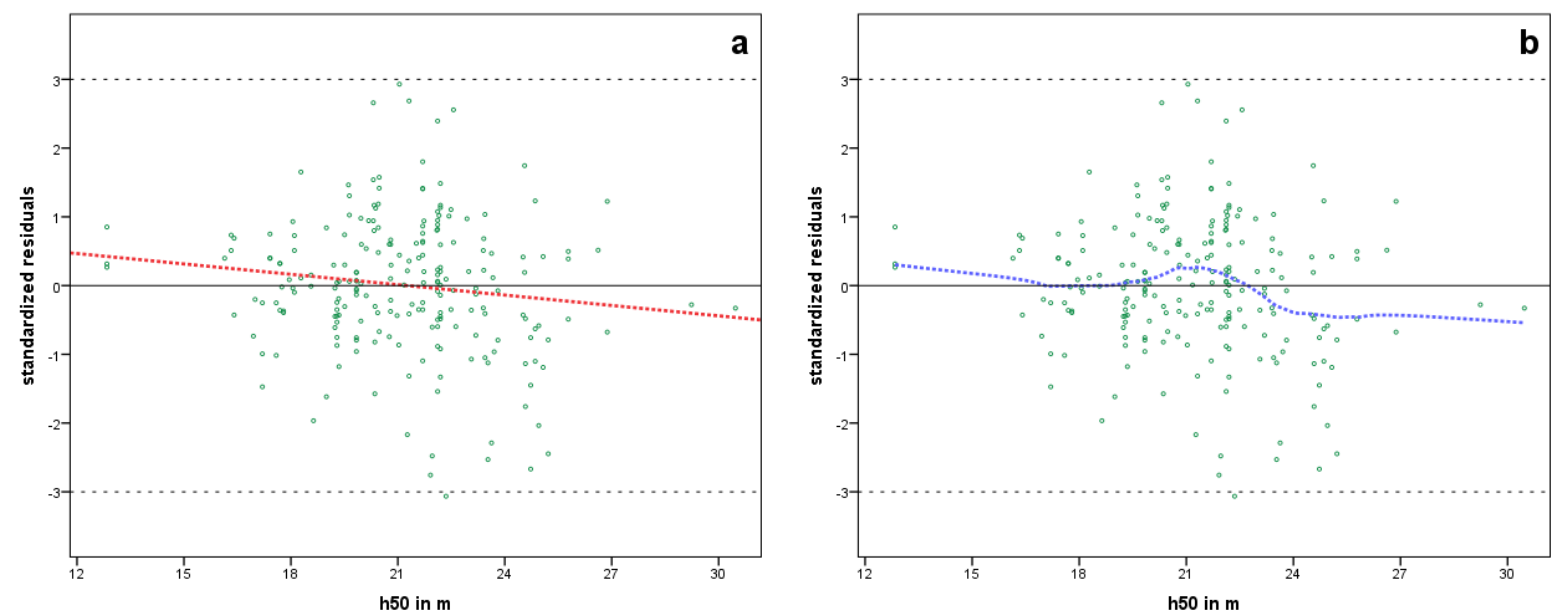

Figuur 14. Gestandaardiseerde residuen van Model (13) in relatie tot de niet-modelvariabele $h_{50}$. De rode lijn (a) geeft de lineaire regressielijn weer door de residuen en de blauwe lijn (b) het voortschrijdend gemiddeld.

Figure 14. Standardized residuals of Model (13) in relation to the non-model variable site index $h_{50}$. The red line (a) shows the linear regression line through the residuals and the blue line the moving average (b).

Het plotniveau zou volgens Formule (11) als kunnen worden bepaald:

$$
i_{G}=\hat{i}_{G_{-} f 13} \cdot P L_{k} \quad \text { for } k \in \text { selection }
$$

Maar aangezien van de 102 plots er slechts 2 op meer dan 5 waarnemingen is een redelijke schatting niet mogelijk.

\section{Conclusie}

Met het model van Jansen et al. (2016) is de grondvlakbijgroei te voorspellen, niet alle elementen van het model bleken toepasbaar. 


\section{Dunningsysteem}

In de dunningproeven van studie 2 en 3 zijn verschillende vaste dunninggraden nagestreefd (zie Tabel 9).

Tabel 9. Dunninggraden.

Table 9. Thinning grades.

\begin{tabular}{|c|c|l|}
\hline Tgr & S\% bij $\mathbf{5 0 ~} \mathbf{~ j r}$ & Omschrijving \\
\hline 1 & 13 & zonder dunning \\
2 & 16 & zwakke laagdunning \\
3 & 19 & matige laagdunning \\
4 & 22 & sterke laagdunning \\
5 & 25 & zeer sterke laagdunning \\
6 & 28 & open stand \\
\hline
\end{tabular}

Er is reden om aan te nemen dat de dunninggraad, zoals hier gedefinieerd via het S\%, op latere leeftijd moet stijgen. De achtergrond van dit fenomeen heeft betrekking op de kroonontwikkeling. Vanaf ongeveer 50 jaar neemt de hoogtegroei af omdat er in toenemende mate topsterfte optreedt. Dit resulteert in een hogere ratio tussen de kroonbreedte en hoogte vanaf die tijd dan ervoor. Het $S \%$ is dan niet langer een constante maar verandert met de tijd:

$$
S \%= \begin{cases}13+3 \cdot\left(\text { Tgr }_{0}-1\right) & \text { age } \leq 50 \\ 13+3 \cdot\left(\text { Tgr }_{0}-1\right)+C_{15} \cdot(\text { age }-50) & \text { age }>50\end{cases}
$$

Vanaf de eerste dunning of sterfte tot een leeftijd van 50 jaar komt het $S \%$, behorend bij de in te stellen dunninggraad $T g r_{0}$, overeen met die uit de tweede kolom van de tabel, daarna loopt het $S \%$ langzaam op.

Een model om $c_{15}$ te schatten luidt:

$$
S \%_{i j}=\left\{\begin{array}{ll}
S \%_{j} & \text { age } \leq 50 \text { and } h_{\text {top }}>7 \\
S \%_{j}+c_{15} \cdot\left(a g e_{i j}-50\right) & \text { age }>50 \text { and } h_{\text {top }}>7
\end{array} \text { for the } i^{\text {th }} \text { record in the } j^{\text {th }}\right. \text { plot }
$$

Gevonden werd $c_{15}=0.1449$, met een ruim $95 \%$ betrouwbaarheidsinterval $\{0.030 ; 0.260\}$. Omdat in het merendeel van de proefperken (de HOSP-plots) geen sprake is van experimentele behandeling met een zekere dunninggraad, komt deze onnauwkeurigheid overeen met onze verwachting.

In de opbrengsttabellen voor Duitsland, België, het Verenigd Koninkrijk en Nederland (zowel de vigerende als oudere tabellen) blijkt het $\mathrm{S} \%$ vanaf 50 jaar ook toe te nemen (zie Tabel 10).

Hier is gekozen voor $c_{15}=0.0742$, de gemiddelde waarde van de opbrengsttabellen uit Tabel 10 , met uitsluiting van de hoogste en de laagste waarde. De dunninggraden hebben dus niet langer een vast maar een variabel $S \%$. 
Tabel 10. Verloop S\% in enige opbrengsttabellen vanaf $\mathbf{5 0}$ jaar.

Table 10. Course of S\% in some yield tables from 50 year and up.

\begin{tabular}{|c|c|c|c|c|}
\hline Tabel & land & dunninggraad & S\% bij $50 \%$ & $\Delta \mathrm{S} \% / \mathrm{jr}$ \\
\hline Becking \& De Vries, $1933^{1)}$ & Nederland & & 20.2 & 0.2752 \\
\hline La Bastide \& Faber, 1972 & Nederland & & 18.0 & 0.0398 \\
\hline Jansen \& Hildebrand, 1986 & Nederland & & 21.9 & 0.0993 \\
\hline Wiedemann, $1936^{2)}$ & Duitsland & matige dunning & 15.6 & 0.0386 \\
\hline Dagnelie, 1988 & België & A behandeling & 16.4 & 0.1193 \\
\hline Hamilton \& Christie, 1973 & Verenigd Koninkrijk & & 20.0 & 0.0162 \\
\hline
\end{tabular}

1) Een bewerking van Møller, 1933

2) In: Schober, 1987

$\mathrm{Er}$ is een verband gedefinieerd tussen het stamtal en de diameter na dunnen of sterfte door Reineke (1933). Dit komt aan de orde in Paragraaf 5.1. La Bastide en Faber (1972) ontwikkelden een model om de diameter na dunning te bereken, dit model wordt in Paragraaf 5.2 besproken.

Bij de analyse in Hoofdstuk 5 zijn de HOSP plots (studie 4) uitgesloten omdat de geschiedenis van de dunning niet bekend is. Daarnaast zijn opnamen uitgesloten die meer dan 2 dunninggraden van voorgaande afwijken (dit is meestal stormschade) en waarbij de diameter van de dunning hoger is dan die voor dunning (dat betreft hier ook stormschade).

\subsection{Reineke's stamtal-diameter-relatie}

Reineke (1933) formuleerde een allometrische relatie tussen stamtal en diameter voor ongedunde opstanden voor diverse soorten in Oregon en Washington (USA) als volgt:

$$
\log N=K+c \cdot \log d_{a m}
$$

Jansen et al. (2016) breidde dit model voor geplante en gedunde opstanden uit tot:

$$
\begin{aligned}
& \log N_{a t}=K_{0}-u-\sqrt{u^{2}+c_{19}^{2}} \\
& \quad \text { where } u=-\frac{1}{2} \cdot\left\{c_{16}-c_{17} \cdot \log d_{a t}-c_{18} \cdot(\operatorname{Tgr}-1)-K_{0}\right\}
\end{aligned}
$$

Met een $R^{2}$ adj van 0.962 werd de volgende oplossing gevonden (zie Tabel 11).

Tabel 11. De geschatte parameters met Model (18).

Table 11. The estimated parameters with Model (18).

\begin{tabular}{|l|r|r|r|r|}
\hline & & & \multicolumn{2}{|c|}{ 95\% Confidence Interval } \\
\cline { 4 - 5 } Parameter & Estimate & Std. Error & Lower Bound & Upper Bound \\
\hline$c_{16}$ & 5.2438 & 0.038 & 5.169 & 5.319 \\
$c_{17}$ & 1.6518 & 0.030 & 1.594 & 1.710 \\
$c_{18}$ & 0.0569 & 0.003 & 0.051 & 0.063 \\
$c_{19}$ & 0 & & & \\
\hline
\end{tabular}


De parameter $c_{19}$ bleek niet significant van 0 te verschillen.

In de plantafstandproef $\mathrm{F} 400 \mathrm{C}$ is het stamtal bij 3 proefperken in de 2e opname door dunning (lang voor de opstand in sluiting kwam) ongeveer gehalveerd van 5000 naar circa 2500. Die proefperken zijn ook uitgesloten.

In Figuur 15 zijn de data grafisch weergegeven.

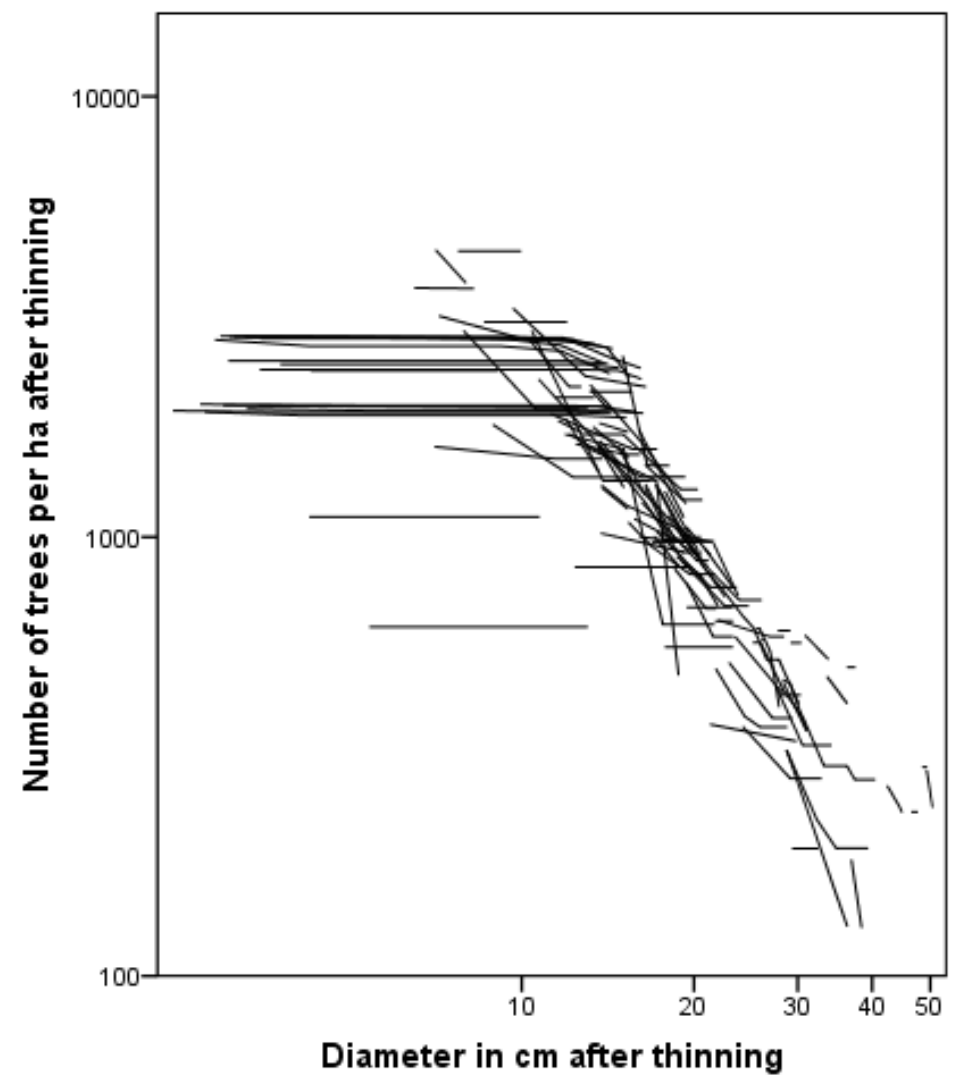

Figuur 15. Relatie stamtal en diameter na dunning.

Figure $15 . \quad$ Relation between stem density and diameter after thinning.

\subsection{Model van La Bastide-Faber voor voorspelling diameter na dunning}

Het stamtal na dunning wordt bepaald met het S-procent van Hart.

Jansen et al. (2016) voorspellen de diameter na dunning met een modificatie van het model van La Bastide en Faber (1972):

$$
\begin{aligned}
& d_{a t}= d_{b t} \cdot\left\{R \cdot \frac{a_{a t}}{a_{b t}}+1-R\right\} \\
& \text { where } R=c_{20}+c_{21} \cdot h_{50}+c_{22} \cdot \sqrt{T g r}+c_{23} \cdot t
\end{aligned}
$$

Met een $R^{2}$ adj van 0.998 worden de volgende constanten gevonden: 
Tabel 12. Parameterschatting met Model (19).

Table 12. Parameter estimation with Model (19).

\begin{tabular}{|l|r|r|r|r|}
\hline & & & \multicolumn{2}{|c|}{ 95\% Confidence Interval } \\
\cline { 4 - 5 } Parameter & Estimate & Std. Error & Lower Bound & Upper Bound \\
\hline$C_{20}$ & 1.0719 & 0.104 & 0.867 & 1.277 \\
$c_{21}$ & -0.0104 & 0.003 & -0.017 & -0.004 \\
$c_{22}$ & -0.2210 & 0.020 & -0.260 & -0.182 \\
$C_{23}$ & -0.0023 & 0.001 & -0.003 & -0.001 \\
\hline
\end{tabular}

Bij de analyse zijn alle opnamen uitgesloten waarbij er minder dan 4 bomen uit het proefperk waren verdwenen, omdat dit meestal geen dunning maar sterfte betreft. Ook opnamen waarbij de diameter voor dunning hoger was dan die na dunning zijn uitgesloten, omdat dit geen normale laagdunning betreft.

\subsection{Conclusie}

In de inleiding is aangegeven hoeveel stammen er afhankelijk van de dunninggraad bij een zekere hoogte gedund worden. Hieruit volgt het stamtal na dunning. Met de inverse van Formule (18) is dan de diameter na dunning te voorspellen. Het probleem daarbij is dat vanwege die logaritmische transformatie de diameter zelf niet zuiver geschat wordt. De andere schatter van de diameter na dunning met Formule (19) uit Paragraaf 5.2 heeft een hogere $R^{2}$ en is zuiver en geniet daarom de voorkeur. 


\section{Constructie Opbrengsttabellen}

Met de in deze studie gevonden relaties zullen nu nieuwe opbrengsttabellen worden gemaakt met verschillende dunninggraden.

Al eerder is besloten een indeling in relatieve boniteiten te maken, met daaraan gekoppeld de "hoogte" op 50 jaar. Er is gekozen voor een presentatie van gegevens op dezelfde wijze als voor de douglas door Jansen et al. (2016).

Voor een groot aantal van deze gegevens kunnen de gevonden relaties in de voorafgaande hoofdstukken worden gebruikt. Maar er zullen nog wat allometrische relaties gefit moeten worden, voor variabelen die tot nu toe nog niet voorkwamen.

\subsection{Overige allometrische relaties}

Dominante hoogte

Het model van Jansen et al. (2016) is gekozen:

$$
h_{d o m}= \begin{cases}h_{t o p}-c_{24} \cdot h_{\text {top }}^{c_{25}} & \text { voor } N_{a t}>250 \\ \frac{N_{a t}-100}{250-100} \cdot\left(h_{t o p}-c_{24} \cdot h_{t o p}^{c_{25}}\right)+\frac{250-N_{a t}}{250-100} \cdot h_{\text {top }} & \text { voor } 100<N_{a t} \leq 250 \\ h_{\text {top }} & \text { voor } N_{a t} \leq 100\end{cases}
$$

Met een $R^{2}$ adj van 0.997 werd gevonden voor 181 waarnemingen: $c_{24}=0.006887$ en $c_{25}=$ 0.9935 .

Dominante diameter

Voor de dominante diameter werd met een $R^{2}$ adj van 0.941 het model van Jansen et al. (2016) gefit:

$$
\begin{aligned}
d_{d o m}= & \begin{cases}d_{d o m 2} & \text { for } h_{\text {top }} \leq 7 \mathrm{~m} \\
\left(2 \cdot d_{\text {dom } 2}+d_{\text {dom } 1}\right) / 3 & \text { for } 7<h_{\text {top }} \leq 9 \mathrm{~m} \\
\left(d_{d o m 2}+2 \cdot d_{d o m 1}\right) / 3 & \text { for } 9<h_{\text {top }} \leq 11 \mathrm{~m} \\
d_{d o m 1} & \text { for } h_{\text {top }}>11 \mathrm{~m}\end{cases} \\
& \text { where } d_{d o m 1}=d_{a t}+\left\{c_{26} \cdot h_{50}^{c_{27}} \cdot\left(d_{a t} / c_{28}\right)^{c_{29}-1} \cdot \exp \left(-\left(d_{a t} / c_{28}\right)^{c_{29}}\right)\right\} \cdot\left(1-c_{30} \cdot \operatorname{Tgr}_{0}\right) \\
& d_{\text {dom2 } 2}=c_{31} \cdot d_{a t}
\end{aligned}
$$

$T g r_{0}$ is the actual thinning grade from Formula 15 with $\max T g r_{0}=7$

De oplossing heeft wat bedenkingen. De parameter $c_{28}$ blijkt niet schatbaar en moet ingesteld worden als schaalfactor (de maximale $d_{d o m}$ ) gekozen is voor $60 \mathrm{~cm}$. De correlatiecoëfficiënt tussen de parameters $c_{26}$ en $c_{27}$ is zeer hoog, namelijk -0.987, de nauwkeurigheid van beide parameters is daarom afzonderlijk gering. 
Tabel 13. Parameterschatting met Model (21).

Table 13. Parameter estimation with Model (21).

\begin{tabular}{|l|r|r|r|r|}
\hline & & & \multicolumn{2}{|c|}{$95 \%$ Confidence Interval } \\
\cline { 4 - 5 } Parameter & Estimate & Std. Error & Lower Bound & Upper Bound \\
\hline$c_{26}$ & 6.1163 & 4.135 & -2.043 & 14.276 \\
$c_{27}$ & 0.3880 & 0.223 & -0.052 & 0.828 \\
$c_{28}$ & 60.0000 & & & \\
$c_{29}$ & 1.7225 & 0.087 & 1.551 & 1.894 \\
$c_{30}$ & 0.0521 & 0.010 & 0.032 & 0.072 \\
$c_{31}$ & 1.3493 & 0.105 & 1.143 & 1.556 \\
\hline
\end{tabular}

Bij de residuen zijn geen belangrijke afwijkingen te vinden, geconcludeerd is dat Formule (21) geschikt is.

\section{Gemiddelde opstandhoogte}

Jansen et al. (2016) vonden voor de gemiddelde hoogte $\left(h_{g}\right)$ na dunning een powerfunctie gevonden met in de loop van de ontwikkeling wijzigende parameters:

$$
\begin{aligned}
& h_{a t}= \begin{cases}h_{a t(2)} & \text { for } h_{t o p} \leq 1.30 \mathrm{~m} \\
h_{a t(2)} & \text { for } h_{a t(1)} \leq h_{a t(2)} \\
h_{a t(1)} & \text { else }\end{cases} \\
& \text { where } h_{a t(1)}=\left(c_{32}+c_{33} \cdot a g e\right) \cdot h_{t o p}^{\left(c_{33}-c_{35} \cdot h_{t o p}\right)} \\
& h_{a t(2)}=c_{44} \cdot h_{t o p} \text { and } c_{44}=0.8 \text { (a set value) }
\end{aligned}
$$

Met een $R^{2}$ adj van 0.989 werden de volgende parameters gevonden.

Tabel 14. Parameterschatting met Model (22).

Table 14. Parameter estimation with Model (22).

\begin{tabular}{|l|r|r|r|r|}
\hline & & & \multicolumn{2}{|c|}{ 95\% Confidence Interval } \\
\cline { 4 - 5 } Parameter & Estimate & Std. Error & Lower Bound & Upper Bound \\
\hline$C_{32}$ & 0.7020 & 0.036 & 0.632 & 0.772 \\
$C_{33}$ & 0.0005015 & 0.000 & 0.000 & 0.001 \\
$C_{34}$ & 1.1073 & 0.023 & 1.061 & 1.153 \\
$C_{35}$ & 0.001213 & 0.000 & 0.000 & 0.002 \\
\hline
\end{tabular}

Voor de hoogte voor dunning volgde:

$$
h_{b t}=c_{36} \cdot h_{a t} \quad \text { with } R^{2} \text { adj }=0.998 \text { and } c_{36}=0.9931
$$

\section{Opstandvolume}

In de data zijn de boomvolumes bepaald met de Formule (24), zie Dik (1984). Dik gebruikte het Schumacher-Hall-model (1933):

$$
v=d^{c_{37}} \cdot h^{c_{38}} \cdot e^{c_{39}} \text { met } d \text { in } \mathrm{cm}, h \text { in } \mathrm{m} \text { en } v \text { in } \mathrm{dm}^{3}
$$


Voor fijnspar geldt $c_{37}=1.75055, c_{38}=1.10897$ en $c_{39}=-2.75863$

Van de perken van de Dorschkamp zijn geen boomgegevens meer beschikbaar, maar alleen opstandgegevens. Deze zijn vermoedelijk met een eerdere versie van (24) berekend met iets afwijkende constanten. Daarom is met vaste waarden voor $c_{37}$ en $c_{38}, c_{39}$ opnieuw geschat, gevonden werd $c_{39}=-2.86110$.

Formule (24) is niet geschikt om het opstandvolume te bepalen. In het verleden werd gebruik gemaakt van de gemodificeerde opstandvolumefunctie van Heisterkamp (1981), de functie luidt:

$$
\begin{aligned}
V= & c_{40} \cdot G^{c_{41}} \cdot h_{\text {top }}^{\left(c_{42}+c_{43} \cdot t_{0}\right)} \text { met } G \text { in } \mathrm{m}^{2} / \text { ha, } h_{\text {top }} \text { in } \mathrm{m} \text { en } V \text { in } \mathrm{m}^{3} / \mathrm{ha} \\
& \text { met } t_{0}=t-t_{1.30}
\end{aligned}
$$

Deze is opnieuw gefit met:

$$
y=V_{b t}+V_{a t}=c_{40} \cdot h_{t o p}^{\left(c_{42}+c_{43} \cdot t_{0}\right)} \cdot\left(G_{b t}^{c_{41}}+G_{a t}^{c_{41}}\right)
$$

Met $R^{2} \mathrm{adj}=0.994$ is gevonden: $c_{40}=0.7419, c_{41}=1.0032, c_{42}=0.8407$ en $c_{43}=0$ (niet significant).

De formule van Heisterkamp is ontwikkeld voor opbrengsttabellen die alle een startwaarde hadden voor de opperhoogte, voor fijnspar was dat $7 \mathrm{~m}$. Daar beneden moet met de Formule (24) worden gewerkt.

\section{Beginstamtal}

Als beginstamtal is gekozen voor $5000\left(=c_{45}\right)$ en 3000 bij een open stand.

\section{Grenswaarde}

De steeds terugkerende grenswaarde voor de opperhoogte van $7 \mathrm{~m}$ is de parameter $c_{46}$ in de modellen. En geeft daarbij de bovengrens aan voor de jeugdgroei.

\subsection{Opbrengsttabellen}

\subsubsection{Keuze voor berekende opbrengsttabellen}

Allereerst is gekozen welke tabellen gepubliceerd zullen worden. Er is gekozen voor een opbrengsttabellen voor Nederland met vijf dunninggraden en vijf boniteiten.

In Tabel 5 in Hoofdstuk 3 is de verdeling over boniteiten en leeftijdsklassen gegeven voor het aantal opstanden in de $4^{\mathrm{e}}$ Bosstatistiek. Dit geeft de behoefte aan tabellen weer, terwijl Tabel 15 een indicatie van de mogelijkheden geeft. 
Tabel 15. Leeftijdsinterval in dataset per dunninggraad en boniteit.

Table 15. Age interval in the data set by thinning grade and site class.

\begin{tabular}{|l|ccccc|}
\hline & \multicolumn{5}{|c|}{ Boniteit } \\
\hline Dunninggraad & I & II & III & IV & V \\
\hline ongedund & & & $47-52$ & & \\
zwakke laagdunning & $17-102$ & $23-80$ & $41-67$ & $58-61$ & \\
matige laagdunning & $12-101$ & $11-59$ & $22-75$ & $73-88$ & $66-80$ \\
sterke laagdunning & $15-84$ & $11-94$ & $26-84$ & & \\
zeer sterke laagdunning & $17-43$ & $11-40$ & $20-67$ & & \\
open stand & $28-41$ & $11-67$ & $54-69$ & $55-68$ & \\
\hline
\end{tabular}

Extrapolatie buiten het waarnemingsmateriaal moet in principe beperkt worden maar is onvermijdelijk (zie Tabel 15). De maximale leeftijd is voor alle boniteiten en dunninggraden op 90 jaar gesteld. Een tabel voor ongedunde fijnspar wordt niet gemaakt.

\subsubsection{Constructie van de opbrengsttabel}

Voor de constructie worden eerst bij een gekozen waarde voor $h_{50}$ (zie Tabel 4 in Hoofdstuk 3 ) en een gekozen dunninggraad de $t_{130}$ en $t_{10}$ berekend met Formule (9) en het bij de dunninggraad behorende $S \%$ van Hart vastgesteld. Verder is het beginstamtal $N_{0}$ vastgesteld op 5000, behalve voor de open stand, waar met een lager beginstamtal van 3000 wordt gewerkt. Daarna is per leeftijd $t$ op het interval $\left\{1, t_{\max }+1\right\}$ een aantal variabelen berekend. Allereerst wordt $h_{\text {top }}$ berekend met Formule (9), daarna $h_{\text {dom }}$ met (20).

Er worden drie situaties onderscheiden:

I. $h_{\text {top }}<7 \mathrm{~m}$. Geen dunning.

Het stamtal is gelijk aan $N_{0}$ (in het model is deze $c_{45}$ ). De $h_{g}$ wordt met Formule (22) berekend. Tot een hoogte van $1.30 \mathrm{~m}$ worden alleen het stamtal, de opperhoogte en de dominante hoogte vermeld;

II. $h_{\text {top }(t)} \leq 7 \mathrm{~m}$ en $h_{\text {top }(t+1)}>7 \mathrm{~m}$

Geen dunning maar wel start berekening van het grondvlak. Allereerst wordt de $t_{7}$ bepaald (de exacte leeftijd waarop een opperhoogte van $7 \mathrm{~m}$ wordt bereikt. Voor de diameter (voor dunning) geldt $d_{7}=c_{6}+c_{7} / \sqrt{N_{0}}$ uit Formule(10). Voor het grondvlak (voor dunning) volgt dan $G_{b t\left(t_{7}\right)}=N_{0} \cdot \frac{\pi}{40000} \cdot c_{13}^{2}$.

Het $S \%$ wordt met $N_{0}$ en $h_{\text {top }}=7$ met Formule (1) berekend, daaruit volgt de dunninggraad voor dunning volgt $\operatorname{Tg} r=(S \%-10) / 3$. De grondvlakbijgroei wordt nu met een aangepaste versie van Formule (13) berekend: 


$$
\begin{aligned}
& i_{G}\left(t_{7}, t+1\right)=\operatorname{cor}_{S \%} \cdot\left\{\frac{c_{14} \cdot \text { Term }_{h}+\left(1-c_{14}\right) \cdot \text { Term }_{t}}{t+1-t_{7}}\right\} \text { for } h_{\text {top }}>7 \\
& \text { where } \operatorname{Term}_{h}=\left\{\left(h_{t+1}-1.30\right)^{b}-(7-1.30)^{b}\right\} \text { and } \operatorname{Term}_{t}=\left\{\left(t+1-t_{130}\right)^{b}-\left(t_{7}-t_{130}\right)^{b}\right\} \\
& \operatorname{cor}_{5 \%} \text { and } b \text { as in Formula 13 }
\end{aligned}
$$

$\mathrm{Na}$ het bepalen van $I_{G}$ wordt het grondvlak voor dunning op het tijdstip $t+1$ bepaald:

$$
G_{b t(t+1)}=G_{b t\left(t_{7}\right)}+i_{G}\left(t_{7}, t+1\right) \cdot\left(t+1-t_{7}\right)
$$

De berekening gaat nu verder als bij situatie III

III. $h_{\text {top }}>7 \mathrm{~m}$. Dit is de situatie waarin gedund kan worden.

Het stamtal voor dunning op tijdstip $t=t$ is gelijk aan het stamtal na dunning op het tijdstip $t=t-1$. Het grondvlak voor dunning is ook bekend, omdat dit op ieder tijdstip een jaar vooruit wordt berekend - de eerste keer met Formule (27) en (28), en later met (30) en (27).

Met de opperhoogte op $t=t$ en $N_{b t}$ wordt actuele dunninggraad (S\%) met formule (1) berekend en daaruit volgt de dunninggraad voor dunning $\operatorname{Tg} r=(S \%-10) / 3$.

Met de reciproke van de grondvlakdefinitie wordt de diameter voor dunning berekend.

$$
d_{b t}=200 \cdot \sqrt{\frac{G_{b t}}{\pi \cdot N_{b t}}}
$$

Op ieder tijdstip wordt verder het volume voor dunning $V_{b t}$ berekend met Formule (25). Alleen bij veelvouden van 5 jaar mag er gedund worden, daartussendoor vindt er wel bijgroei plaats, maar wordt er niet gedund en geldt "de situatie na dunning is gelijk aan die voor dunning". Bij die veelvouden van 5 jaar worden ook de dominante hoogte en de dominante diameter berekend met de Formules (20) en (21).

Het gewenste stamtal na dunning wordt berekend met $N_{a t}=\left(10746 /\left(S \% \cdot h_{d o m}\right)\right)^{2}$. Hierin wordt het gewenste S\% berekend met Formule (15):

N.B. tot 50 jaar zijn deze gewenste $S$-percentages ook in Tabel 9 vermeld.

Indien het gewenste stamtal $N_{a t}$ kleiner is dan $N_{b t}$ wordt er gedund. De diameter na dunning $d_{a t}$ wordt berekend met Formule (19), dus $d_{a t}=d_{b t} \cdot\left\{R \cdot \frac{a_{a t}}{a_{b t}}+1-R\right\}$ waarbij geldt $R=c_{20}+c_{21} \cdot h_{50}+c_{22} \cdot \sqrt{T g r}+c_{23} \cdot t$. Voor het grondvlak na dunning volgt $G_{a t}=N_{a t} \cdot \pi \cdot\left(d_{a t} / 200\right)^{2}$, voor dat van de dunning geldt $G_{t h}=G_{b t}-G_{a t}$, evenzo $N_{t h}=N_{b t}-N_{a t}$ en $d_{t h}=200 \cdot \sqrt{G_{t h} /\left(\pi \cdot N_{t h}\right)}$ 
Voor de gemiddelde hoogte na en voor dunning gelden respectievelijk de Formules (22) en (23). Het volume voor en na dunning wordt berekend met Formule (25) en het verschil tussen beide waarden is het volume van de dunning.

Alle relevante informatie van de situatie met en zonder dunning is nu bekend en alvorens naar een volgend jaar te gaan wordt de grondvlakbijgroei tot het volgende jaar $t=t+1$ met de uit Formule (13) afgeleide volgende formule berekend:

$$
\begin{aligned}
& I_{G}(t, t+1)=\operatorname{cor}_{S \%} \cdot\left\{c_{14} \cdot \text { Term }_{h}+\left(1-c_{14}\right) \cdot \text { Term }_{t}\right\} \text { for } h_{\text {top }}>7 \\
& \text { where } \text { Term }_{h}=\left\{\left(h_{t+1}-1.30\right)^{b}-\left(h_{t}-1.30\right)^{b}\right\} \text { and } \text { Term }_{t}=\left\{\left(t+1-t_{130}\right)^{b}-\left(t-t_{130}\right)^{b}\right\}
\end{aligned}
$$

cor $_{5 \%}$ and $b$ as in Formula 13

De dunninggraad in formule (30) is de actuele dunninggraad na eventuele dunning. $\mathrm{Na}$ het bepalen van $I_{G}$ wordt het grondvlak voor dunning op $t=t+1$ bepaald:

$$
G_{b t(t+1)}=G_{a t(t)}+I_{G}(t, t+1)
$$

Verder wordt er een telwerk bijgehouden van het grondvlak en volume van de uitgevoerde dunningen en wordt het totaal geproduceerde volume berekenend met $V_{\text {tot }}=V_{a t}$ $+\Sigma V_{t h}$, evenzo $G_{t o t}=G_{a t}+\Sigma G_{t h}$. Alle resultaten worden per leeftijd opgeslagen, daarna worden de gemiddelde en lopende volumebijgroei berekend met

$\operatorname{ImV}=\frac{V_{t o t(t)}}{t}$

$I C V=\frac{V_{t o t(t+1)}-V_{t o t(t-1)}}{2}$

Op vergelijkbare wijze worden de gemiddelde en lopende bijgroei van het grondvlak berekend.

In tabel 16 is een lijst met de geschatte parameters opgenomen. 
Tabel 16. Lijst met alle parameters

Table 16. List with all parameters.

\begin{tabular}{|c|c|c|}
\hline Parameter & Formula number & Thinning from below \\
\hline$c_{1}$ & (9) & 1.7858753 \\
\hline$c_{2}$ & (9) & 2181.7777369 \\
\hline$c_{3}$ & (9) & 29.2173181 \\
\hline$c_{4}$ & (10) & 3.8454710 \\
\hline$c_{5}$ & (10) & 0.1485590 \\
\hline$c_{6}$ & (10) & 7.2516678 \\
\hline$c_{7}$ & (10) & 120.4952596 \\
\hline$c_{8}$ & (13) & 40.4054428 \\
\hline$c_{9}$ & (13) & 0.0936135 \\
\hline$c_{10}$ & (13) & 14.2873893 \\
\hline$c_{11}$ & (13) & 0.3884765 \\
\hline$c_{12}$ & (13) & 0.0536575 \\
\hline$c_{13}$ & (13) & 10.9979202 \\
\hline$c_{14}$ & (13) & 0.4254250 \\
\hline$c_{15}$ & (15) & 0.0742458 \\
\hline$c_{16}$ & (18) & 5.1279158 \\
\hline$c_{17}$ & (18) & 1.5644403 \\
\hline$c_{18}$ & (18) & 0.0616198 \\
\hline$c_{19}$ & (18) & 0 \\
\hline$c_{20}$ & (19) & 0.6709309 \\
\hline$c_{21}$ & (19) & 0.0000000 \\
\hline$c_{22}$ & (19) & -0.1894587 \\
\hline$c_{23}$ & (19) & 0.0000000 \\
\hline$c_{24}$ & (20) & 0.0068872 \\
\hline$c_{25}$ & (20) & 0.9934647 \\
\hline$c_{26}$ & (21) & 6.1163245 \\
\hline$c_{27}$ & (21) & 0.3880067 \\
\hline$c_{28}$ & (21) & 60.0000000 \\
\hline$c_{29}$ & (21) & 1.7225150 \\
\hline$c_{30}$ & (21) & 0.0520899 \\
\hline$c_{31}$ & (21) & 1.3493317 \\
\hline$c_{32}$ & (22) & 0.7020440 \\
\hline$c_{33}$ & (22) & 0.0005015 \\
\hline$c_{34}$ & (22) & 1.1073394 \\
\hline$c_{35}$ & (22) & 0.0012134 \\
\hline$c_{36}$ & (23) & 0.9931394 \\
\hline$c_{37}$ & (24) & 1.7505500 \\
\hline$c_{38}$ & (24) & 1.1089700 \\
\hline$c_{39}$ & (24) & -2.8610957 \\
\hline$C_{40}$ & (25) & 0.7419436 \\
\hline$c_{41}$ & (25) & 1.0031808 \\
\hline$C_{42}$ & (25) & 0.8407194 \\
\hline$c_{43}$ & (25) & 0.0000000 \\
\hline$c_{44}$ & (22) & 0.8000000 \\
\hline$C_{45}$ & $N_{0}$ & 5000.00000003000 for $\operatorname{Tg} r=6$ \\
\hline$C_{46}$ & & 0.7000000 Border value for $h_{\text {top }}$ \\
\hline
\end{tabular}


In Paragraaf 6.3 wordt de kwaliteit van het ontwikkelde model beoordeeld. In Paragraaf 6.4 worden enkele eigenschappen van de uiteindelijk tabellen vergeleken met andere opbrengsttabellen. In Bijlage 1 zijn de geproduceerde opbrengsttabellen weergegeven.

\subsection{Kwaliteit van de voorspelling}

Om de kwaliteit van het opbrengsttabelmodel te beoordelen moet de ontwikkeling van bestaande opstanden worden voorspeld en vergeleken met de gemeten verandering. Het ontwikkelde groeimodel van Paragraaf 6.2 om opbrengsttabellen te maken moet daartoe gemodificeerd worden tot een "stand projection model".

Van een bepaalde opstand moet en de leeftijd, de opperhoogte, het stamtal en het grondvlak bekend zijn, waarmee alle andere toestandvariabelen kunnen worden berekend. Daarna kan de situatie over een aantal jaren voorspeld worden en een dunning worden gesimuleerd, en de veranderingen in de opstandkenmerken worden voorspeld. Door dit voor de proefperken (zowel van die van de dataset als die van de controle-set) te doen kan de modelvoorspelling worden vergeleken met de gemeten kenmerken. Het "stand projection model" werkt als volgt:

\section{Stap 1. Boniteit bepalen}

Allereerst moet de site index $h_{50}$ met de reciproke van Formule (9), de leeftijd en $h_{\text {top }}$ worden bepaald:

Er wordt daartoe begonnen met een startwaarde voor $h_{50}$, stel $h_{50 \text { old }}=17.8$ (het gemiddelde uit Hoofdstuk 3). Daarna een nieuwe waarde bepalen voor $h_{50}$ met Formule (33)

$$
h_{50 \text { new }}=h_{\text {top }} /\left\{\frac{t^{c_{1}} \cdot\left(50^{c_{1}} \cdot R+c_{2}\right)}{50^{c_{1}} \cdot\left(t^{c_{1}} \cdot R+c_{2}\right)}\right\} \text {, where } R=Z+\sqrt{Z^{2}+\frac{2 \cdot c_{2} \cdot h_{50 \text { old }}}{50^{c_{1}}}} \text { and } Z=h_{50}-c_{3}
$$

Vervolgens een nieuwe beginwaarde bepalen met:

$$
h_{50 \text { old }}=\left(3 \cdot h_{50 \text { old }}+h_{50 \text { new }}\right) / 4
$$

Daarna Formule (33) en (34) herhalen tot $h_{50}=h_{50 \text { new }}=h_{50 \text { old }}$.

\section{Stap 2.}

Met de definitie van de Formules (1) en (15) wordt vervolgens de dunninggraad voor en na dunning bepaald. De grondvlakbijgroei per jaar wordt berekend met de waarden voor $S \%$, $h_{\text {top }}$ en $t$ over het interval $\left\{t_{1} ; t_{2}\right\}$. In Paragraaf 6.2 is beschreven welke formules daartoe gebruikt worden. Hieruit volgt het grondvlak voor dunning op tijdstip $t_{2}$ en hieruit weer de diameter voor dunning $\left(\hat{d}_{b t 2}\right)$.

$\underline{\text { Stap } 3 .}$

Hierna wordt de opperhoogte berekend op het $2^{\mathrm{e}}$ tijdstip met Formule (9). De voorspelde diameterbijgroei op het interval $\left\{t_{1}, t_{2}\right\}$ bedraagt:

$$
\Delta_{d}=\hat{d}_{b t 2}-d_{a t 1}
$$


Er worden evenveel bomen gedund als in werkelijkheid maar de diameter na dunning $\left(\hat{d}_{a t 2}\right)$ wordt berekend met Formule (19).

\section{$\underline{\text { Vervolg }}$}

Stap 2 en 3 kunnen nu herhaald worden voor een $3^{e}$ tijdstip en eventuele vervolgtijdstippen. De stamtallen van de dunning en die voor en na dunning zijn bekend, hiermee en met de formules uit het opbrengsttabel model kunnen alle andere opstandkenmerken worden berekend.

Om de kwaliteit van het model te meten is deze procedure voor series van 4 opnamen doorgerekend (veel perken hebben echter maar 3 opnamen, daar is met 3 opnamen gewerkt). Voor bijvoorbeeld een perk met 6 opnamen ontstaan zo drie voorspellingseries op de intervallen $\left\{t_{1}, t_{4}\right\},\left\{t_{2}, t_{5}\right\}$ en $\left\{t_{3}, t_{6}\right\}$. Vervolgens is de zuiverheid en nauwkeurigheid van de voorspellingen van de bereikte opperhoogte, de diameter na dunning en het opstandgrondvlak na dunning in de laatste (dus de $3^{\mathrm{e}}$ of $4^{\mathrm{e}}$ ) opname bekeken. Het gemiddelde tijdvak bedroeg $11.0 \mathrm{jr}$. Ook werd de grondvlakbijgroei over 10 jaar bekeken (zie Tabel 17 voor de resultaten). De zuiverheid van alle berekende voorspellingen blijkt matig tot slecht, met $0.9 \%$ overschatting van diameter na dunning tot $2.1 \%$ overschatting van de opperhoogte (zie Tabel 17). De nauwkeurigheid is zeer gering (zeer hoge variatiecoëfficiënt). De onzuiverheid komt vooral voor rekening van het proefveldcomplex Gieten waar de hoogtegroei in de jeugd zeer afwijkend is.

Tabel 17. Eigenschappen van enige schatters.

Table $17 . \quad$ Properties of some estimators.

\begin{tabular}{|l|rrrrrr|}
\hline & gesultaten bij laatste opname \\
& gemeten & geschat & bias & bias\% & stdev & CV \\
\hline$h_{\text {top }}$ & 17.73 & 17.36 & 0.373 & $2.10 \%$ & 1.466 & $8.3 \%$ \\
$d_{a t}$ & 21.53 & 21.71 & -0.187 & $-0.87 \%$ & 1.527 & $7.1 \%$ \\
$G_{a t}$ & 31.75 & 31.72 & 0.024 & $0.08 \%$ & 4.200 & $13.2 \%$ \\
$i G_{10}$ & 16.74 & 16.47 & 0.274 & $1.64 \%$ & 4.037 & $24.1 \%$ \\
\hline
\end{tabular}

\subsection{Vergelijking met andere opbrengsttabellen}

Hierna zijn enkele andere opbrengsttabellen voor de fijnspar in Europa vergeleken met het hier gevonden resultaat.

\subsubsection{Hoogteontwikkeling}

Er zijn 3 landen waarvoor tabellen beschikbaar zijn, namelijk die van Dagnelie (1988) voor België, die van Wiedemann (1936, in Schober 1987) voor Duitsland, die van Hamilton en Christie (1971) voor Groot-Brittannië, daarnaast zijn de tabellen van Becking \& de Vries, 1959), die van la Bastide \& Faber (1972) en die van Jansen \& Hildebrand (1986) voor Nederland vergeleken. 


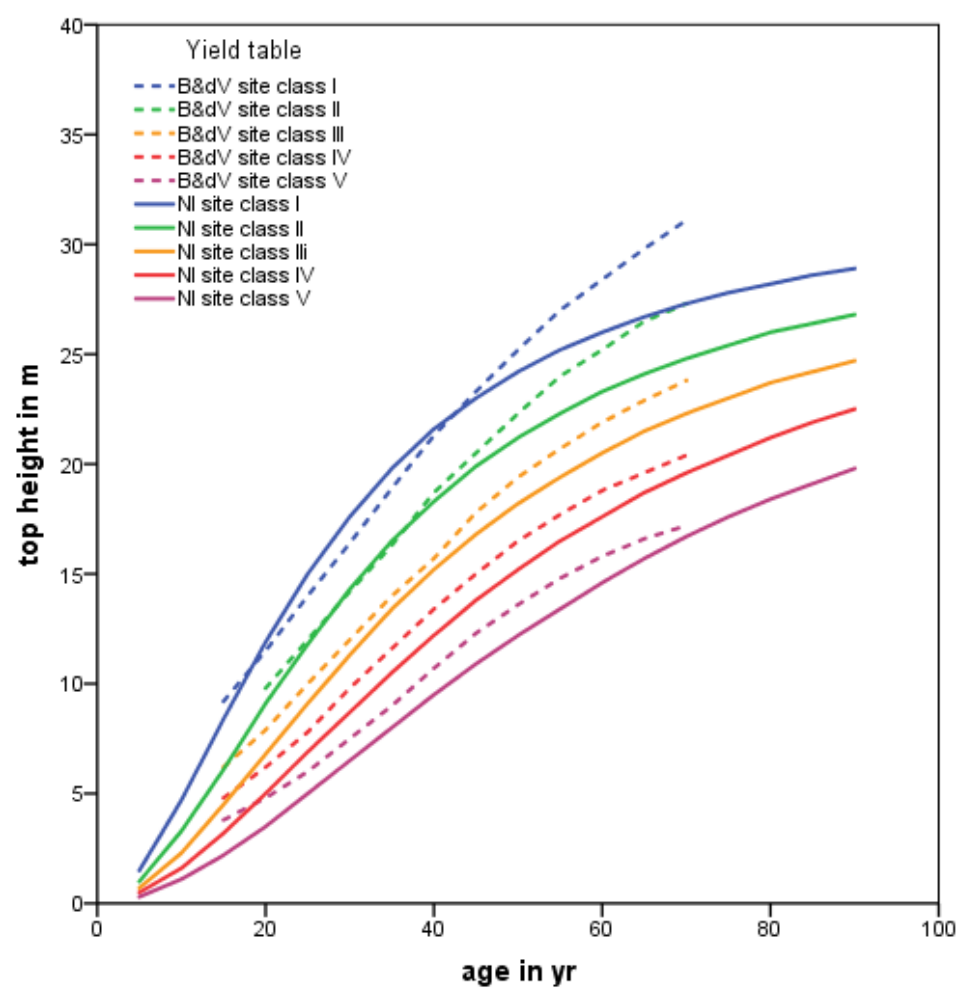

Figuur 16. Hoogteontwikkeling bij Becking \& de Vries en het nieuwe model voor Nederland.

Figure 16. Height development at Becking \& De Vries' yield table and the new model for Netherlands.

De hoogteontwikkeling komt overeen met de oudere Nederlandse opbrengsttabel van Becking en de Vries uit 1959 (zie Figuur 16), dit is een bewerking van de tabel van Møller voor Denemarken uit 1933. De jeugdgroei tot ongeveer 9 wijkt erg af vooral voor de lagere boniteiten, deze is bij Becking en de Vries veel steiler. 


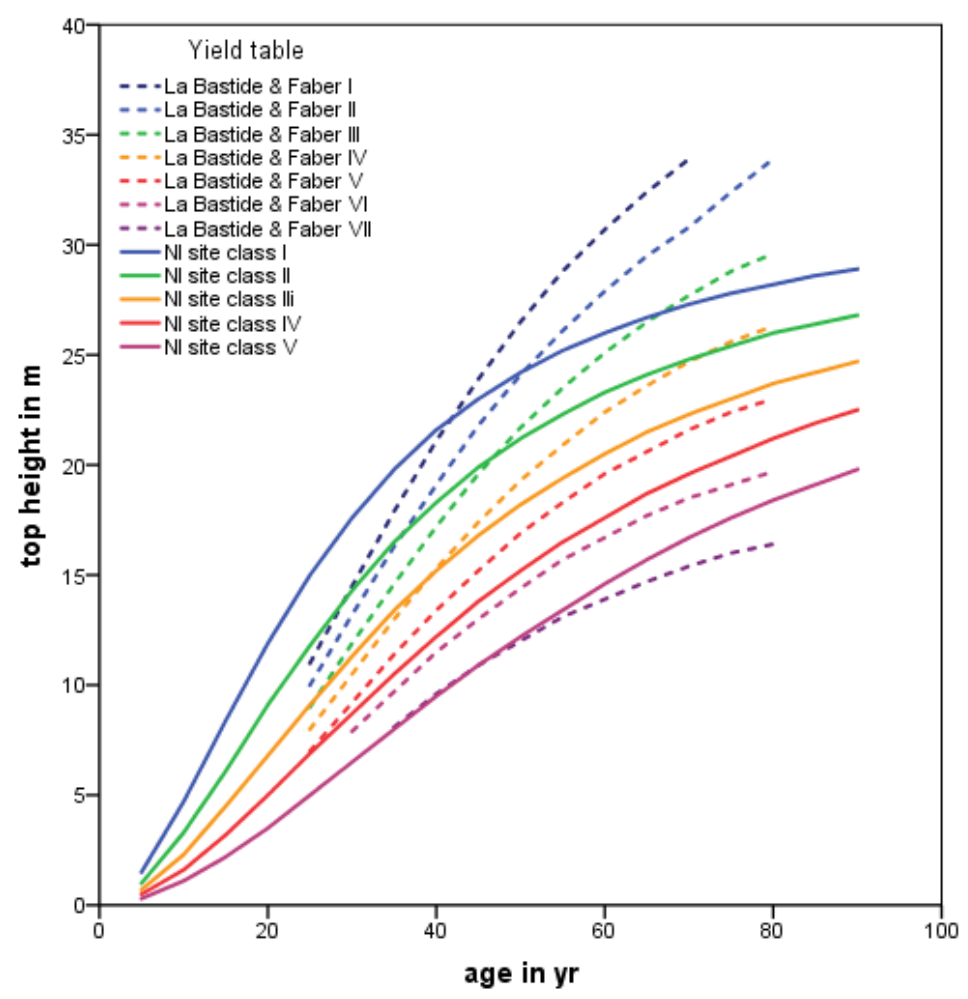

Figuur 17. Hoogteontwikkeling bij van la Bastide \& Faber en het nieuwe model voor Nederland.

Figure 17. Height development at la Bastide \& Faber's yield table and the new model for Netherlands.

De tabel van La Bastide \& Faber (1972) komt wat betreft vorm overeen met de nieuwe tabellen voor Nederland voor de lagere boniteiten overeen met de nieuwe tabellen voor Nederland. Voor de betere boniteiten is het verschil groot door het homomorfe karakter van het oude model en het heteromorfe karakter van het nieuwe model. Van afplatting is bij La Bastide \& Faber geen sprake (zie Figuur 17). 


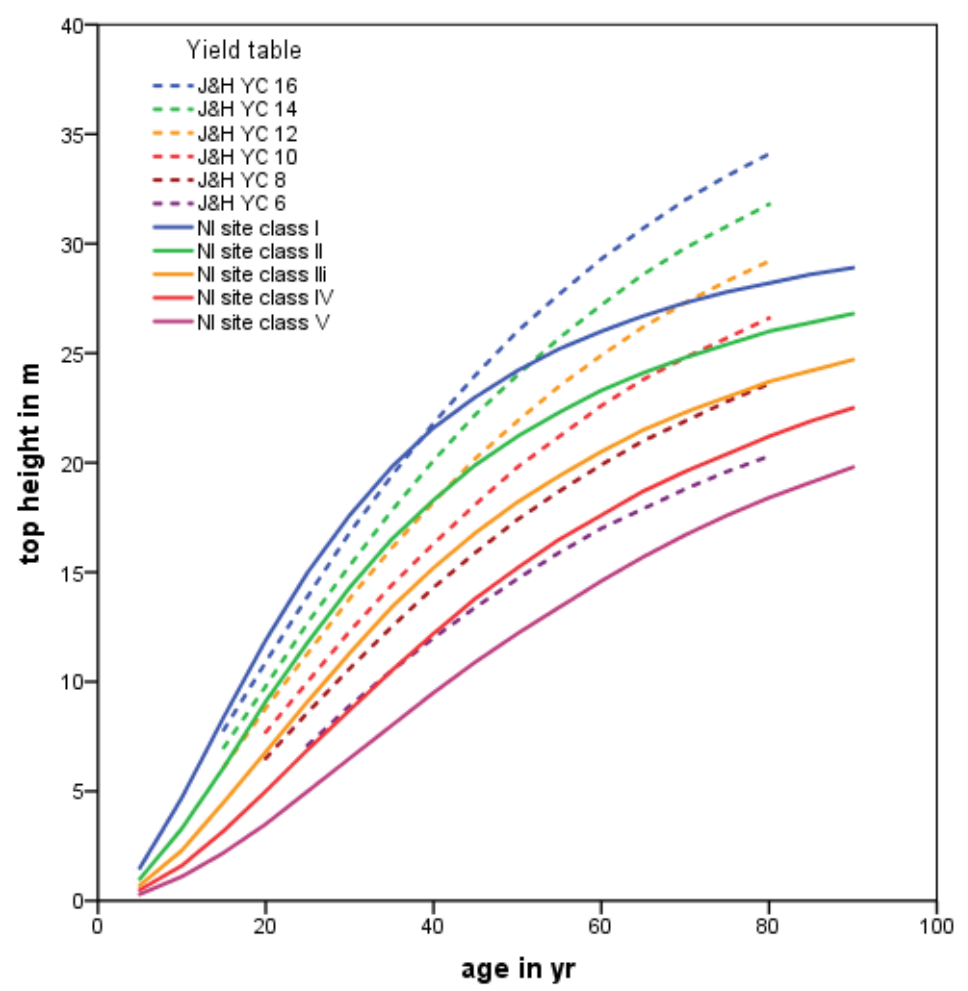

Figuur 18. Hoogteontwikkeling bij van Jansen \& Hildebrand en het nieuwe model voor Nederland.

Figure 18. Height development at Jansen \& Hildebrand's yield table and the new model for Netherlands.

Bij het model van Jansen \& Hildebrand (1986) is nog nauwelijks sprake van een afplattingshoogte, en ook de jeugdgroei is voor de lagere steiler geweest dan in het nieuwe model. De overeenkomst is over het algemeen gering (zie Figuur 18), behalve voor de slechtste boniteit.

Van alle oude Nederlandse modellen komt het oudste van Becking \& De Vries (1959) nog het meest overeen met het nieuwe model voor Nederland.

De opbrengsttabel van Dagnelie (1988) voor België komt voor de III en IVe boniteit zeer goed overeen met de $\mathrm{I}^{\mathrm{e}}$ en $\mathrm{II}^{\mathrm{e}}$ boniteit van de nieuwe tabel voor Nederland. Een vergelijking beneden een hoogte van 15 meter is niet mogelijk doordat Dagnelie die gegevens niet vermeldt. Verder blijken er ongeveer 2 boniteiten boven de beste in de nieuwe tabel voor $\mathrm{Ne}-$ derland voor te komen, en de 2 laagste boniteiten komt bij Dagnelie niet voor (zie Figuur 19). 


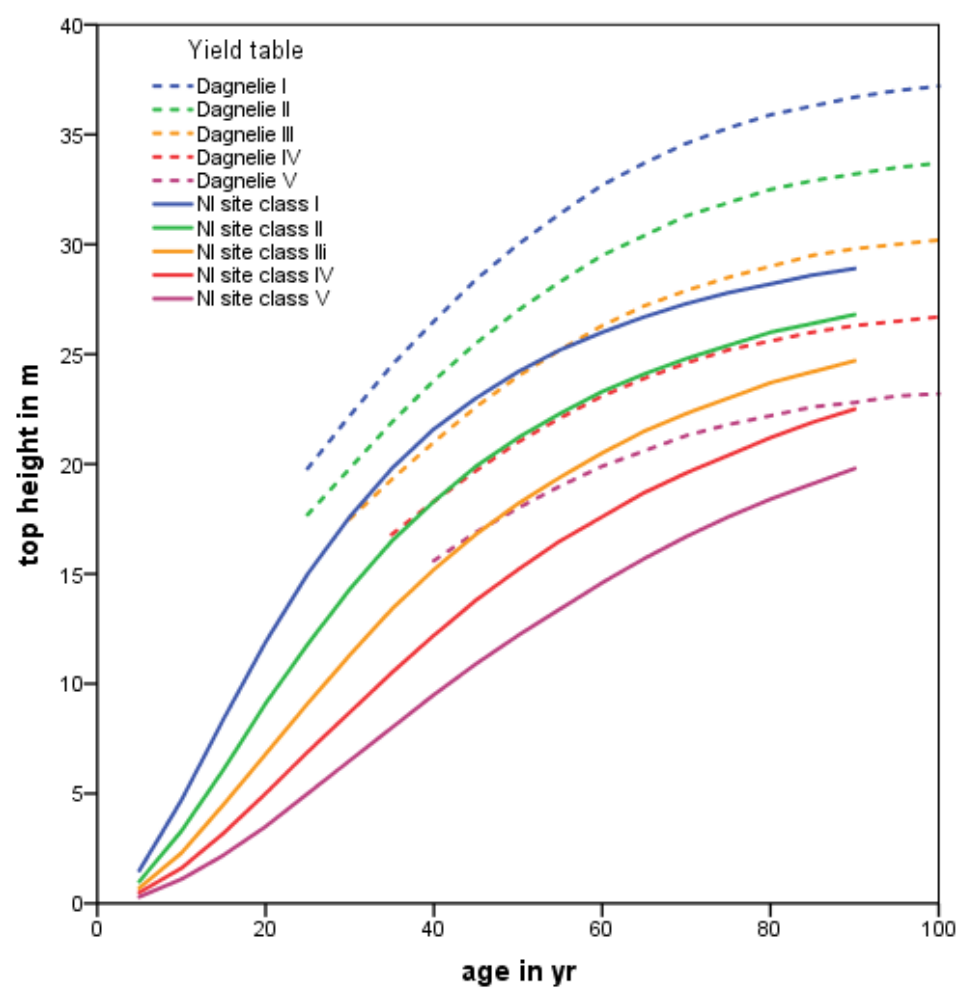

Figuur 19. Hoogteontwikkeling bij Dagnelie en het nieuwe model voor Nederland.

Figure 19. Height development at Dagnelie's yield table and the new model for Netherlands.

Bij Wiedemann (1936) komen er lagere boniteiten voor dan in de nieuwe tabel voor Nederland (zie Figuur 20). Alleen in het traject $20-40$ jaar is er enige overeenkomst bij de middelste boniteiten. Van een afplattingshoogte is bij Wiedemann zelfs tot een leeftijd van 120 jaar geen sprake. 


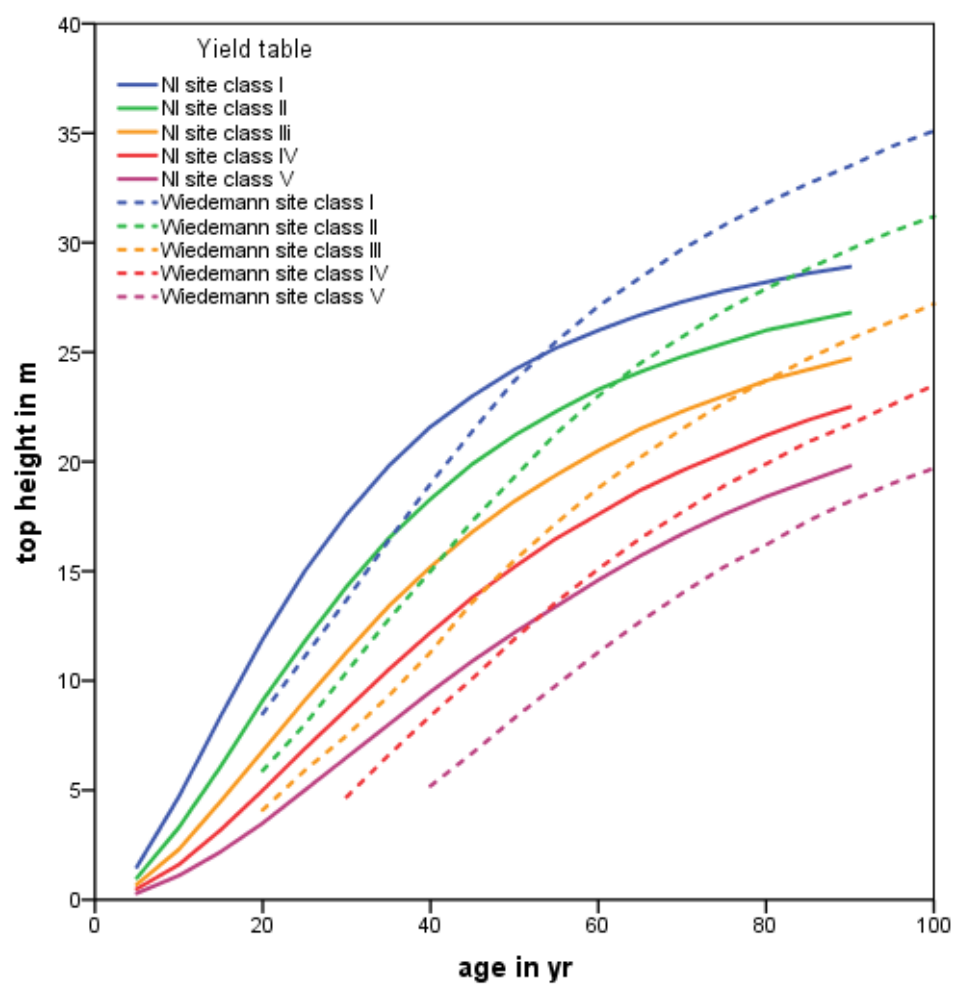

Figuur 20. Hoogteontwikkeling bij Wiedemann en het nieuwe voor Nederland.

Figure 20. Height development at Wiedemann's yield table and the new model for Netherlands.

Bij de vergelijking met de tabel van Hamilton \& Christie (1971) blijkt de vorm van de curve yield class 10 zeer goed overeen te komen met de II ${ }^{\mathrm{e}}$ boniteit van de nieuwe tabel voor $\mathrm{Ne}$ derland. Omdat Hamilton \& Christie een homomorf model gebruiken zijn de verschillen bij de andere boniteiten iets groter (zie Figuur 21) 


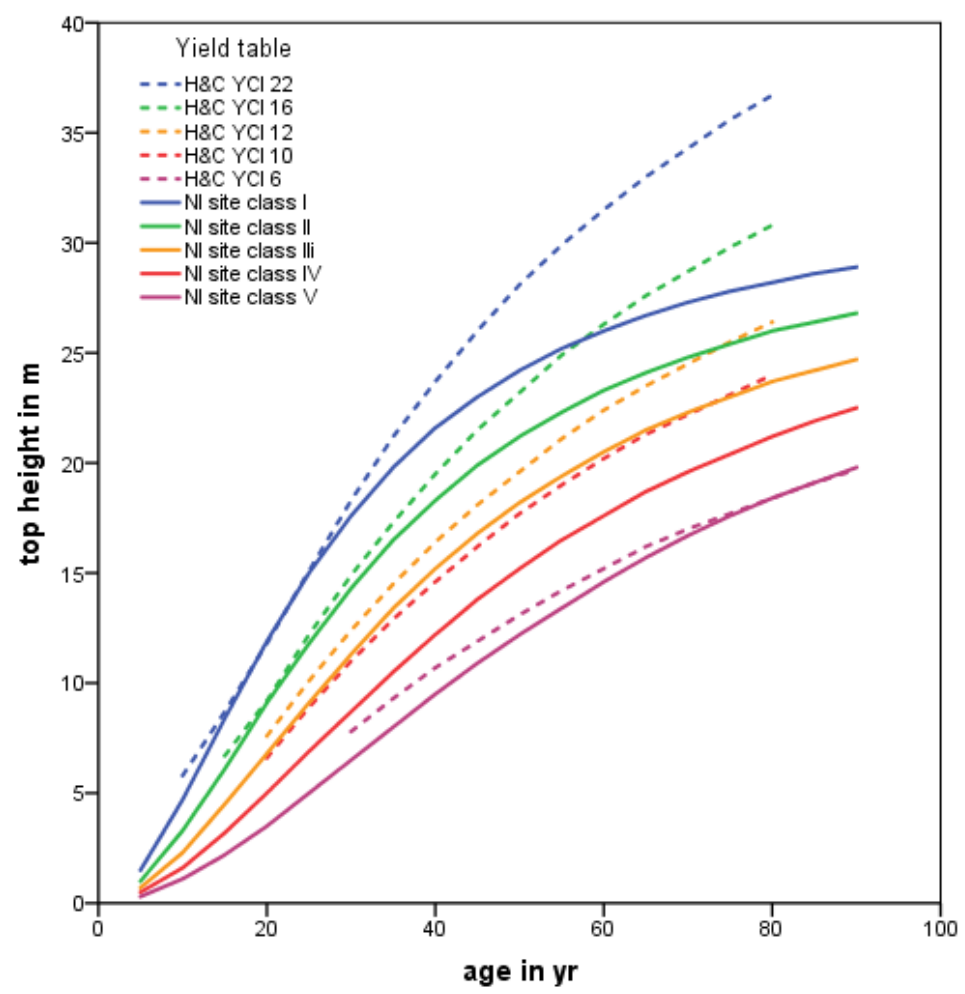

Figuur 21. Hoogteontwikkeling bij Hamilton \& Christie en het nieuwe model voor Nederland.

Figure 21. Height development at Hamilton and Christie's yield table and the new model for Netherlands.

De hoogteontwikkeling bij de vergeleken opbrengsttabellen van België, Groot-Brittannië en die van Becking \& De Vries voor Nederland lijken redelijk overeen te komen met het in deze studie gevonden model. De jeugdgroei was alleen te vergelijken met die bij Becking \& De Vries, daar blijkt deze de jeugdgroei tot een hoogte van ongeveer 8 meter af te wijken. De groei in de opbrengsttabel van Wiedemann voor Duitsland wijkt erg af.

\subsubsection{Productieniveau}

Het productieniveau wordt bij voorkeur gemeten op basis van de gemiddelde volumebijgroei bij zekere leeftijd. Hier is echter naar de totale grondvlakproductie gekeken.

In Figuur 22 is de totale grondvlakproductie per opbrengsttabel uitgezet tegen de opperhoogte voor alle boniteiten. Voor tabellen met meerdere dunninggraden is er steeds één tabel gekozen. Voor de nieuwe tabellen voor Nederland en die van Wiedemann is gekozen voor de matige dunning, duidelijk is het verschil in dunninggraad bij beide tabellen, dus de definitie van een matige dunning verschilt bij die Wiedemann met de alhier gebruikte definitie. Bij de tabel van Dagnelie is gekozen voor behandeling A. De overige tabellen hebben één dunninggraad.

Bij Hamilton \& Christie en ook bij de tabel van Jansen \& Hildebrand vallen alle boniteitlijnen over elkaar. Hier is overduidelijk met een constante $R G B$ (de relatieve grondvlakbijgroei $=$ $\Delta G / \Delta h$ ) in het model gewerkt 
De meeste opbrengsttabellen hebben als startpunt de eerste dunning bij een hoogte van ongeveer $7 \mathrm{~m}$, die van Dagnelie begint na $15 \mathrm{~m}$ en de nieuwe tabel vanaf $1.3 \mathrm{~m}$.

Volgens de "uitgebreide wet van Eichhorn" (Gehrhardt, 1909) zouden bij een presentatie van $V$ tot in relatie tot $h_{\text {top }}$ alle boniteitlijnen over elkaar moeten vallen, dat geldt dan ook min of meer voor Gtot. De modellen van Hamilton \& Christie, van La Bastide \& Faber en van Jansen \& Hildebrand voldoen aan die eis. Maar ook die van Wiedemann voldoet daar redelijk aan $\left(1^{\mathrm{e}}, 2^{\mathrm{e}}\right.$ en $3^{\mathrm{e}}$ boniteit min of meer één lijn, zo ook voor de $4^{\mathrm{e}}$ en $5^{\mathrm{e}}$ boniteit), dat geldt in iets mindere mate voor de tabel van Becking \& De Vries. Let wel, dat hoeft geen rechte lijn te zijn zoals in de $R G B$-modellen.

De tabel van Dagnelie wijkt hier erg vanaf. De nieuwe tabel divergeert op dit punt vanaf een hoogte van $7 \mathrm{~m}$, dit is het gevolg van Model (13).

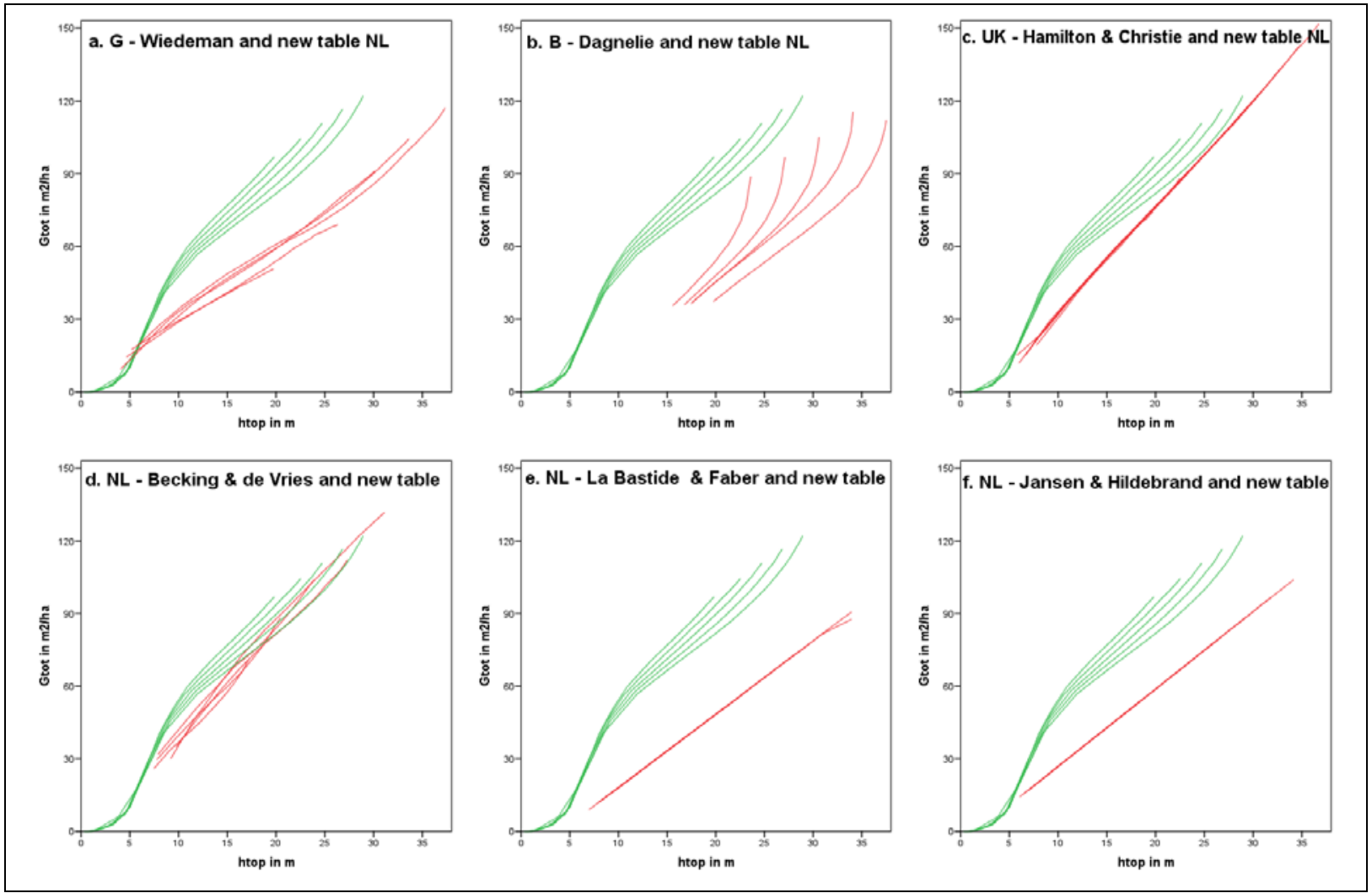

Figuur 22. De totale grondvlakproductie Gtot in relatie tot de opperhoogte bij de nieuwe tabel voor Nederland (in groen) in vergelijking met de opbrengsttabellen (in rood) van a. Wiedemann, b. Dagnelie, c. Hamilton \& Christie, d. Becking \& De Vries, e. La Bastide \& Faber en f. Jansen \& Hildebrand.

Figure 22. Total basal area production Gtot in relation to top height for the new table for the Netherlands (in green) in comparison with other yield tables (in red) from a. Wiedemann, b. Dagnelie, c. Hamilton \& Christie, d. Becking \& De Vries, e. La Bastide \& Faber and f. Jansen \& Hildebrand.

Het productieniveau van de nieuwe opbrengsttabellen komen het meest overeen met dat van de tabellen van Hamilton \& Christie, daarnaast is er redelijke overeenkomst met dat van de tabellen van Becking \& De Vries.

Een andere manier van vergelijken betreft de leeftijd waarop de totale grondvlakproductie wordt bereikt. 
Uit Figuur 23 blijkt nu dat de vorm van de curven van de nieuwe tabel voor Nederland eveneens de grootste overeenkomst vertoont met de tabel van Becking \& de Vries (1959) en die van Hamilton \& Christie (1971).

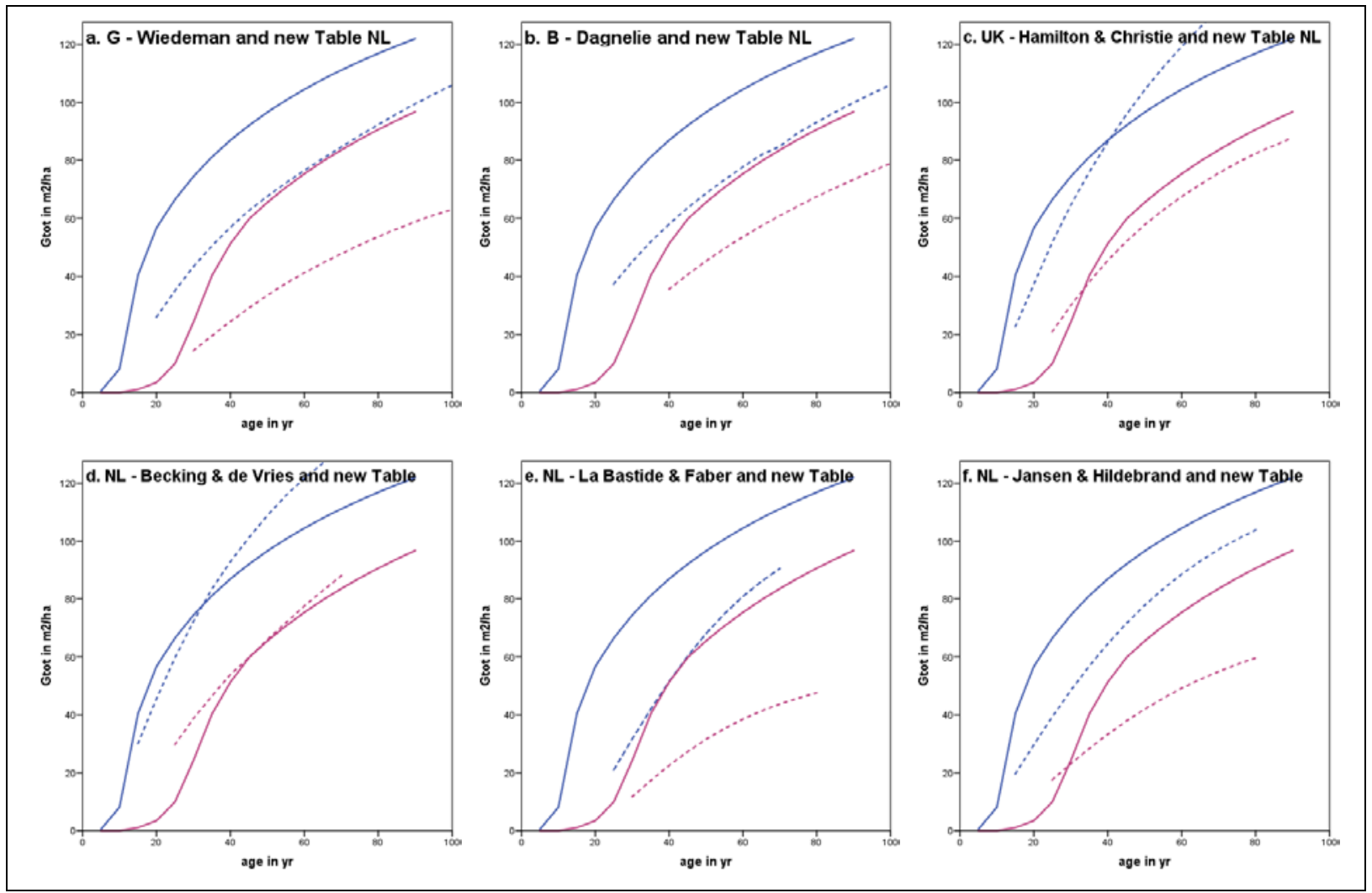

Figuur 23. De totale grondvlakproductie Gtot in relatie tot de leeftijd voor de le boniteit (blauw) en de $V^{e}$ boniteit (paars) bij de nieuwe tabel voor Nederland (volle lijnen) in vergelijking met andere opbrengsttabellen (gestreepte lijnen) voor $a$. Wiedemann, b. Dagnelie, c. Hamilton \& Christie, d. Becking \& De Vries, e. La Bastide \& Faber en $f$. Jansen \& Hildebrand.

Figure 23. Total basal area production Gtot in relation to age for the best site class (blue) and the worst site class (purple) in the new table for the Netherlands (full lines) in comparison with other yield tables (hashed lines) from a. Wiedemann, b. Dagnelie, c. Hamilton \& Christie, d. Becking \& De Vries, e. La Bastide \& Faber and f. Jansen \& Hildebrand.

\subsubsection{Dunningsysteem}

In Paragraaf 5.2 is een ander Model (19) ontwikkeld voor de dunningen dan het Reineke Model (17). In Figuur 29 zijn de in de nieuwe opbrengsttabel gevonden relaties tussen $N_{a t}$ en $d_{g \text { - }}$ at weergegeven (links tabel waarden, rechts na vereffening over de boniteiten). Het blijkt dat de lijnen nagenoeg overeenkomen met die uit Formule (18). De hellingshoek $\left(c_{16}\right)$ wijkt af $(4.8 \%)$ van de eerder met Formule (18) gevonden waarde op plotniveau was deze -1.652, nu bedraagt deze -1.730 voor. De parameter $c_{17}$ blijkt 0.072 in plaats van de regressiewaarde 0.057. De ruis in de lijnen wordt veroorzaakt door verschillen per boniteit door de Formule (13). 
De vraag is of in de vergeleken tabellen ook sprake is van vergelijkbare waarden, daarbij is gekeken naar de hellinghoek en of de dunninggraad relevant is voor de intercept. Alle bekeken tabellen, blijken een vergelijkbare hellingshoek te hebben, namelijk tussen -1.527 en 1.770. De bij de nieuwe tabellen gevonden waarde is aan de ruime kant. De waarden zijn berekend met Formule (18)

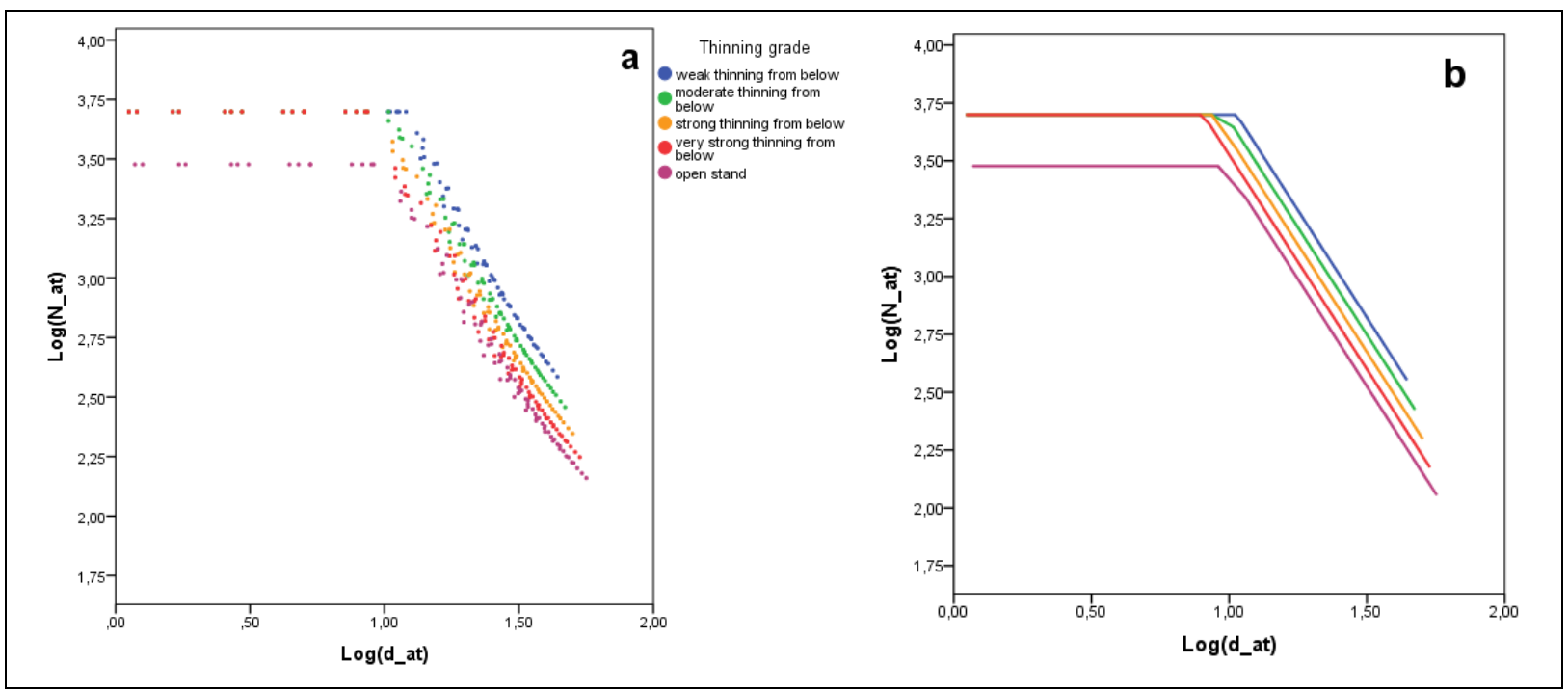

Figuur 24. Reineke-relatie in de nieuwe opbrengsttabellen voor Nederland. Met alle boniteiten en dunninggraden (a), en na vereffening met Formule (18) over de boniteiten (b).

Figure 24. Reineke's model in the new yield tables for The Netherlands. All site classes and thinning grades (a). After smoothing over the site classes with Formula (18) in b.

Tabel 18. Vergelijking parameters in gemodificeerd Reineke Model (18) bij diverse opbrengsttabellen.

Table 18. Comparison of the parameters in the modified Reineke model (18) for various yield tables.

\begin{tabular}{|lc|ccccccc|}
\hline variable & parameter & NL new & Belgium & Germany & UK & NL B \& dV & NL LB \& F & NL J \& H \\
\hline Constant & $c_{16}$ & 5.519 & 5.283 & 5.209 & 5.023 & 5.219 & 4.960 & 5.107 \\
Log_d & $c_{17}$ & 1.730 & 1.770 & 1.633 & 1.527 & 1.689 & 1.423 & 1.606 \\
Tgr & $c_{18}$ & 0.072 & -0.004 & 0.046 & 0.018 & 0.034 & 0.084 & 0.032 \\
\hline
\end{tabular}

\subsection{Effecten dunning op productie}

Volgens de gangbare opvatting in het bosbeheer (Assmann, 1961, Wenk et al., 1990) zullen opstanden met een zwaardere dunninggraad ten opzichte van een opstand met een lichtere dunninggraad onder overige gelijke omstandigheden:

1. Een geringere volume- en grondvlakbijgroei hebben;

2. Een dikkere diameter (geldt zowel voor de $d_{g}$; als voor de $d_{d o m}$ ) hebben.

Om een vergelijking mogelijk te maken is het gebruikelijk het in een opbrengsttabel weergegeven grondvlak per ha na dunning aan te geven als het normale grondvlak. Het werkelijke grondvlak van een opstand met dezelfde leeftijd en boniteit zal daarvan afwijken, maar ook 
opbrengsttabellen met een andere dunninggraad wijken daarvan af. Dit wordt de volkomenheidgraad genoemd.

De volkomenheidgraad van een opstand wordt als volgt gedefinieerd:

$$
\begin{aligned}
s d=\frac{G_{r}}{G_{n}} & \\
\text { where } G_{r} & =\text { the real stand basal area per ha } \\
G_{n} & =\text { the normal basal area per ha } \\
s d & =\text { stocking degree }
\end{aligned}
$$

Het opstandvolume kan nu geschat worden met:

$$
\begin{aligned}
& \hat{V}_{r}=s d \cdot V_{n} \\
& \begin{aligned}
\text { where } \hat{V}_{r}=\text { the estimation of the real stand volume per ha } \\
V_{n}=\text { the normal volume per ha. }
\end{aligned}
\end{aligned}
$$

Dit betreft een berekening over de huidige toestand. De vraag is wat dit betekent voor de bijgroei. Doordat de overgebleven bomen na zo'n sterkere dunning de groeiruimte beter benutten zal de onder punt 1 genoemde geringere volume- en grondvlakbijgroei niet domweg het product zijn van de volkomenheidsgraad en de normale bijgroei uit de tabel. In de literatuur zijn talloze dunningproeven beschreven, waaruit deze teneur blijkt. Als definitie van het normale grondvlak is het grondvlak na dunning voor de nieuwe opbrengsttabel met een matige dunning gekozen. Voor alle boniteiten tezamen werd met een $R^{2}$ adj van 0.957 de volgende functie voor $G_{n}$ gevonden:

$$
G_{n}=48.582+0.2525 \times t-0.003567 \cdot t^{2}-2.204 \times h_{\text {top }}+0.04539 \cdot h_{\text {top }}^{2}+0.01004 \cdot t \cdot h_{t o p}
$$

De vraag is of de eerste veronderstelling aan het begin van deze paragraaf klopt in de ontwikkelde opbrengsttabellen. Hiertoe is het niveau van de grondvlakbijgroei voor dunninggraad 2 op 1 gesteld en die van de andere dunninggraden als fractie daarvan uitgedrukt. Gekozen is om de toestand bij 50 jaar te presenteren. In Figuur 26 is te zien dat de correctiefactor voor de grondvlakbijgroei iets lager is aan als de hierboven gedefinieerde volkomenheidgraad per dunninggraad. De volgende relatie werd in concreto gevonden:

$$
c f= \begin{cases}1 & s d \geq 1 \\ 0.996 \cdot s d^{0.417} & s d<1\end{cases}
$$

Deze Formule (39) sluit redelijk aan bij de Staatsbosbeheer-benadering ${ }^{3}$ voor alle soorten:

\footnotetext{
3 Formule Error! Reference source not found. was opgenomen in de software waarmee de opstandinventarisatie van het Staatsbosbeheer werd verwerkt in de periode 1970-1985.
} 


$$
c f= \begin{cases}1 & s d \geq 0.8 \\ \sqrt{s d} & s d<0.8\end{cases}
$$

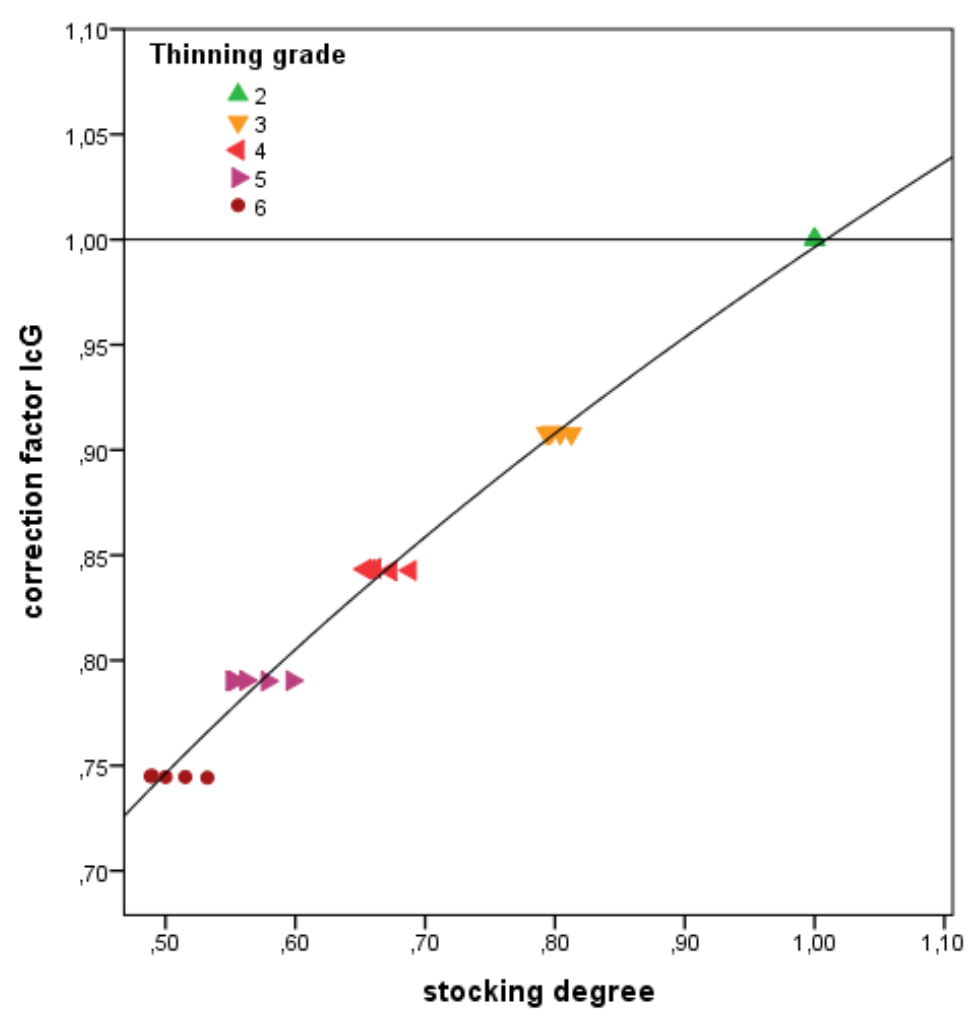

Figuur 25. Correctiefactor grondvlakbijgroei en volkomenheidgraad met de punten uit de nieuwe opbrengsttabel en de daarbij behorende lijnen bij 50 jaar.

Figure 25. Correction factor for basal area increment and stocking degree with the points from the new yield tables and associated lines at 50 year.

De andere voorveronderstelling met betrekking tot de effecten van een lagere volkomenheidsgraad gingen over de diameterontwikkeling. In Figuur 26 is duidelijk dat deze wat betreft de gemiddelde diameter na dunning en de dominante diameter opgaat, want de volkomenheidgraad is gerelateerd aan de dunninggraad, deze weer aan het $S$-procent, en deze aan de wortel uit het stamtal. Om hetzelfde relatieve grondvlak te houden zal de diameter dus sneller moeten groeien.

In Figuur 26 is te zien dat bijvoorbeeld een III ${ }^{\mathrm{e}}$ boniteit de diameter na dunning bij een matige laagdunning $22.5 \mathrm{~cm}$ is en dat deze in een open opstand $26.3 \mathrm{~cm}$ bedraagt, deze afleiding is weer bij 50 jaar uitgevoerd. Voor de dominante diameter bedragen deze waarden respectievelijk 29.0 en $31.9 \mathrm{~cm}$. 

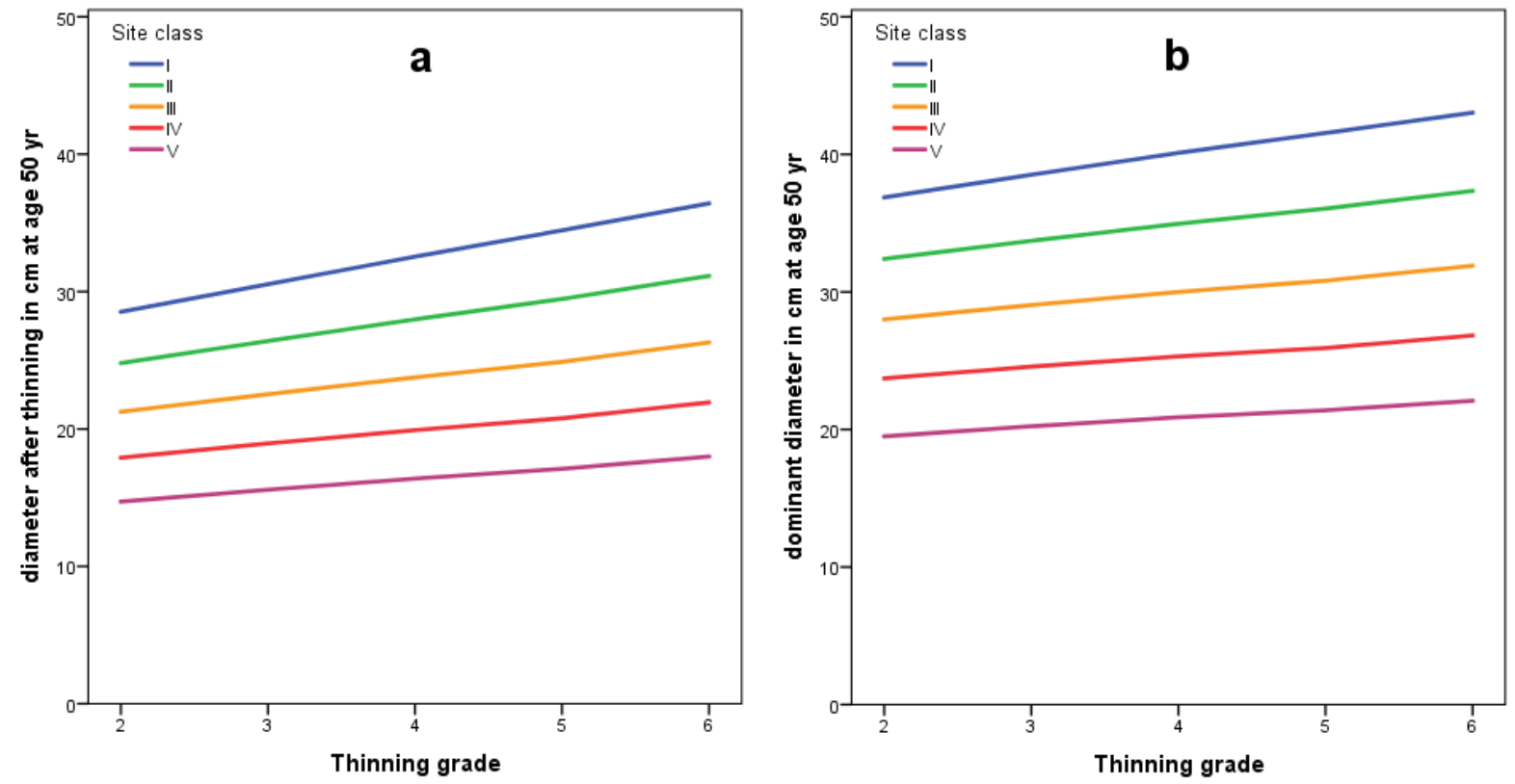

Figuur 26. Relatie tussen diameter (a) en dominante diameter (b) na dunning op 50 jaar met boniteit en dunninggraad.

Figure 26. Relation between diameter (a) or dominant diameter (b) after thinning and thinning grade by site class at 50 years. 


\section{Discussie en conclusies}

\subsection{Hoogtegroei}

De hoogteontwikkeling van de opstand is een resultante van hoogtegroei en topsterfte. Een biologisch relevant groeimodel moet een buigpunt en een asymptoot hebben. Over dat buigpunt en de asymptoot zijn kwantitatieve gegevens afgeleid daarnaast is bekend wat de leeftijd op borsthoogte moet zijn. Met nog wat aanvullende criteria zijn vijf modellen getest, geen voldeed volledig aan alle criteria. Het model van Cieszewski voldeed het best.

$$
h_{\text {top }}=h_{50} \cdot \frac{t^{c_{1}} \cdot\left(50^{c_{1}} \cdot R+c_{2}\right)}{50^{c_{1}} \cdot\left(t^{c_{1}} \cdot R+c_{2}\right)}, \text { where } R=Z+\sqrt{Z^{2}+\frac{2 \cdot c_{2} \cdot h_{50}}{50^{c_{1}}}} \text { and } Z=h_{50}-c_{3}
$$

Voor boniteren geldt dan:

$$
\rightarrow h_{50}=h_{\text {top }} \cdot \frac{50^{c_{1}} \cdot\left(t^{c_{1}} \cdot R+c_{2}\right)}{t^{c_{1}} \cdot\left(50^{c_{1}} \cdot R+c_{2}\right)} \text { and } S=h_{50} \cdot \frac{50^{c_{1}} \cdot R+c_{2}}{50^{c_{1}} \cdot R}
$$

De asymptoot, hier de site index $S$ genoemd, is een maat voor de geschiktheid van de standplaats (boniteit) voor de fijnspar, in de praktijk wordt echter $h_{50}$ als maat voor de boniteit gebruikt. Boniteren is met dit model lastig, want vereenvoudigd staat in Formule (42)

$h_{50}=f\left(h_{t o p}, t, h_{50}\right)$, je moet dus met een startwaarde voor $h_{50}$ werken en iteratief naar een oplossing werken.

De $R^{2}$ adj bleek met een waarde van 0.982 vrij laag, en behalve bij grove den waar 0.970 werd gevonden, lager dan in andere studies werd gevonden, namelijk 0.986 voor douglas, 0.984 voor Japanse lariks. In al deze studies werd ook een heteromorf groeimodel gevonden. De hoogteontwikkeling bij de vergeleken opbrengsttabellen van Duitsland, Groot-Brittannië, België en Nederland zijn er altijd boniteiten die wat betreft de vorm goed overeenkomen met het in deze studie gevonden model. Het meeste overeenkomst is er met opbrengsttabel van Hamilton \& Christie (1971) voor Groot-Brittannië. Verder vertoont de nieuwe tabel meer overeenkomst met de oude tabel van Becking \& De Vries (1967) dan met de vigerende tabel voor Nederland van Jansen \& Hildebrand (1986).

\subsection{Diameter en grondvlak}

In Paragraaf 4.2 is het model voor de lopende bijgroei van het grondvlak ontwikkeld. Dit model start na het bereiken van een opperhoogte van $7 \mathrm{~m}$. In Paragraaf 7.2.2 wordt hierop ingegaan. Om een startwaarde voor de diameter voor dunning en het grondvlak per ha voor dunning te hebben op het tijdstip $t_{7}$ is in Paragraaf 4.1 een model ontwikkeld voor de diameterontwikkeling. In Paragraaf 7.2.1 wordt dit besproken. 


\subsubsection{Diameterontwikkeling}

In Paragraaf 4.1 werd Formule (10) gevonden voor de diameterontwikkeling gevonden, in vereenvoudigde vorm luidt dit:

$$
\begin{gathered}
d_{b t}=f_{2}\left(h_{\text {top }}, d_{7}\right) \text { for } h_{\text {top }} \leq 7 \\
\text { where } d_{7}=f_{1}\left(N_{0}\right) \quad \text { (the diameter at a height of } 7 \mathrm{~m} \text { ) } \\
N_{0}=\text { initial number of trees }
\end{gathered}
$$

Omdat Formule (43) het grondvlak niet zuiver schat zijn de parameters geschat met $G_{b t}=N_{b t} \cdot 1 / 4 \cdot \pi \cdot f_{2}^{2}$. In alle vergeleken opbrengsttabellen is dit traject niet beschreven en starten de tabellen bij de eerste dunning in de buurt van een hoogte van $7 \mathrm{~m}$, en bij Dagnelie nog later met een beginwaarde voor $N_{b t}, G_{b t}$ en $d_{b t}$.

Voor de ontwikkeling van de opbrengsttabel set betekent dit dat $d_{b t}$ bij de open stand $5.5 \%$ dikker is bij een hoogte van $7 \mathrm{~m}$ dan bij de overige dunninggraden. In de dataset komt ook een proefperk voor met $N_{0}=625$, bij een dergelijke dichtheid is $d_{b t}$ modelmatig $35 \%$ dikker bij een hoogte van $7 \mathrm{~m}$ ten opzichte van een proefperk met $N_{0}=5000$. Bij de laatste opname was de opperhoogte ruim $7 \mathrm{~m}$, en met een $\mathrm{S} \%$ van 56 bij lange na nog niet in sluiting. Hoe de groei tot aan sluiting verder verloopt was niet te modelleren bij gebrek aan waarnemingen. Opmerkelijk is dat de $H D$-ratio zelfs bij een beginstamtal van 10000 ver onder 100 is.

\subsubsection{Grondvlakbijgroei}

In Paragraaf 4.2 werd Formule (13) voor de grondvlakbijgroei gevonden, in vereenvoudigde vorm luidt dit:

$$
i_{G, i j k}=f_{1}(s \%) \cdot\left\{\frac{F_{3}\left(t_{2}, h_{2}\right)-F_{3}\left(t_{1}, h_{1}\right)}{t_{2}-t_{1}}\right\}
$$

for the $k^{e}$ plot in the $j^{e}$ calendar year at age $i=t_{m}=\left(t_{1}+t_{2}\right) / 2$

Ook hier bleek een power-functie voor $F_{3}$ het meest geschikt. Net als bij de douglas (Jansen et al. 2016) bleek de power-parameter $b$ afhankelijk van de opperhoogte. De grondvlakbijgroei stijgt met toenemende boniteit, de stijging is alleen een gevolg van $F_{3}$. In de opbrengsttabellen van Jansen \& Hildebrand is een relatieve grondvlakbijgroei $R G B$ (zie La Bastide en Faber, 1972) gebruikt, deze geeft een min of meer rechtevenredig verband tussen grondvlak en hoogte. De afgeleide van de $F_{3}$ functie uit Formule (13) is een ingewikkelde functie van de opperhoogte en geen constante $R G B$. De verschillen tussen de diverse vergeleken opbrengsttabellen is dus deels modelmatig. Maar in Figuur 23 is goed te zien dat de totale grondvlakproductie van de nieuwe opbrengsttabel veel hoger is dan bij Wiedemann (1936) voor Duitsland en bij Jansen \& Hildebrand (1986) voor Nederland, maar goed overeenkomt met die van Hamilton \& Christie (1971) voor Groot-Brittannië en de oude tabel voor Nederland van Becking \& de Vries (1959), wel is de vorm anders en nog een opvallend verschil 
blijkt het uitwaaieren in meerdere lijnen vanaf een hoogte van $7 \mathrm{~m}$ in de nieuwe tabel (Figuur 22). Hiermee is het model in strijd met de "uitgebreide wet van Eichhorn" (Gehrhardt, 1909).

\subsection{Variatie in groei tussen verschillende jaren}

Er is onvoldoende materiaal om een jaarindex (zie Figuur 11b) te bepalen. Maar anders dan bij de douglas en de Japanse lariks werd geen significante correctiefactor voor het jaar van opname gevonden.

\subsection{Dunninggraad}

De diameter blijkt per dunninggraad met gemiddeld 6\% te stijgen ten opzichte van opstanden met een zwakke laagdunning. Boven een dunninggraad van 2 neemt de lopende grondvlakbijgroei met ruim $6 \%$ per dunninggraad af. Voor overige effecten van de dunning zie Tabel 19.

Tabel 19. Relatieve waarden $I_{G}, d_{a t}$ en $d_{d o m}$ per dunninggraad en verdwijnend stamtal en grondvlak door dunning bij III boniteit en $\mathbf{5 0} \mathrm{jr}$.

Table 19. Relative values of $I_{\mathrm{G}}$, $\mathrm{d}_{\mathrm{at}}$ and dom per thinning grade and the changing stem density and basal area and by thinning at $\mathrm{III}^{\mathrm{e}}$ site class and age $=50 \mathrm{yr}$.

\begin{tabular}{|r|rrrr|rr|}
\hline $\boldsymbol{T} \boldsymbol{g}$ & $\boldsymbol{I} \boldsymbol{c}_{\boldsymbol{g}}$ & $\boldsymbol{I m}_{\boldsymbol{g}}$ & $\boldsymbol{d}_{\boldsymbol{a t}}$ & $\boldsymbol{d}_{\boldsymbol{d o m}}$ & $\boldsymbol{N}_{\text {th }}$ & $\boldsymbol{G}_{\boldsymbol{t h}}$ \\
\hline 2 & $100 \%$ & $100 \%$ & $100 \%$ & $100 \%$ & $73 \%$ & $45 \%$ \\
3 & $91 \%$ & $94 \%$ & $106 \%$ & $104 \%$ & $81 \%$ & $53 \%$ \\
4 & $84 \%$ & $90 \%$ & $112 \%$ & $107 \%$ & $86 \%$ & $60 \%$ \\
5 & $79 \%$ & $87 \%$ & $117 \%$ & $110 \%$ & $89 \%$ & $64 \%$ \\
6 & $74 \%$ & $72 \%$ & $124 \%$ & $114 \%$ & $85 \%$ & $62 \%$ \\
\hline
\end{tabular}

Ter vergelijking zijn dezelfde waarden bij een III ${ }^{\mathrm{e}}$ boniteit en 50 jaar bij Wiedemann (1936) vergeleken. De matige dunning heeft bij 50 jaar een dunninggraad van 1.4 en ligt ongeveer op het niveau waar we in Nederland een ongedunde opstand veronderstellen. De sterke dunning heeft bij Wiedemann een dunninggraad van 2.3 en ligt dus nog onder de matige dunning van de nieuwe tabel voor Nederland in.

Tabel 20. Relatieve waarden $I_{G}$, en $d_{a t}$ per dunninggraad en verdwijnend stamtal en grondvlak door dunning bij III boniteit en 50 jr bij Wiedemann (1936).

Table 20. Relative values of $I_{G}, d_{a t}$ per thinning grade and the changing stem density and basal area and by thinning at III ${ }^{\mathrm{e}}$ site class and age $=50 \mathrm{yr}$ by Wiedemann (1936).

\begin{tabular}{|r|rrr|rr|}
\hline $\boldsymbol{T} \boldsymbol{g} \boldsymbol{r}$ & $\boldsymbol{I c}_{\boldsymbol{g}}$ & $\boldsymbol{I m}_{\boldsymbol{g}}$ & $\boldsymbol{d}_{\boldsymbol{t}}$ & $\boldsymbol{N}_{\boldsymbol{t h}}$ & $\boldsymbol{G}_{\boldsymbol{t h}}$ \\
\hline $\mathrm{mD}$ & $100 \%$ & $100 \%$ & $100 \%$ & $60 \%$ & $33 \%$ \\
$\mathrm{sD}$ & $106 \%$ & $103 \%$ & $116 \%$ & $74 \%$ & $44 \%$ \\
\hline
\end{tabular}


Opmerkelijke verschillen bij Wiedemann met de nieuwe tabel is de totale grondvlakproductie. Door sterkere dunning blijkt er bij 50 jaar meer geproduceerd te zijn terwijl de lopende grondvlak bijgroei inmiddels wel lager is bij de matige dunning. Ook lijkt het weinig invloed op de diameter te hebben. Het verschil blijkt te liggen dat de lopende bijgroei bij Wiedemann tot 30 jaar bij de sterke dunning hoger is dan bij de matige dunning. In onze data is dit niet waargenomen.

Jansen et al. (2016) vonden bij de douglas veel grotere effecten van de dunning, de diameter na dunning was $67 \%$ dikker in de open stand ten opzichte van de zwakke dunning, bij de fijnspar is dat $24 \%$. Ook bij de Japanse lariks werd een groter effect (49\%) gevonden.

\subsection{Kwaliteit van het model}

Om de kwaliteit van het model te toetsen zijn de eerste $n-3$ opnamen van ieder proefperk modelmatig drie opnamen "doorgegroeid" waarbij dezelfde dunning van het stamtal als in werkelijkheid werd doorgevoerd, bij perken met maar 3 opnamen zijn dat $n-2$ opnamen (zie Tabel 17).

De schattingen voor zowel de opperhoogte, het grondvlak na dunning, de grondvlakbijgroei als de diameter na dunning van de $4^{\mathrm{e}}$ vervolgopname bleken onzuiver, en werden respectievelijk met $2.1,0.1,1.6$ onderschat en $0.9 \%$ overschat. Aangezien de afzonderlijke opnamen een andere gewicht in deze analyse hebben dan in de oplossing van het regressiemodel (13) kan hieraan geen consequentie worden verbonden. Overigens bleken deze onzuiverheden grotendeels te zijn terug te voeren tot een matige voorspelling van de hoogte bij de 18 jonge perken in de plantafstandproef in Gieten.

In de eerdergenoemde toets op de modelkwaliteit is sprake van dunning en ook in de besproken modellen is een dunninggraad gebruikt. De in Duitsland gebruikelijke indeling met een $A$ - tot en met D-graad gebaseerd op het dunnen van bomen behorend tot een of meerdere Kraftse boomklassen is in Nederland nooit aangeslagen. Becking (1953) vindt deze methode te weinig kwantitatief en kiest voor een S\% (volgens Hart, 1928) van 16\% voor een zwakke laagdunning, met $3 \%$ erbij is dan sprake van de volgende dunninggraad, namelijk bij $19 \%$ een matige laagdunning. In Tabel 9 is een volledig overzicht van het S\% en de bijbehorende namen. Bij de douglas (Jansen et al., 2016) bleek dat het systeem van Becking probleemloos was uit te breiden tot een tabel zonder dunning, hier paste een S\% van $13 \%$ bij. Omdat er bij de fijnspar slechts 6 opnamen voorkomen waarbij en tijdelijk sprake is van een S\% tussen de 13 en $14.5 \%$ ontbreekt iedere mogelijkheid zo'n modelsimulatie te controleren. Daarom is ervan af gezien een tabel zonder dunning op te nemen. In andere opbrengsttabellen is een geleidelijk toename een bepaald S\% te zien vanaf ongeveer 50 jaar. Dit is logisch omdat op latere leeftijd de kroonvorm verandert, waardoor bij gelijkblijvende standruimte een hogere $\mathrm{S} \%$ nodig is. Omdat dit niet in het onderzoek is meegenomen is op basis van die andere opbrengsttabellen geschat wat een geschikt S\% zou zijn en in Formule (15) weergegeven. De logaritmische relatie tussen het stamtal en de diameter na (zelf)dunning blijkt goed te voldoen aan het Reineke-model (Reineke, 1933), ook in andere Europese opbrengsttabellen voor de fijnspar blijkt de hellingshoek een tangens van ongeveer -1.6 te hebben. 
Het Reineke model is minder geschikt om het effect van een bepaalde dunning te kwantificeren. Het ratiomodel (19) van La Bastide en Faber (1972) is gemodificeerd, waarbij de ratio afhankelijk is van de boniteit, de leeftijd en de dunninggraad.

Tabel 21. Groeiklasse per dunninggraad en boniteit.

Table 21. Yield class (mean annual volume increment at $50 \mathrm{yr}$.) per thinning grade and site class.

\begin{tabular}{|l|rrrrr|}
\hline \multirow{2}{*}{ Dunninggraad } & I & II & III & IV & V \\
\hline zwakke laagdunning & 19.3 & 16.6 & 13.8 & 11.1 & 8.3 \\
matige laagdunning & 17.9 & 14.9 & 12.5 & 10.1 & 7.7 \\
sterke laagdunning & 15.9 & 13.6 & 11.4 & 9.3 & 7.2 \\
zeer sterke laagdunning & 14.7 & 12.6 & 10.6 & 8.7 & 6.8 \\
open stand & 12.8 & 10.9 & 9.1 & 7.3 & 5.6 \\
\hline
\end{tabular}

In Tabel 21 is de groeiklasse per boniteit aangegeven. Deze groeiklasse is het totaal geproduceerde (en deels geoogste) gemiddelde spilhoutvolume in $\mathrm{m}^{3} \mathrm{ha}^{-1} \mathrm{jr}^{-1}$ bij een leeftijd van 50 jaar.

De nieuwe tabel voor de zwakke dunning geeft de maximale grondvlakproductie aan. Als het grondvlak na dunning als het normale grondvlak wordt gedefinieerd met een volkomenheidgraad van 1. Bij een hogere dunninggraad daalt de volkomenheidgraad naar 0.80 bij een matige dunning tot 0.50 bij een open stand, terwijl de grondvlakbijgroei op respectievelijk $94 \%$ en $72 \%$ bleef.

De volumeproductie is in Tabel 22 ook vergeleken met andere opbrengsttabellen, nu bij 70 jaar.

Tabel 22. Groeiklasse per opbrengsttabel en boniteit.

Table 22. Yield class at 70 year for some yield tables and site classes.

\begin{tabular}{|l|l|rrrrr|}
\hline \multirow{2}{*}{ Yield table } & \multirow{2}{*}{ Thinning grade } & I & II & III & IV & V \\
\hline New table Netherlands & moderate & 16.0 & 13.8 & 12.0 & 10.3 & 8.5 \\
\hline Dagnelie et al ., 1988 & moderate & 15.7 & 13.9 & 11.7 & 9.7 & 7.8 \\
Wiedemann, 1936 & weak & 11.9 & 9.2 & 6.7 & 4.5 & 2.9 \\
Hamilton \& Christie, 1971 & extra heavy & 21.9 & 17.8 & 13.8 & 9.7 & 5.6 \\
Møller, 1933 & extra heavy & 18.7 & 15.3 & 12.1 & 9.2 & 6.6 \\
\hline
\end{tabular}

1) in: Becking \& de Vries (1959) 


\section{Samenvatting}

Dit is een rapport over de groei en productie van de fijnspar (Picea abies) in Nederland. Er is onderzocht hoe de ontwikkeling van de hoogte, diameter en het grondvlak in de tijd is geweest en hoe deze beïnvloed wordt door de dunning. Met de gevonden relaties en andere allometrische relaties is een set opbrengsttabellen opgesteld voor diverse dunninggraden. De gebruikte dataset betreft de gegevens die sinds 1951 in Nederland in groei- en productieonderzoek bij de fijnspar zijn verzameld door diverse bosbouwonderzoekgroepen die nu alle tot de WUR behoren. De grootste verzameling data betreft het groei- en productieonderzoek van de voormalige Dorschkamp, gemeten tussen 1959 en 1989; dit omvat 41 proefperken. Daarnaast het dunningonderzoek van Becking; dit omvat 8 proefperken, gemeten tussen 1951 en 1982. De rest van de collectie bestaat uit 24 proefperken in een plantafstandenproef. Daarnaast zijn 51 plots uit de $4^{\mathrm{e}}$ bosstatistiek, en later de HOSP, toegevoegd. Hiervan zijn 116 proefperken met in totaal 388 opnamen geselecteerd voor dit onderzoek.

Per opname zijn leeftijd, opnamedatum en opperhoogte bekend en per toestand voor, na en van de dunning stamtal, grondvlak, diameter, hoogte en volume. Van een groot aantal proefperken zijn ook de basisgegevens per boom bekend, inclusief de stamvoetcoördinaten. In deze studie is hiervan geen gebruik gemaakt.

De hoogteontwikkeling is onderzocht met vijf bekende groeimodellen en bleek het best te verklaren met het model van Cieszewski (2001), dit heteromorfe model luidt:

$$
h_{\text {top }}=h_{50} \cdot\left\{t^{c_{1}} \cdot\left(50^{c_{1}} \cdot R+c_{2}\right)\right\} /\left\{50^{c_{1}} \cdot\left(t^{c_{1}} \cdot R+c_{2}\right)\right\} \text { met } R=Z+\sqrt{Z^{2}+\frac{2 \cdot c_{2} \cdot h_{50}}{50^{c_{1}}}} \text { en } Z=h_{50}-c_{3} \text {. }
$$

Hierin is $h_{50}$ een proefperkspecifieke parameter en maat voor een absolute hoogteboniteit, $c_{1}, c_{2}$ en $c_{3}$ soortspecifieke parameters die de vorm van de curve bepalen. Met voorwaardelijk niet-lineaire regressie (CNLR) en $R^{2}$ adj $=0.982$ werd een oplossing gevonden, naast het $R^{2}$ adj werden 5 andere criteria in de keuze meegewogen te weten variatiecoëfficiënt van de $h_{50}$-parameter, en de gemiddelde en intervallen voor de schattingen van $S, t_{130}$ (leeftijd op borsthoogte), $h_{\text {if }}$ (buigpunt) en $h_{50}$ (hoogte op 50 jaar) en de nauwkeurigheid van de schattingen van de overige parameters per model.

De diameterontwikkeling (voor dunning: $d_{b t}$ ) tot een hoogte van $7 \mathrm{~m}$. werd het best verklaard met een Gompertz-functie: $d_{b t}=d_{7} \cdot \exp \left(-c_{4} \cdot e^{-c_{5} \cdot\left(h_{\text {top }}-1.30\right)}\right) / \exp \left(-c_{4} \cdot e^{-c_{5} \cdot(7-1.30)}\right)$. De diameter bij een hoogte van $7 \mathrm{~m}$ bleek een functie van het beginstamtal $d_{7}=c_{6}+c_{7} / \sqrt{N_{0}}$. Met een stamtal $N_{0}$ van 5000 bleek de diameter bij een hoogte van $7 \mathrm{~m}\left(d_{7}\right) 9.0 \mathrm{~cm}$, bij een stamtal van 625 (plantverband $4 \times 4 \mathrm{~m}$ ) is dat $12.1 \mathrm{~cm}$. De $R^{2}$ adj bleek 0.976 . Het model is alleen gebruikt om de diameter- en grondvlakontwikkeling tot een hoogte van $7 \mathrm{~m}$ te voorspellen. Voor het traject boven een hoogte van $7 \mathrm{~m}$ is de grondvlakbijgroei gemodelleerd met een op de wet van Eichhorn (Gehrhardt, 1909) gebaseerd model: $i_{G}=f\left(h_{\text {top }}, S \%\right)$ waarbij gebruik gemaakt is van een powermodel. Voor $S \%>14.3$ daalt de grondvlakbijgroei niet-lineair in $S \%$ met gemiddeld $6.4 \%$ per eenheid. De $R^{2}$ adj is 0.857 . Het jaar van opname bleek geen significante bijdrage te leveren. Maar in strijd met de wet van Eichhorn bleek het ook afhankelijk van de leeftijd. 
Het effect van de dunning op de diameter na dunning $\left(d_{a t}\right)$ is gemodelleerd met een modificatie van het La Bastide-Faber model (1972); het model van Reineke (1933) is als controle op de uitkomsten gebruikt.

Met deze modellen is een stand projection model gemaakt om de werking van de integratie van de modellen voor hoogtegroei, grondvlakgroei en het effect van de dunning te toetsen. Het resultaat van deze test bleek matig, en bleek terug te voeren tot de hoogteontwikkeling in de jeugdgroei inde plantafstandproef in Gieten (18 proefperken met iets afwijkende jeugdgroei). Met de geïntegreerde modellen zijn opbrengsttabellen gemaakt voor een leeftijd tot 90 jaar met 5 boniteiten en 5 dunninggraden. Deze zijn vergeleken met tabellen in België, Duitsland en het Verenigd Koninkrijk en met die van Becking \& De Vries, La Bastide \& Faber en Jansen \& Hildebrand voor Nederland. De overeenkomsten varieerden van slecht tot goed.

Op hoofdlijnen bleek het model van Jansen et al. (2016) voor de douglas ook bruikbaar voor de fijnspar. 


\section{Summary}

This report concerns growth and production of Norway spruce (Picea abies) in Netherlands. The report deals with development of the height, diameter and basal area in the time, based on permanent field plots, and how these characteristics are affected by thinning. The regularities and allometric relationships found, were used to construct a set of yield tables for various thinning grades in even-aged stands of Norway spruce.

The dataset used in this study consists is composed of all growth and production related research of Norway spruce in the Netherlands, carried out since 1951 by various forestry research groups, now all part of Wageningen University and Research (WUR). The largest data collection concerns the growth and production research done at the former Dorschkamp research institute, with 41 permanent plots measured between 1959 and 1989.

In addition, a thinning trial initiated by Becking in 1948, including 8 experimental plots measured between 1951 and 1982, was included. Furthermore, the dataset includes 24 plots of a stand density trial. Finally, 51 plots from the 4th Dutch National Forest Inventory, and later on the timber prognosis system HOSP, were added. In total, the dataset consists of 116 plots with 388 recordings.

For each plot record, stand age, recording date and top height are known, as well as stem density, basal area, diameter, height and volume before and after thinning, as well as of the thinning itself. In many plots, the individual tree attributes within the plots are also known, including stem coordinates, but these were not used in the analysis reported here.

Height development was analysed using five well-known equations, and the best fit was found with Cieszewski's model (2001); this polymorphic model is given by:

$h_{\text {top }}=h_{50} \cdot\left\{t^{c_{1}} \cdot\left(50^{c_{1}} \cdot R+c_{2}\right)\right\} /\left\{50^{c_{1}} \cdot\left(t^{c_{1}} \cdot R+c_{2}\right)\right\}$ where $R=Z+\sqrt{Z^{2}+\frac{2 \cdot c_{2} \cdot h_{50}}{50^{c_{1}}}}$ and

$Z=h_{50}-c_{3}$. Here, $h_{50}$ is a plot specific parameter and a measure for site index, and $c_{1}, c_{2}$ and $c_{3}$ are species-specific parameters that determine the shape of the curve. With conditionally non-linear regression (CNLR) and $R^{2}$ adj $=0.982$ a solution was found. Besides $R^{2}$ adj five other criteria were used in the selection process: the coefficient of variation for the $h_{50}$-parameter, and the means and intervals of the estimates for $S, t_{130}$ (age when breast height is reached), $h_{\text {if }}$ (inflection point of height curve) and $h_{50}$ (height at 50 years), together with the precision of the estimates for the other parameters of the model.

The diameter development (before thinning: $d_{b t}$ ) to a height of $7 \mathrm{~m}$ was best explained by a Gompertz function: $d_{b t}=d_{7} \cdot \exp \left(-c_{4} \cdot e^{-c_{5} \cdot\left(h_{\text {top }}-1.30\right)}\right) / \exp \left(-c_{4} \cdot e^{-c_{5} \cdot(7-1.30)}\right)$. The diameter at a height of $7 \mathrm{~m}$ could be expressed as a function of the initial density $d_{7}=c_{6}+c_{7} / \sqrt{N_{0}}$. With $N_{0}=5000$, diameter at a height of $7 \mathrm{~m}\left(d_{7}\right)$ was $9.0 \mathrm{~cm}$, with a stem density of 625 (spacing 4 x $4 \mathrm{~m}$ ) this was $12.1 \mathrm{~cm}$. The $R^{2}$ adj was 0.976 . The model was only used for diameter and basal area development up to a height of $7 \mathrm{~m}$. For the development above $7 \mathrm{~m}$ height, basal are increment was modelled using a model based on Eichhorn's law (Gehrhardt, 1909): $i_{G}=f\left(h_{\text {top }}, S \%\right)$, using a power function. For $S \%>14.3$ the basal area increment decreases nonlinearly relative to $S \%$ with $6.4 \%$ per unit. The $R^{2}$ adj is 0.857 . The year of recording did 
not have a significant contribution. However, Eichhorn's law turned out to be depended on the age.

The effect of thinning on diameter after thinning $\left(d_{a t}\right)$ was modelled with a modification of the La Bastide-Faber model (1972); Reineke's model (1933) was used as an overall check of the results.

With these models a stand projection model was made to analyze the integration of the models for height and basal area growth, as well as the effect of the thinning. The results of this test appeared limited, largely related to juvenile height growth in the spacing trial in Gieten (18 experimental plots with slightly different juvenile growth). Using the integrated models, yield tables were created for even-aged stands of ages up to 90 years, using 5 site classes and 5 thinning grades. These yield tables have been compared with tables from Belgium, Germany and the United Kingdom and with those published by Becking \& De Vries (1959), La Bastide \& Faber (1972) and Jansen \& Hildebrand (1986) for The Netherlands.

Overall, the model of Jansen et al. (2016) for Douglas fir, turned out to be suitable also for Norway spruce. 


\section{Literatuur}

Assmann, E., 1961. Waldertragskunde : organische Produktion, Struktur, Zuwachs und Ertrag von Waldbestaenden. München.

Bartelink, H.H., A.F.M. Olsthoorn, A. Oosterbaan \& S.M.J. Wijdeven, 2001. Overzicht van een eeuw onderzoek naar groei en opstandsontwikkeling in relatie tot groeiplaats en beheer. Alterra, Research Instituut voor de Groene Ruimte, Wageningen, Alterrarapport 256.

Becking, J. H., 1953. Thinning research in forestry. Netherlands Journal of Agricultural Science; 1953. 1(2):122-9.

Becking, J.H. en P.G. de Vries, 1959. Richtlijnen voor de bedrijfsregeling van bosbezit in Nederland: samengesteld door de commissie bosbedrijfsregeling van de Nederlandsche Boschbouwvereeniging, ingesteld op 7 januari 1954

Burkhart, H,E. \& R.B. Tennent, 1977. Site index equations for radiata pine in New Zealand. New Zealand Journal of Forestry Science 7: 408416.

C.B.S. (Centraal Bureau voor de Statistiek),1985. De Nederlandse Bosstatistiek, deel 1: de oppervlakte bos,1980 1983. Staatsuitgeverij, s'Gravenhage

Cieszewski C.J., 2001. Three methods of deriving advanced dynamic site equations demonstrated on inland Douglas-fir site curves. Can. J. For. Res. 31: 165-173 .

Dagnelie, P. 1988. Tables de production relatives à l'épicéa commun. Les presses Agronomiques de Gembloux, Gembloux, Belgium. 124 p

Dik, E.J., 1984. De schatting van het houtvolume van staande bomen van een aantal in de bosbouw gebruikte soorten. Uitvoerig verslag Rijksinstituut voor onderzoek in de bos en landschapsbouw "De Dorschkamp" Band 19(1), Wageningen.

La Bastide, J.G.A. \& P.J. Faber, 1972. Revised yield tables for six tree species in the Netherlands. Uitvoerig Verslag Bosbouwproefstation "De Dorschkamp", band 11, nr. 1.

Gehrhardt, E., 1909. Über Bestandeswachstumsgesetze und ihre Anwendung zur Aufstellung von Ertragstafeln. Allg. Forst- u. J.-Ztg. 85: 117-128.

Gompertz, B. 1832. "On the Nature of the Function Expressive of the Law of Human Mortality, and on a New Mode of Determining the Value of Life Contingencies." Phil. Trans. Roy. Soc. London 123, 513-585

Hamilton, G.J. and J.M. Christie, 1971. Forest management tables (metric). Forestry Commission Booklet no. 34. HMSO, London.

Hart, H.M.J., 1928. Stamtal en dunning : een orienteerend onderzoek naar de beste plantwijdte en dunningswijze voor den djati. Proefschrift Wageningen. Mededeelingen Proefstation voor het Boschwezen (21) 219 p. + 7 bijl. Veenman, Wageningen.

Heisterkamp, S.H., 1981. Opstandsinhoudsfuncties. Rapport Rijksinstituut voor onderzoek in de bos- en landschapsbouw "De Dorschkamp" 271, Wageningen.

IUFRO, 1959. The standardization of symbols in forest mensuration. International Union of Forest Research Organizations, Londen.

Jansen, J.J. \& J.W. Hildebrand, 1986. Een nieuwe opbrengsttabel voor de fijnspar (Picea abies Karst.) in Nederland. Landbouwhogeschool, Vakgroep Boshuishoudkunde, Wageningen.

Jansen, J.J., A. Oosterbaan, L.G. Goudzwaard, J.F. Oldenburger, G.M. Mohren \& J. den Ouden, 2016. FEM growth and yield data Monocultures - Norway spruce. DANS. http://dx.doi.org/10.17026/dans-ztn-p5uj. 
Jansen, J.J., A. Oosterbaan, G.M.J. Mohren \& J. den Ouden, 2018. Groei en productie van Japanse lariks in Nederland. FEM Groei en productie rapport $2018-1$, Wageningen Universiy. https://doi.org/10.18174/444088

Jansen, J.J., J. Sevenster \& P.G. Faber (redactie), 1996. Opbrengsttabellen voor belangrijke boomsoorten in Nederland. IBN rapport 96/Hinkeloord reports No.17, 202 pag.

Jansen, J.J., H. Schoonderwoerd, G.M.J. Mohren and J. den Ouden, 2016. Groei en productie van douglas in Nederland. Becking's dunningproeven ontsloten. Wageningen Academic Publishers. https://doi.org/10.3920/978-90-8686-827-8

Korf, V. (1939): Příspevěk k matematické formulaci vzrůstového zákona lesních porostů. [Contribution to mathematical definition of the law of stand volume growth.] Lesnická práce, 18: 339-379.

Møller, C., 1933. Boniteringstabellcr og bonitetsvise Tilvækstoversigter for Bøg, Eg og Rødgran i Danmark.

Pienaar, L.V., \& K.J. Turnbull, 1973. The Chapman-Richards generalization of von Bertallanffy's growth model for basal area growth and yield in even-aged stands. Forest Science 19: 2-22.

Reineke, L.H., 1933. Perfecting a stand density index for even-aged forests. Jour. Agric. Res. 46, 627-638.

Richards, F. J. (1959). "A Flexible Growth Function for Empirical Use". Journal of Experimental Botany 10 (2): 290-300.

Schober, R., 1987. Ertragstafeln wichtiger Baumarten bei verschiedener Durchforstung. Dritte neubearb. Aufl. Sauerländer, Frankfurt a. M.

Wenk, G., Antanaitis, V. and Smelko, S., 1990. Waldertragslehre. Landwirtschaftsverlag, Berlin.

Wiedemann, E. Die Fichte 1936. In: Schober, R., 1987. Ertragstafeln wichtiger Baumarten bei verschiedener Durchforstung. Dritte neubearb. Aufl. Sauerländer, Frankfurt a. M. 


\section{Bijlage 1. Opbrengsttabellen voor fijnspar}

\section{Toelichting opbrengsttabellen}

In de kop van de opbrengsttabellen zijn een aantal standaard symbolen (IUFRO, 1959). In onderstaande tabel wordt de SI-eenheid vermeld en de betekenis van het symbool weergegeven.

\begin{tabular}{|l|l|l|}
\hline symbool & eenheid & betekenis \\
\hline Boniteit & & relatieve indeling in groeiklassen \\
$h 50$ & $\mathrm{~m}$ & Site index (opperhoogte op $50 \mathrm{jr})$ \\
$P 50$ & $\mathrm{~m}^{3} \mathrm{ha}^{-1} \mathrm{j}^{-1}$ & Productieklasse op $50 \mathrm{jr}$ 1) \\
$t$ & $\mathrm{j}$ & leeftijd vanaf kieming \\
$h_{\text {top }}$ & $\mathrm{m}$ & opperhoogte \\
$h_{d o m}$ & $\mathrm{~m}$ & dominante hoogte \\
$d_{d o m}$ & $\mathrm{~cm}$ & gemiddelde diameter van dominante hoogte boom \\
$N$ & $\mathrm{ha}^{-1}$ & stamtal per ha \\
$S \%$ & $\mathrm{~m}^{2} \mathrm{ha}^{-1}$ & Hart-Becking dunning-index \\
$G$ & $\mathrm{~cm}$ & grondvlak per ha \\
$d_{g}$ & $\mathrm{~m}^{3}$ & diameter (1,30 m) van de middenboom ${ }^{2)}$ \\
$h_{g}$ & $\mathrm{~m}^{3} \mathrm{ha}^{-1}$ & hoogte van de middenboom \\
$V$ & $\mathrm{~m}^{2} \mathrm{ha}^{-1} \mathrm{j}^{-1}$ & volume per ha ${ }^{3)}$ \\
$I_{G}$ & $\mathrm{~m}^{2} \mathrm{ha}^{-1} \mathrm{j}^{-1}$ & lopende grondvlakbijgroei per ha op leeftijd $t$ jaar \\
$I C_{V}$ & $\mathrm{~m}^{3} \mathrm{ha}^{-1} \mathrm{j}^{-1}$ & lopende volumebijgroei oer ha op leeftijd $t$ jaar \\
$I m_{G}$ & $\mathrm{~m}^{3} \mathrm{ha}^{-1} \mathrm{j}^{-1}$ & gemiddelde grondvlakbijgroei per ha tot op leeftijd $t$ jaar \\
$I m_{V}$ & gemiddelde volumebijgroei per ha tot op leeftijd $t$ jaar \\
\hline
\end{tabular}

1) gemiddelde productie, inclusief dunning maar exclusief sterfte (volumebijgroei) per ha tot op leeftijd 50 jaar

2) boom met gemiddeld boomgrondvlak en boomvolume

3) Het volume is gedefinieerd als het spilhoutvolume met schors. 


\section{Explanation yield tables}

In the header of the yield tables a number of standard symbols (IUFRO, 1959) are used. In the table below the SI units and the meaning of the symbols are given.

\begin{tabular}{|c|c|c|}
\hline symbol & unit & meaning \\
\hline Site class & & relative partition in site classes \\
\hline$h 50$ & $\mathrm{~m}$ & Site index (top height at $50 \mathrm{yr}$ ) \\
\hline P50 & $\mathrm{m}^{3} \mathrm{ha}^{-1} \mathrm{yr}^{-1}$ & Production class at $50 \mathrm{yr}^{1)}$ \\
\hline$t$ & j & age since germination \\
\hline$h_{\text {top }}$ & $\mathrm{m}$ & top height \\
\hline$h_{\text {dom }}$ & $\mathrm{m}$ & dominant height \\
\hline$d_{d o m}$ & $\mathrm{~cm}$ & mean diameter of dominant height tree \\
\hline$N$ & ha-1 & Number of stems per ha \\
\hline$S \%$ & & S\% (Hart-Becking spacing index) \\
\hline$G$ & $m^{2} h a^{-1}$ & Basal area per ha \\
\hline$d_{g}$ & $\mathrm{~cm}$ & diameter $(1,30 \mathrm{~m})$ of the basal area mean tree \\
\hline$h_{g}$ & $\mathrm{~m}$ & height of the basal area mean tree \\
\hline$V$ & $m^{3} h a^{-1}$ & volume per ha ${ }^{2)}$ \\
\hline$I c_{G}$ & $m^{3} h a^{-1} y^{-1}$ & current basal area increment per ha per year at age $t$ \\
\hline$I c_{V}$ & $\mathrm{~m}^{2} h a^{-1} \mathrm{yr}^{-1}$ & current volume increment per ha per year at age $t$ \\
\hline $\operatorname{Im}_{G}$ & $\mathrm{~m}^{3} \mathrm{ha}^{-1} \mathrm{yr}^{-1}$ & mean basal area increment per ha per year until age $t$ \\
\hline $\operatorname{lm} m_{V}$ & $\mathrm{~m}^{3} \mathrm{ha}^{-1} \mathrm{yr}^{-1}$ & mean volume increment per ha per year until age $t$ \\
\hline
\end{tabular}

1) Mean production, including thinning but excluding mortality (volume increment) per ha until age $50 \mathrm{yr}$.

2) The volume is defined as the stem volume over bark. 
Fijnspar Nederland 2018

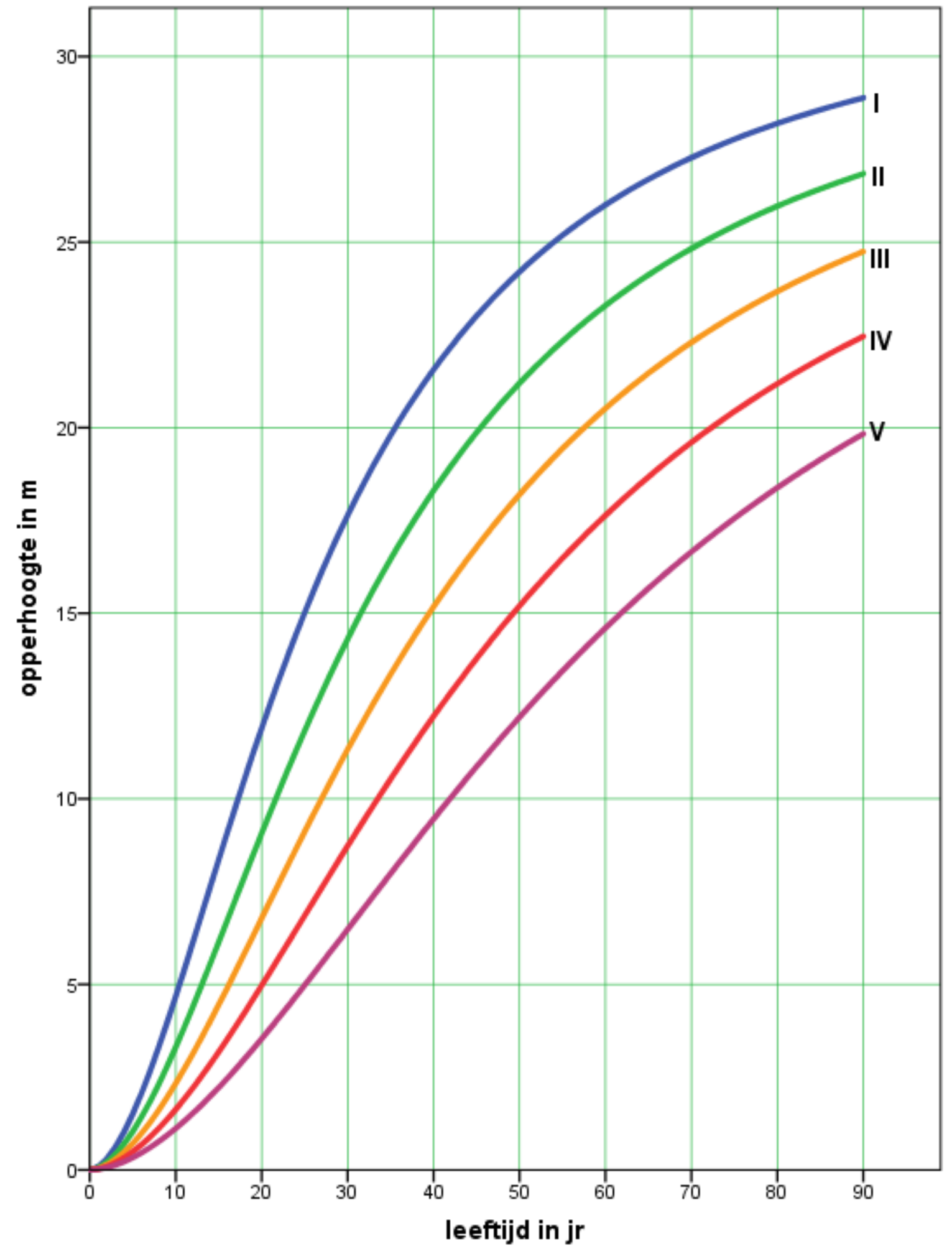




\begin{tabular}{|c|c|c|}
\hline \multirow{2}{*}{ 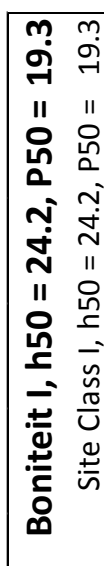 } & w & 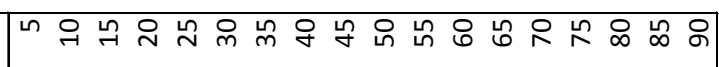 \\
\hline & 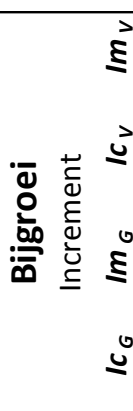 & 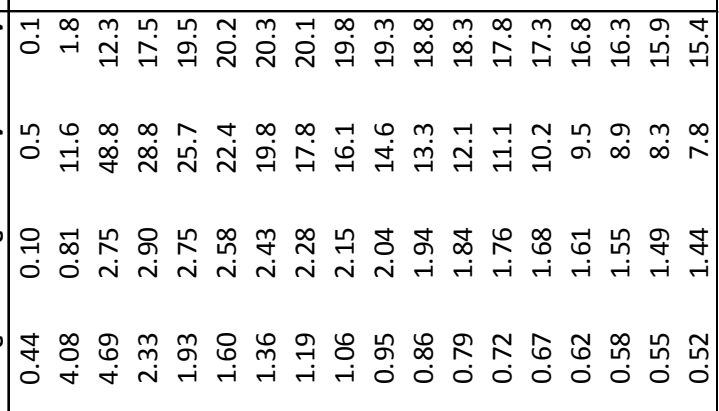 \\
\hline & 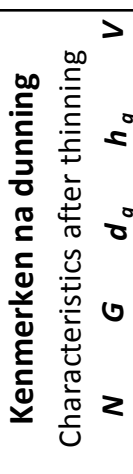 & 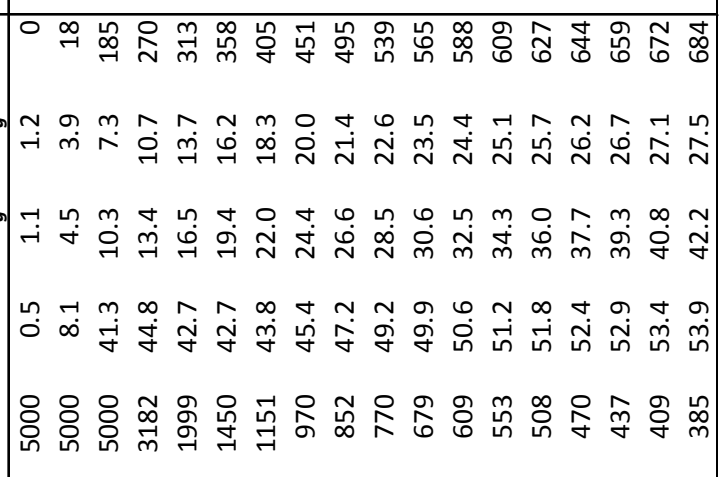 \\
\hline 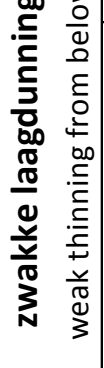 & 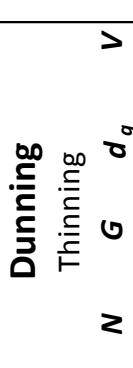 & 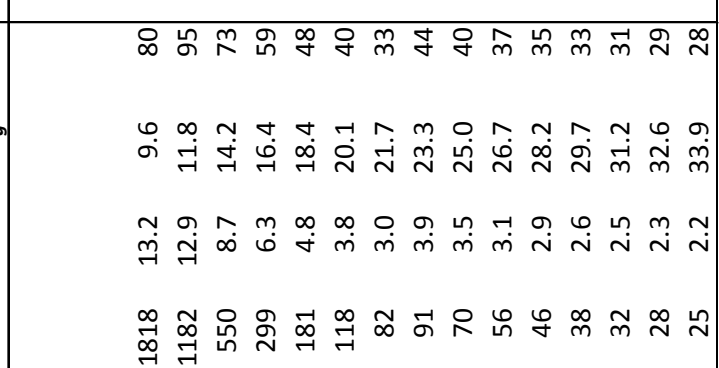 \\
\hline & 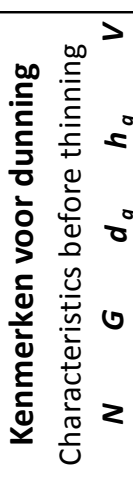 & 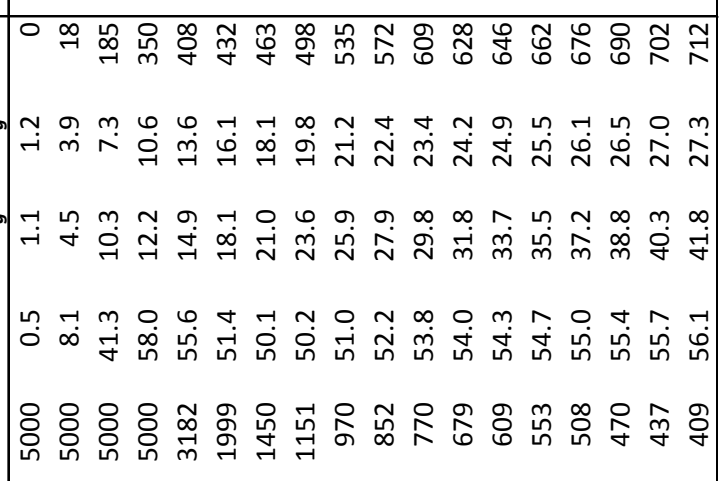 \\
\hline $\begin{array}{l}\frac{v_{2}}{2} \\
\frac{1}{2}\end{array}$ & 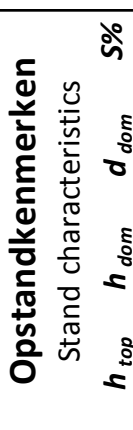 & 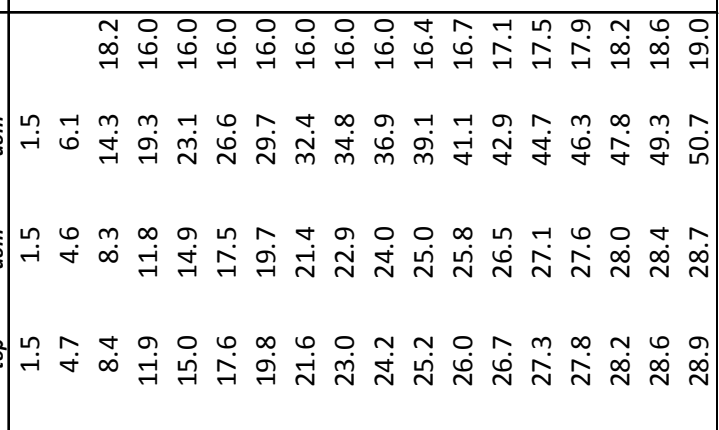 \\
\hline & 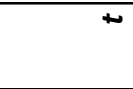 & 74 \\
\hline
\end{tabular}




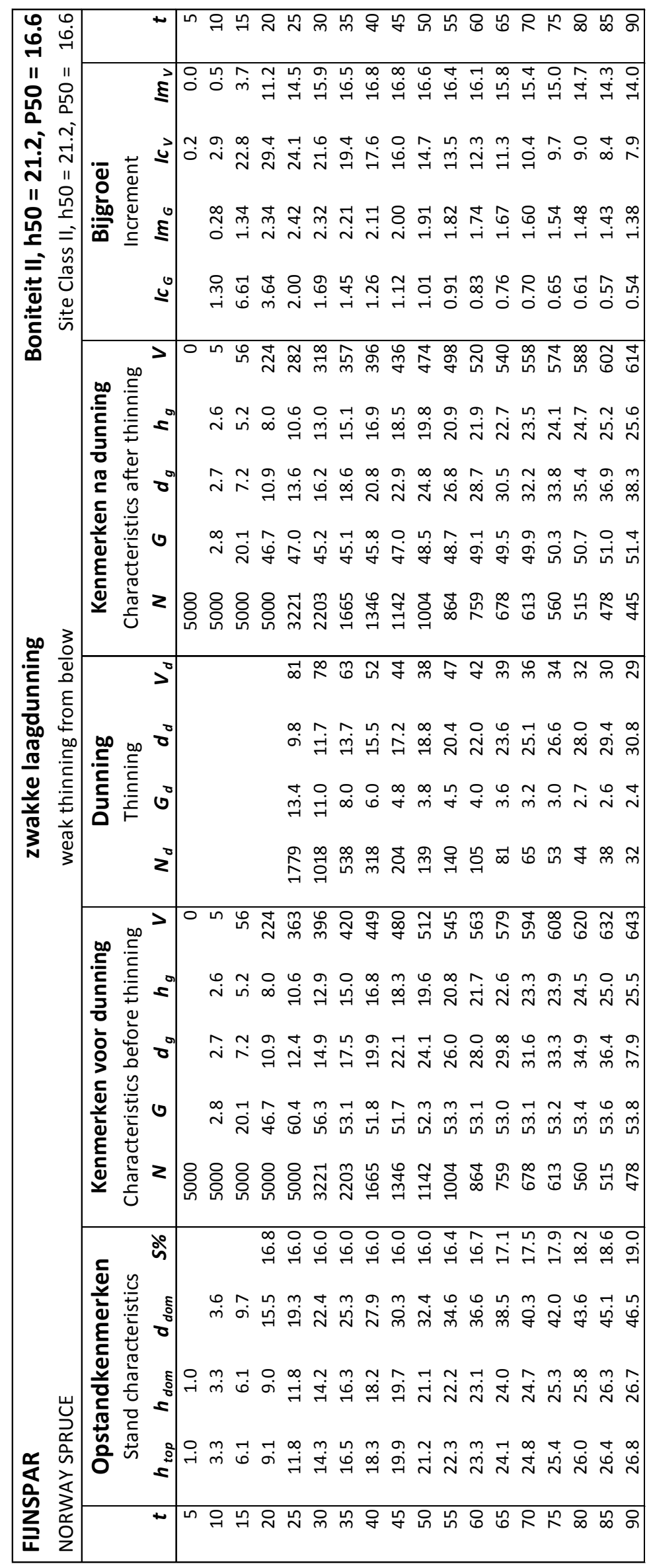




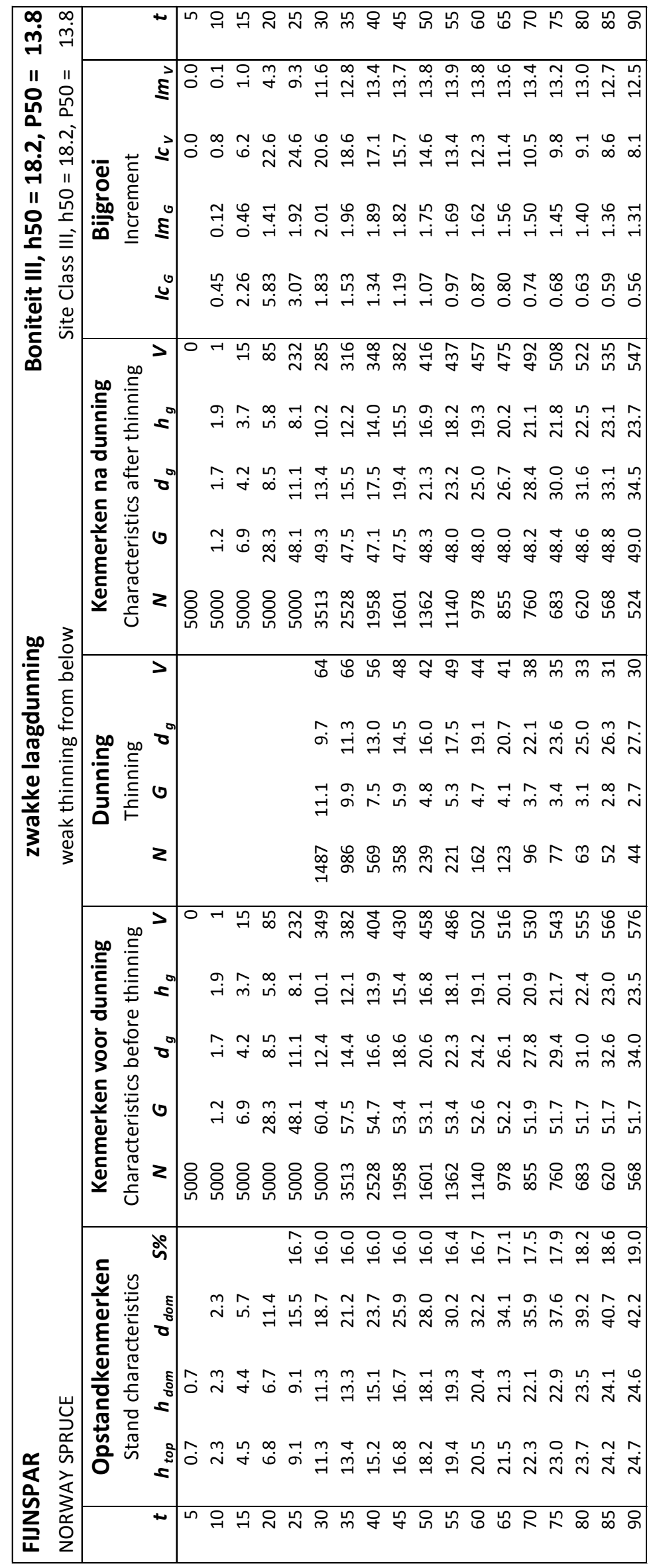




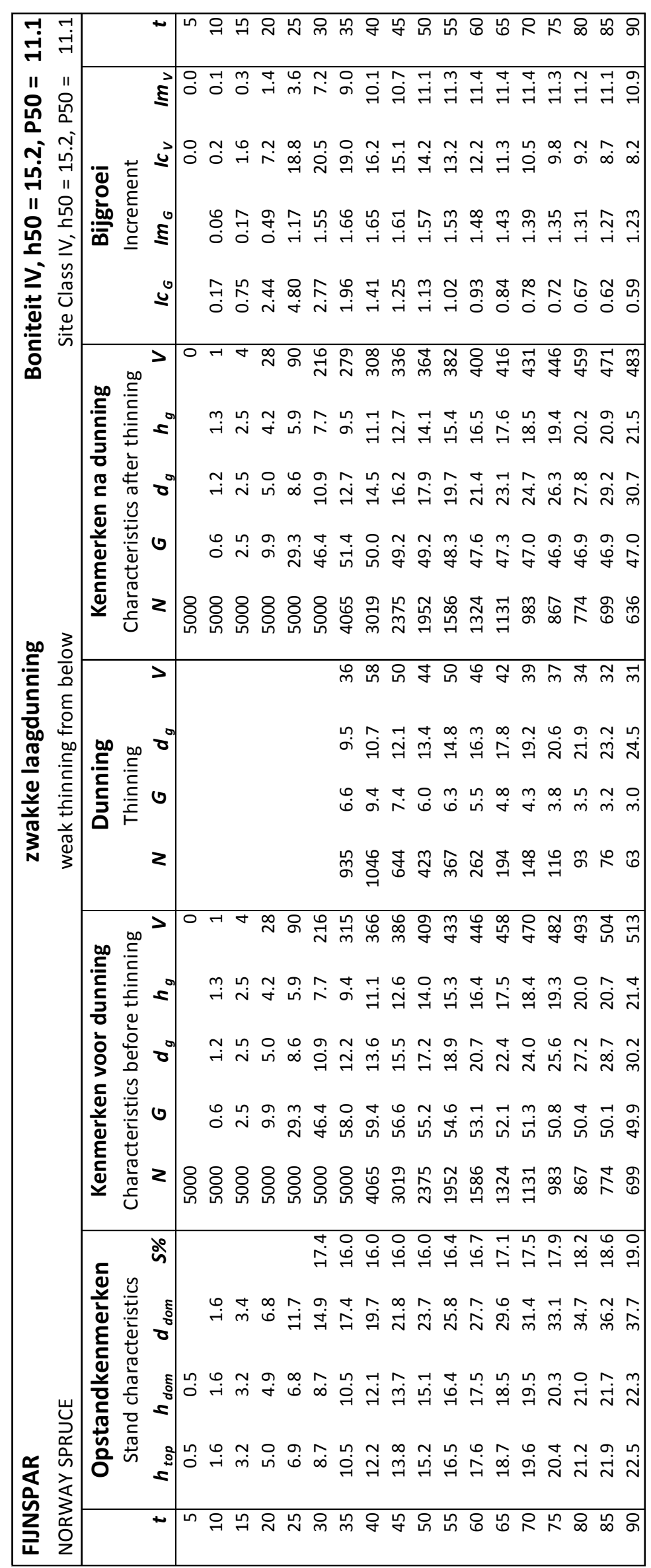




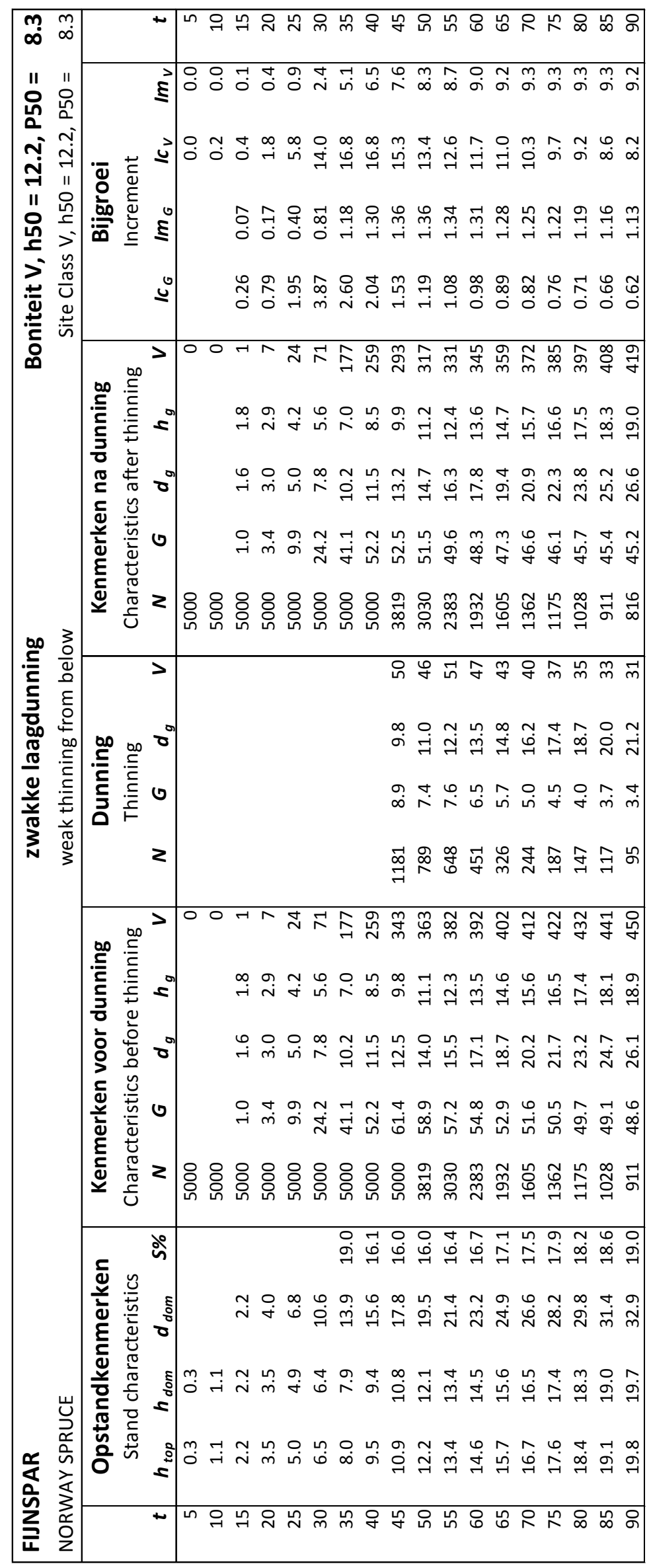




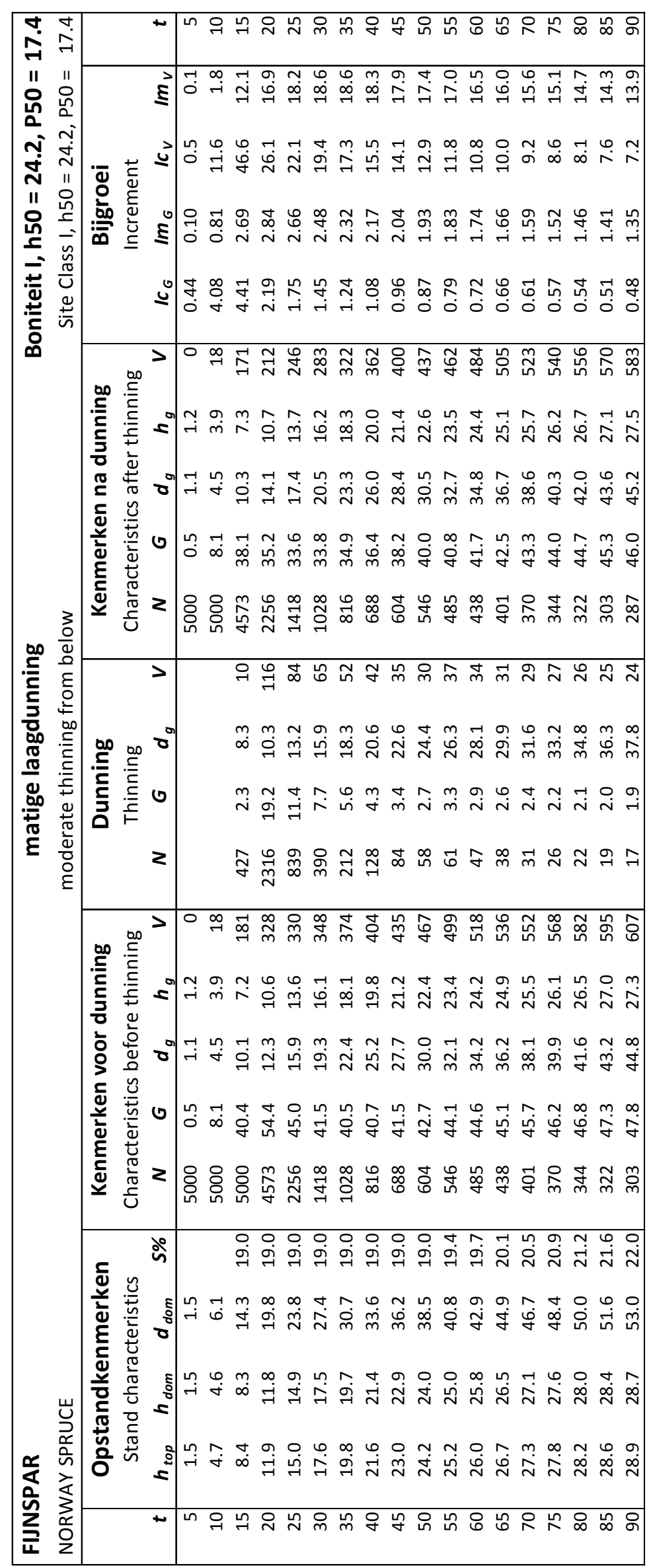




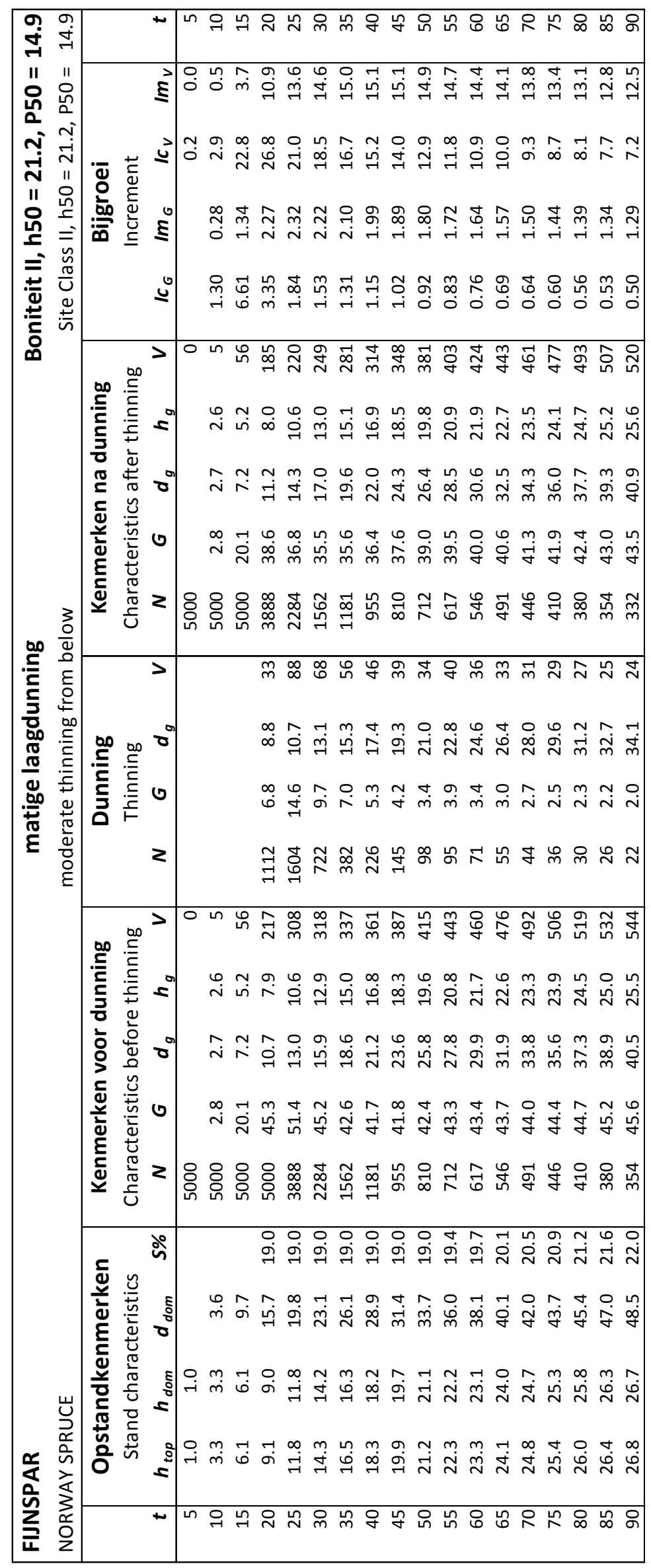




\begin{tabular}{|c|c|c|}
\hline \multirow{2}{*}{ 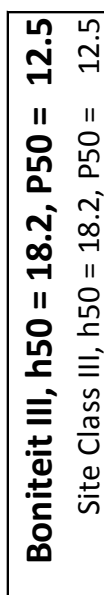 } & 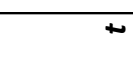 & \\
\hline & 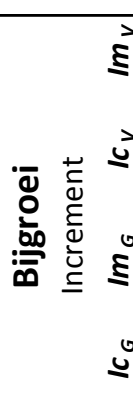 & 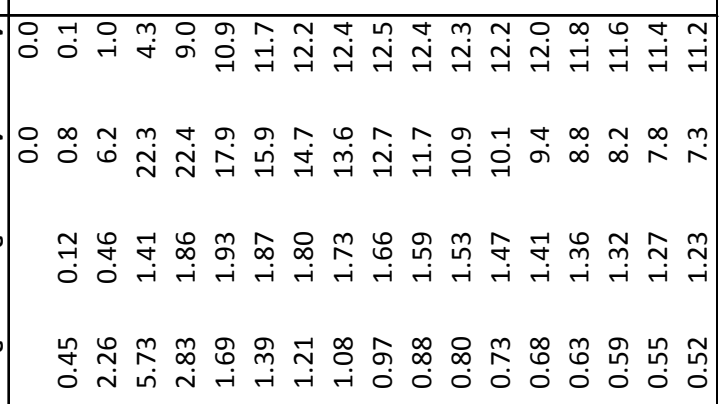 \\
\hline $\bar{c}$ & 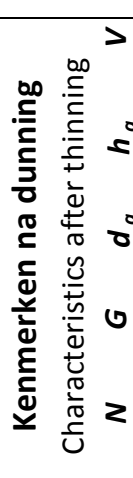 & 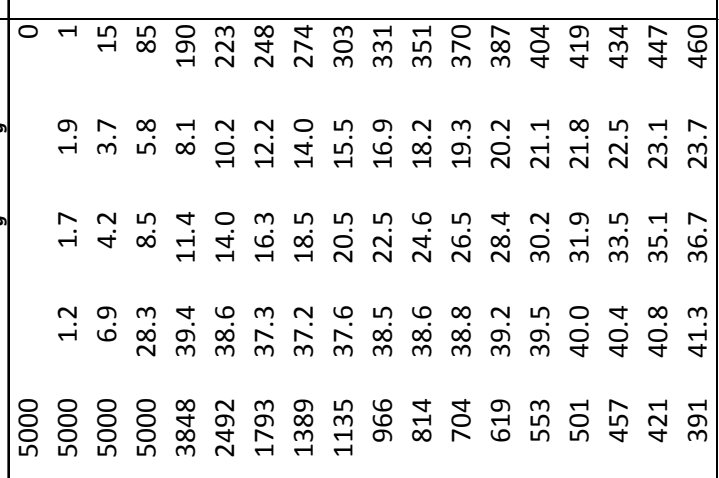 \\
\hline 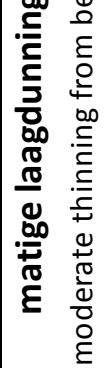 & 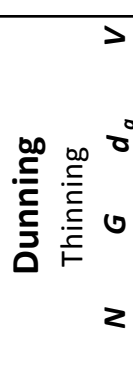 & 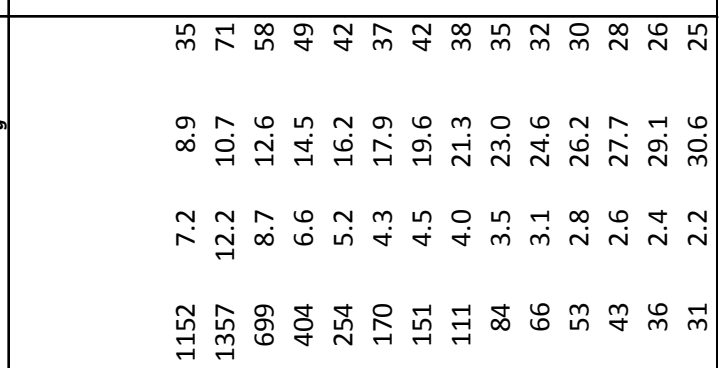 \\
\hline . & 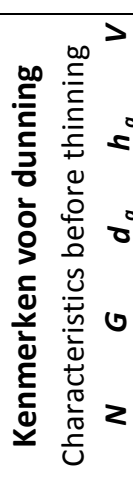 & 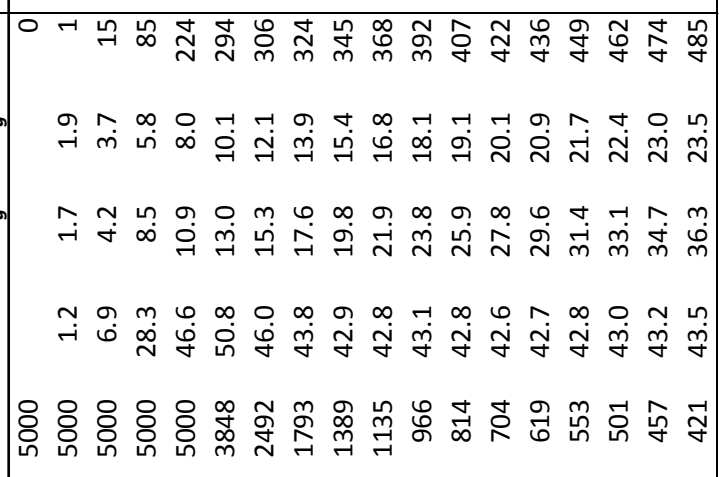 \\
\hline 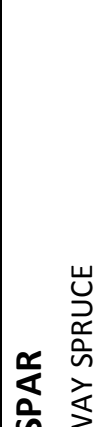 & 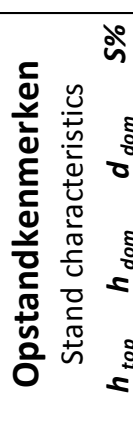 & 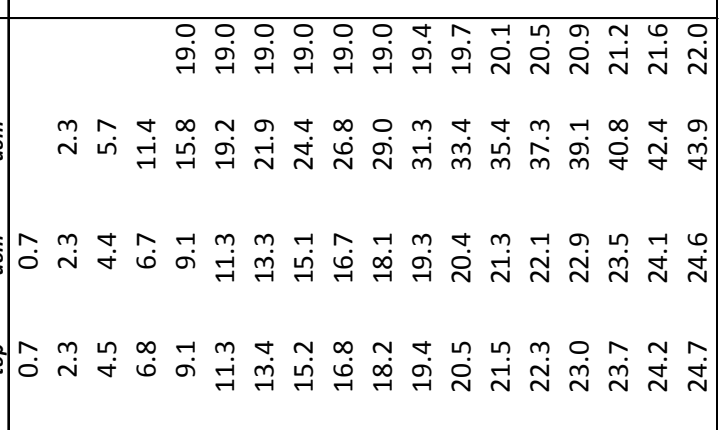 \\
\hline $\begin{array}{ll}n & 3 \\
2 & 0 \\
2\end{array}$ & & In 60 r \\
\hline
\end{tabular}




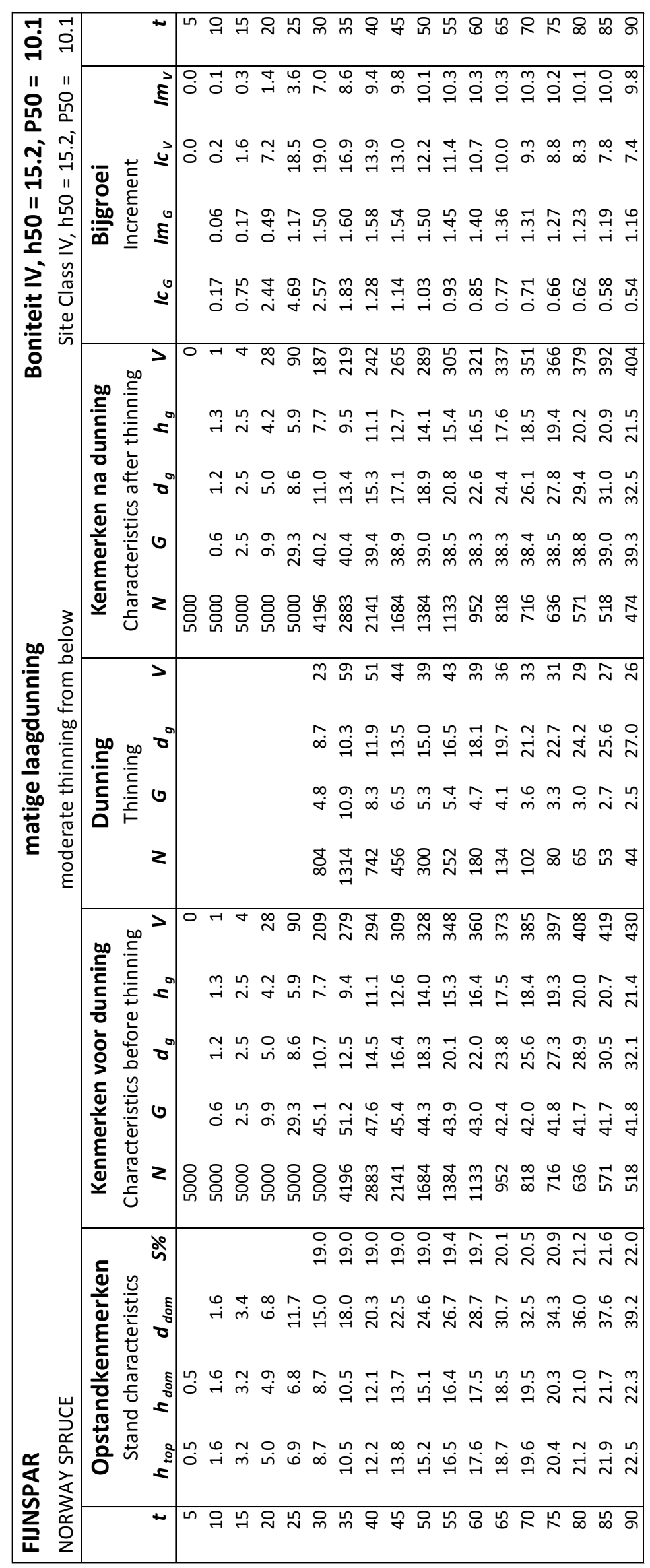




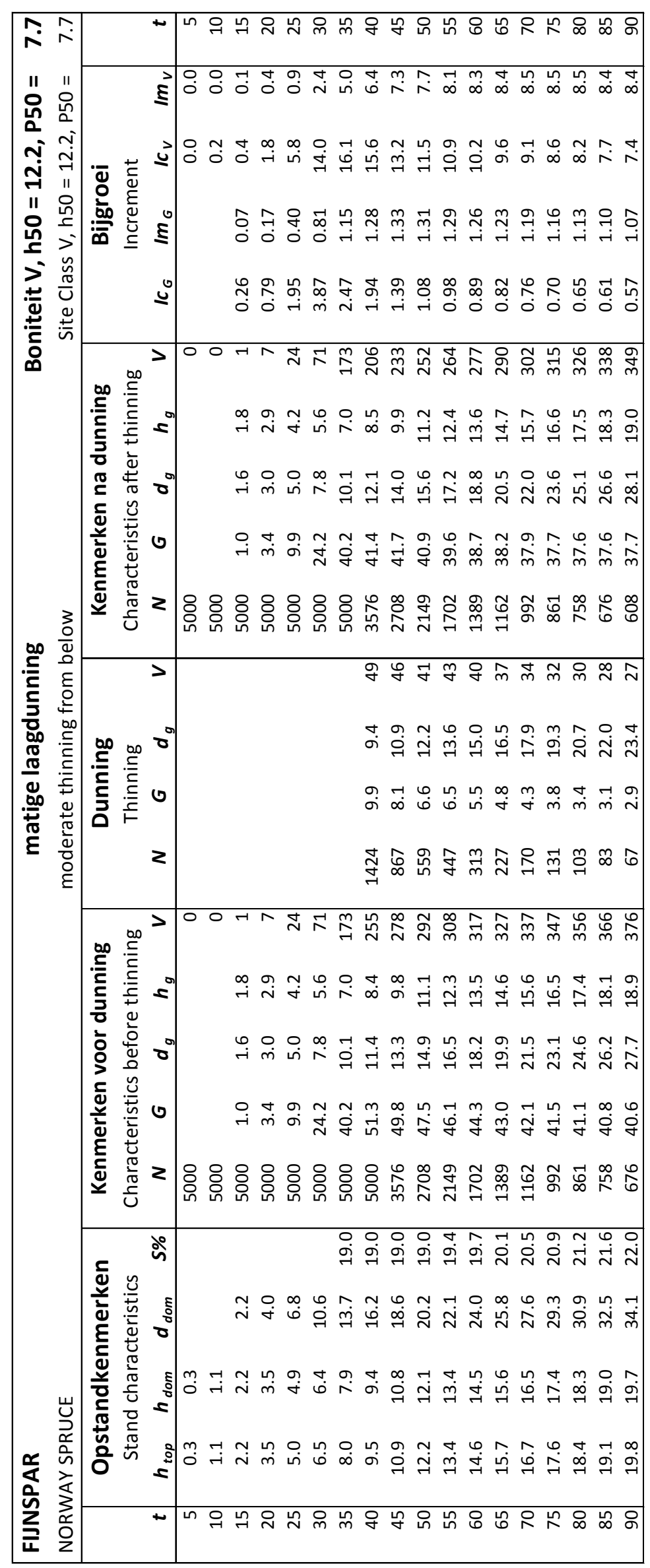




\begin{tabular}{|c|c|c|}
\hline \multirow{3}{*}{ 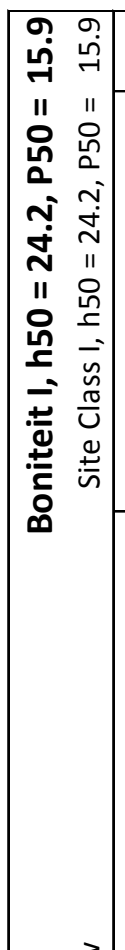 } & + & 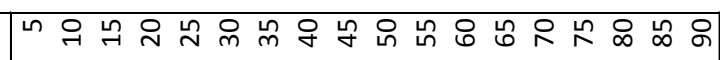 \\
\hline & 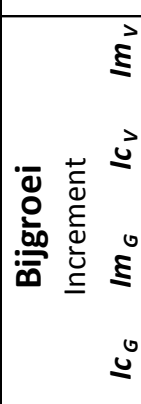 & 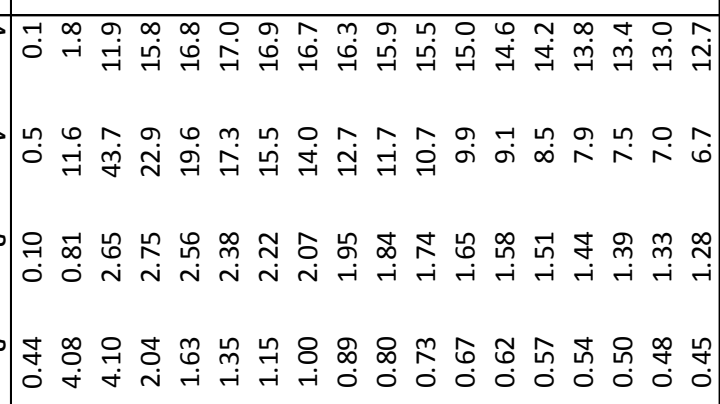 \\
\hline & 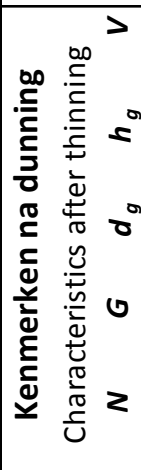 & 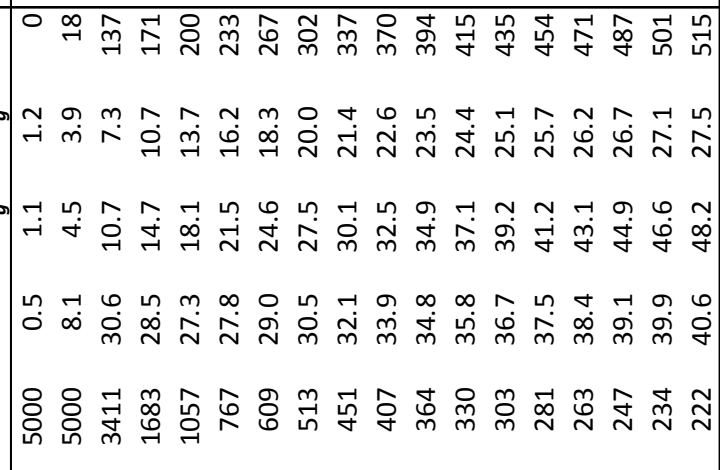 \\
\hline \multirow[t]{2}{*}{ 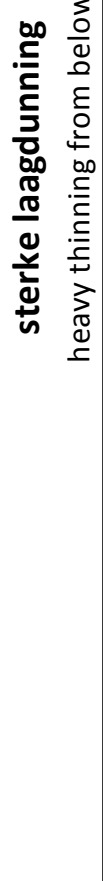 } & 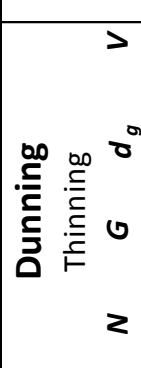 & 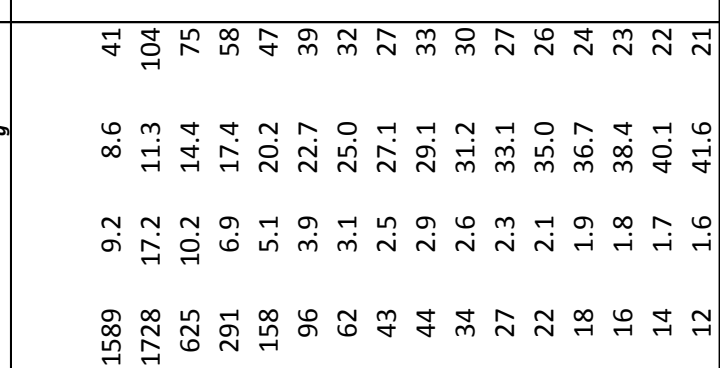 \\
\hline & 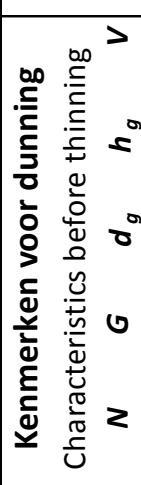 & 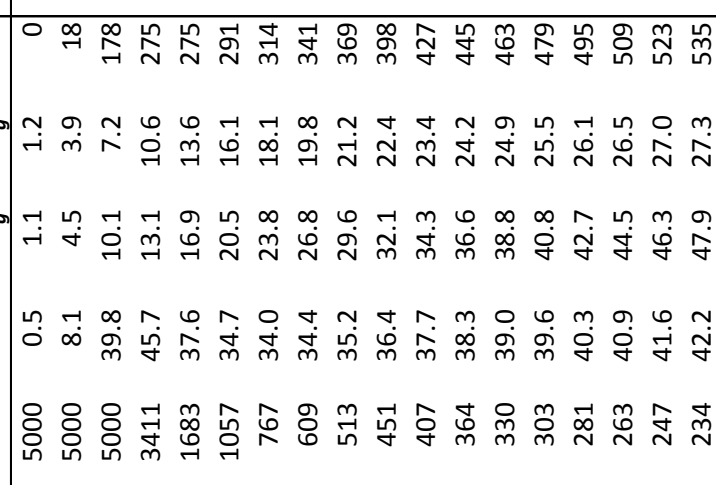 \\
\hline 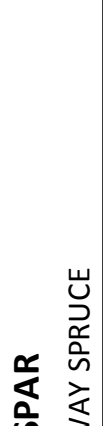 & 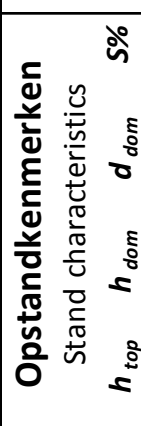 & 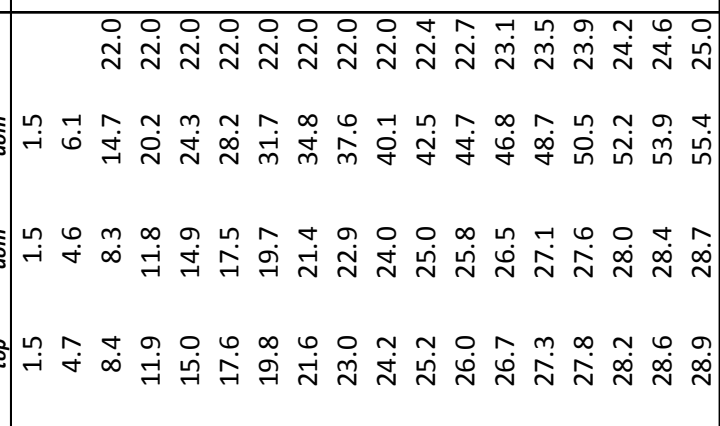 \\
\hline 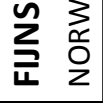 & N & 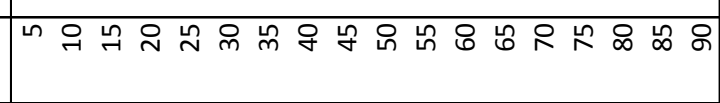 \\
\hline
\end{tabular}




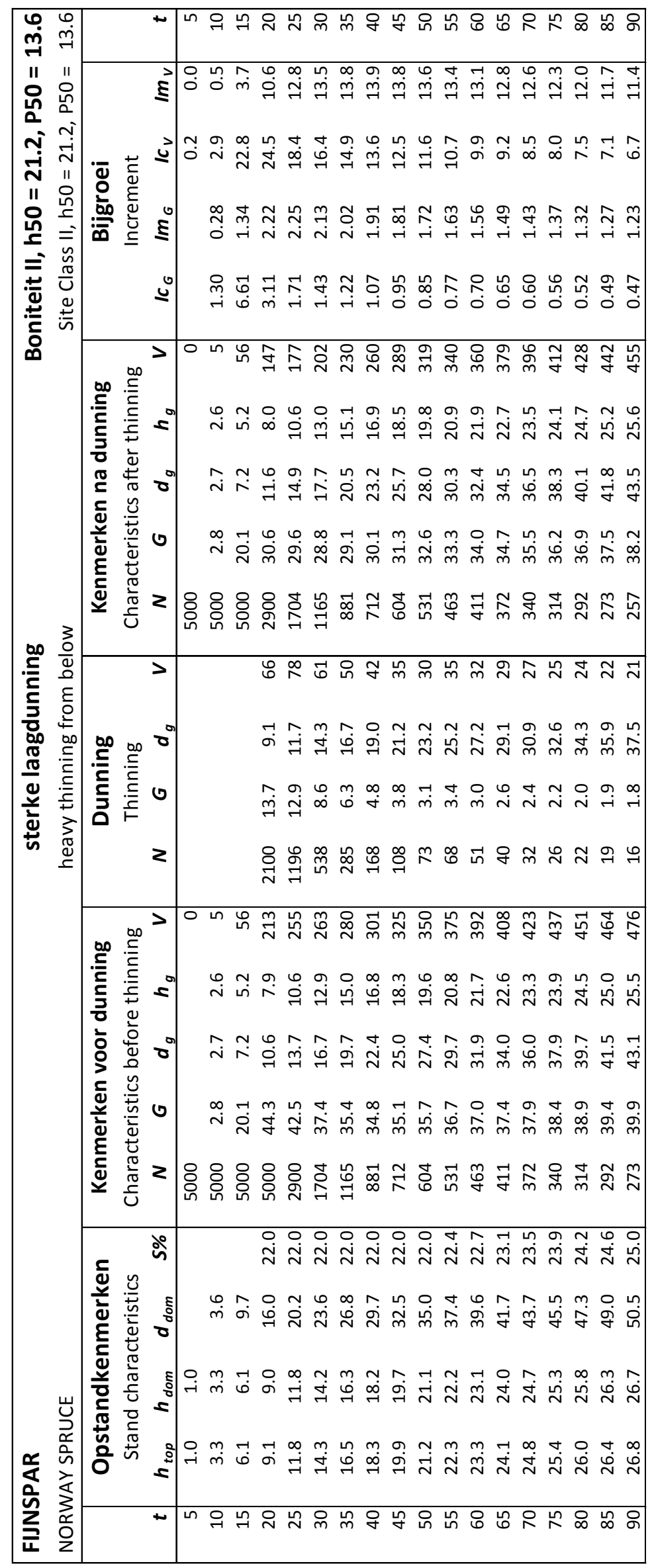




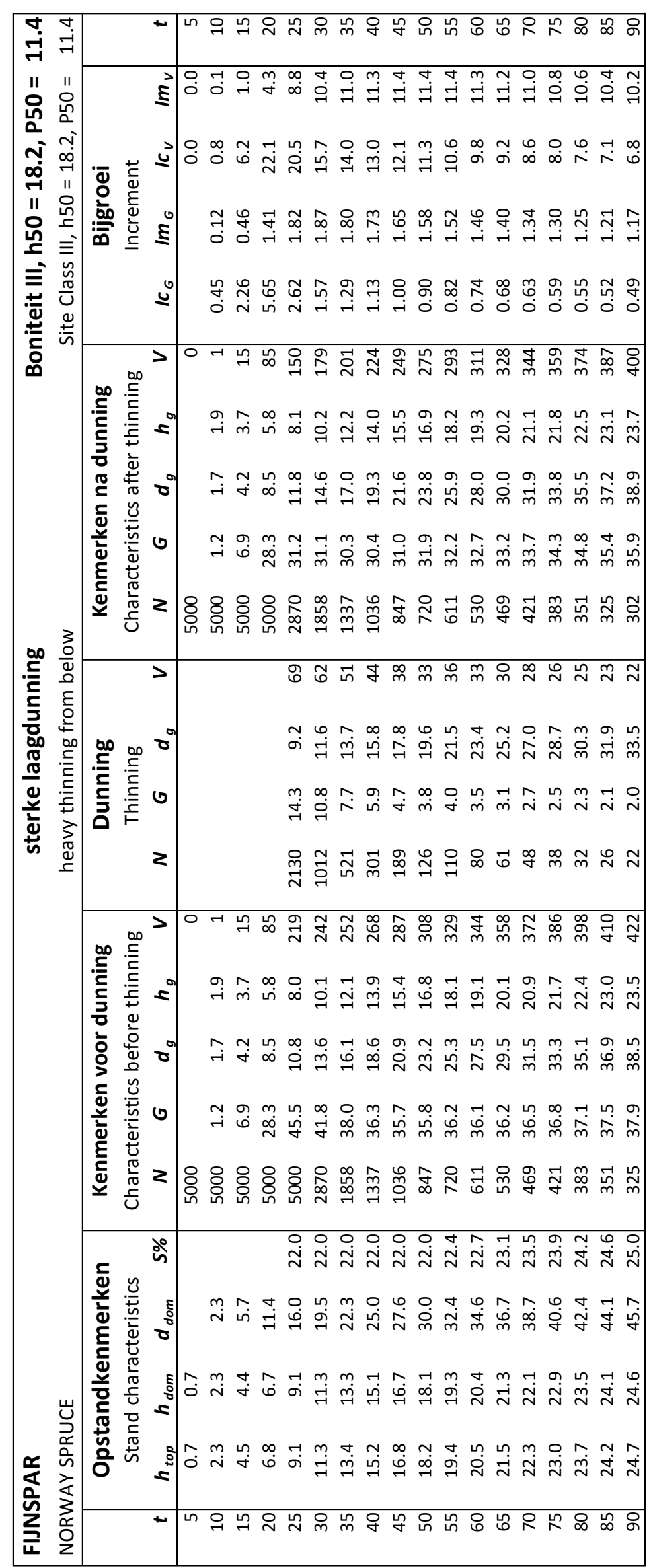




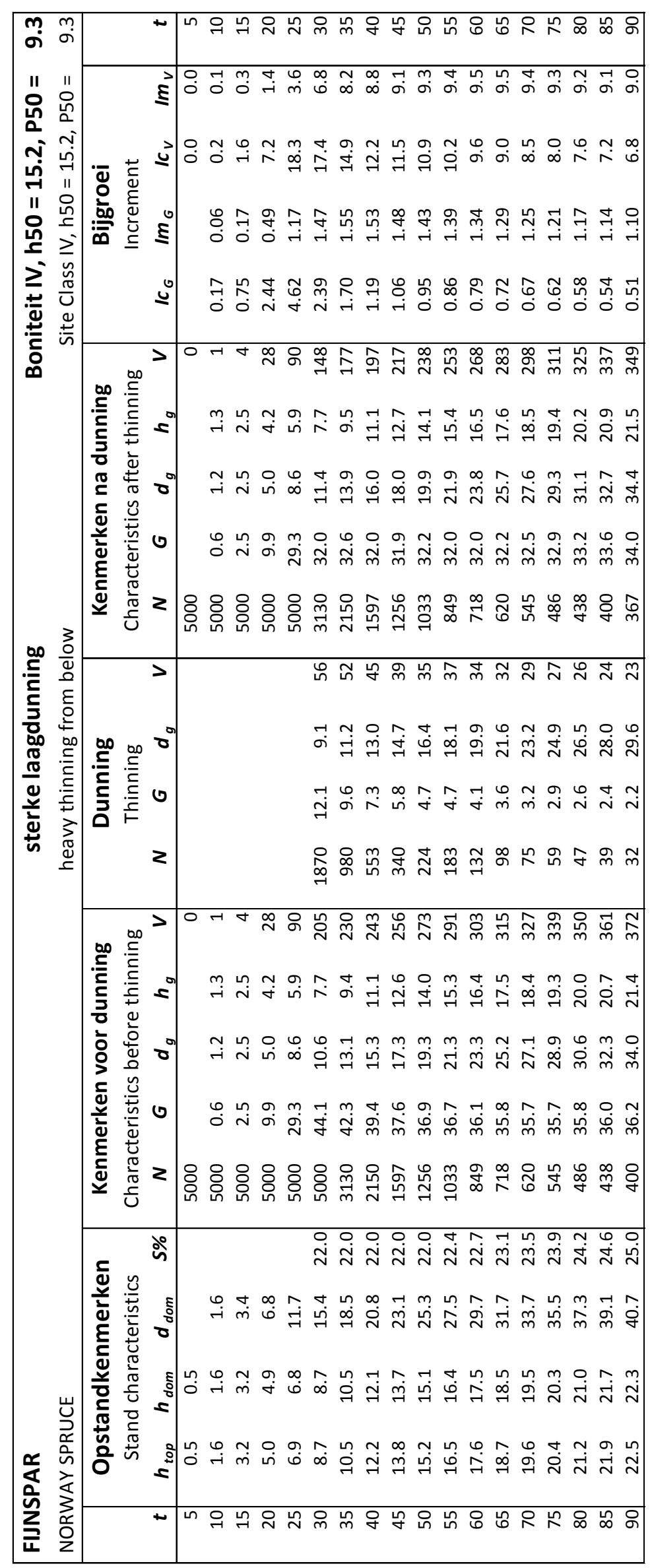




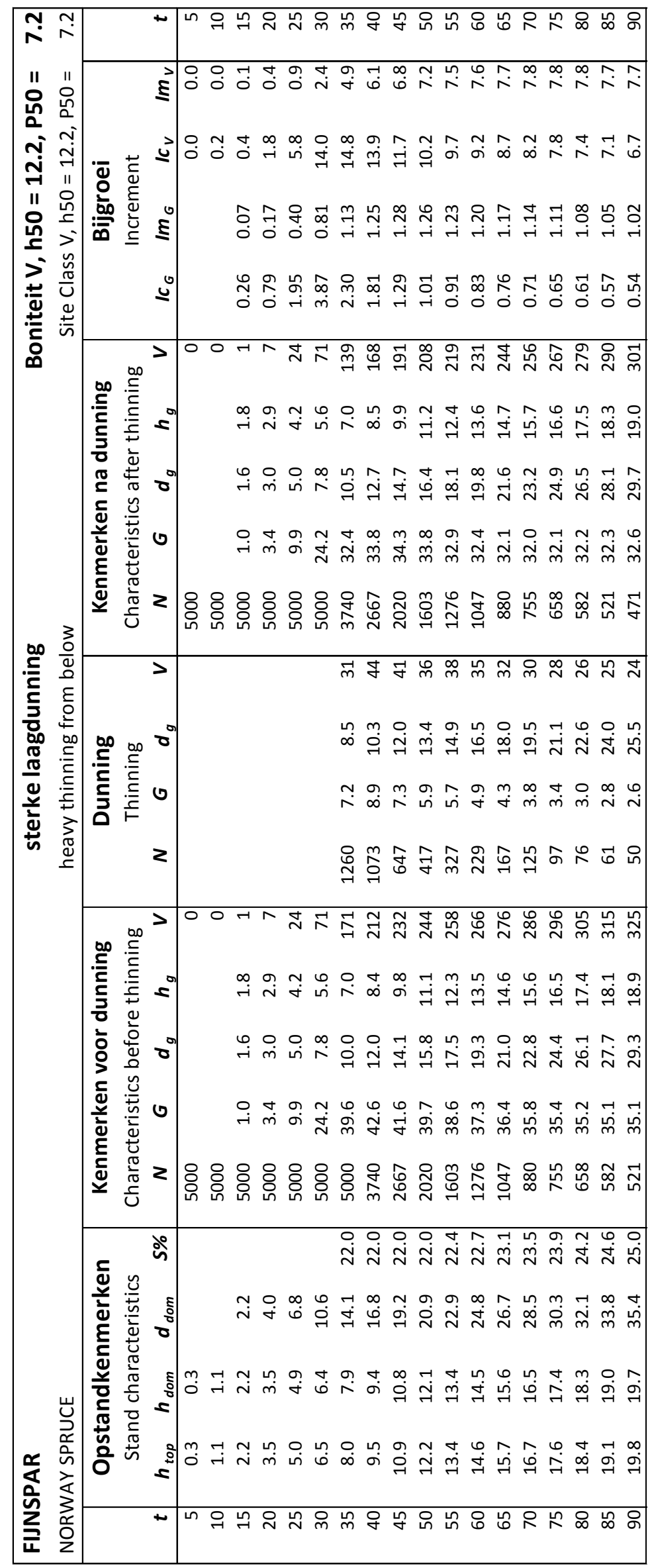




\begin{tabular}{|c|c|c|}
\hline \multirow{2}{*}{ 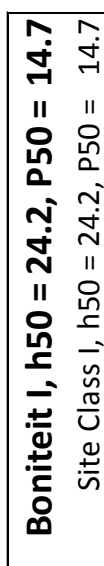 } & + & 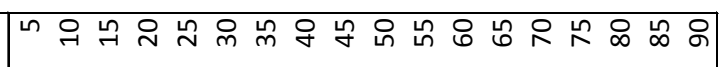 \\
\hline & 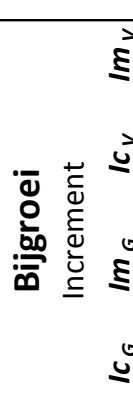 & 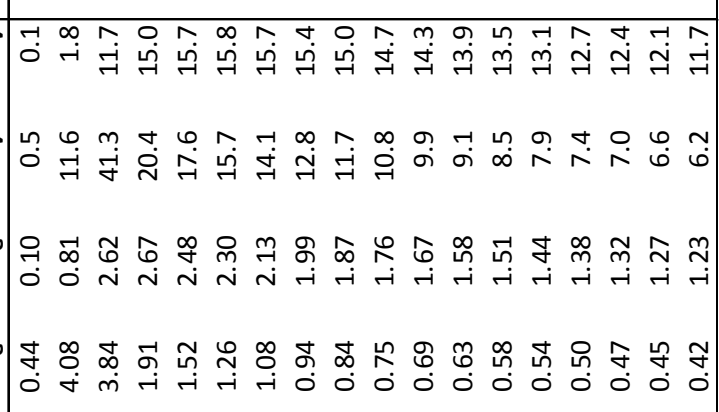 \\
\hline & 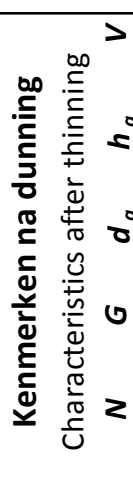 & 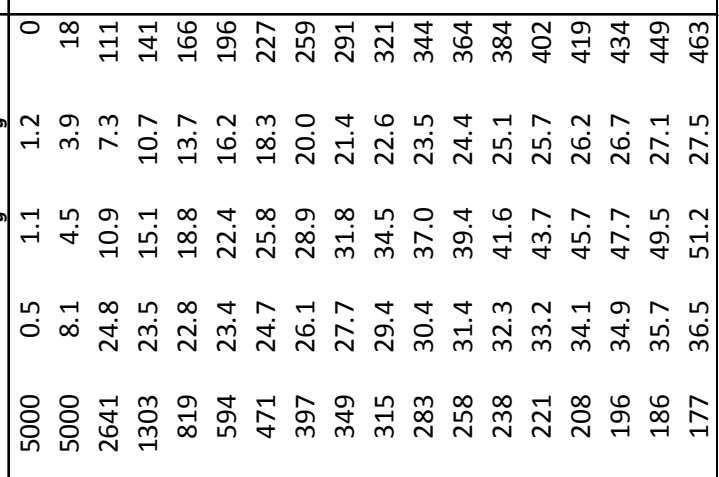 \\
\hline 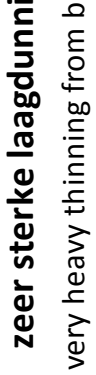 & 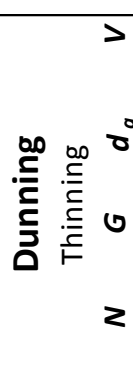 & 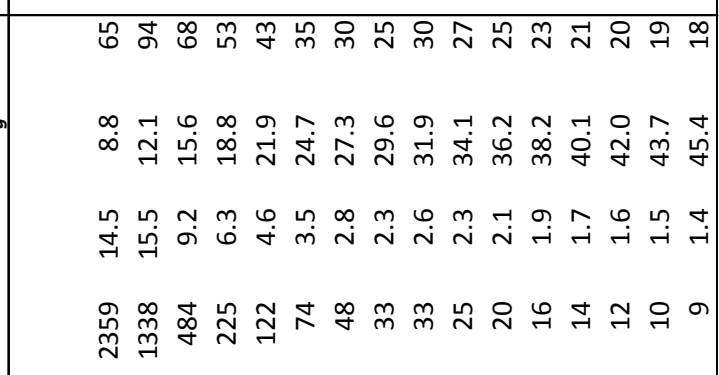 \\
\hline & 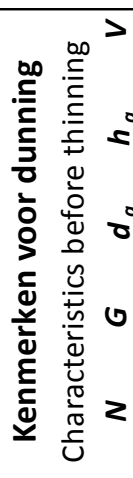 & 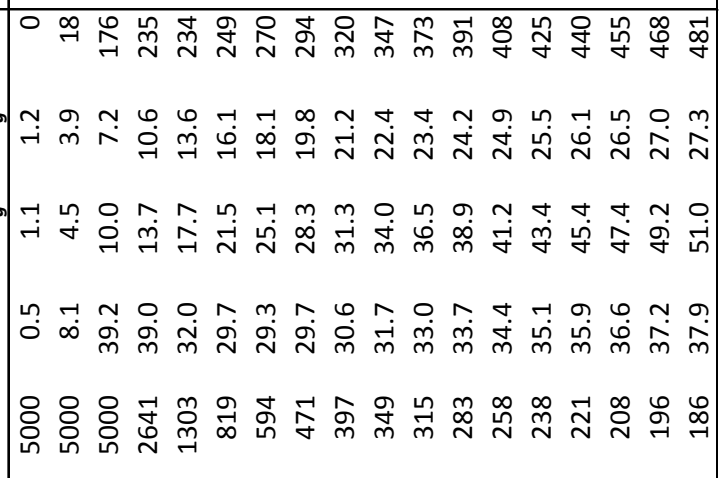 \\
\hline$\frac{x^{\frac{\gamma}{2}}}{\frac{\gamma}{n}}$ & 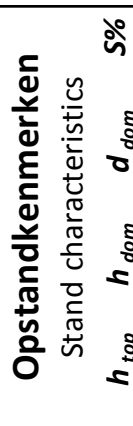 & 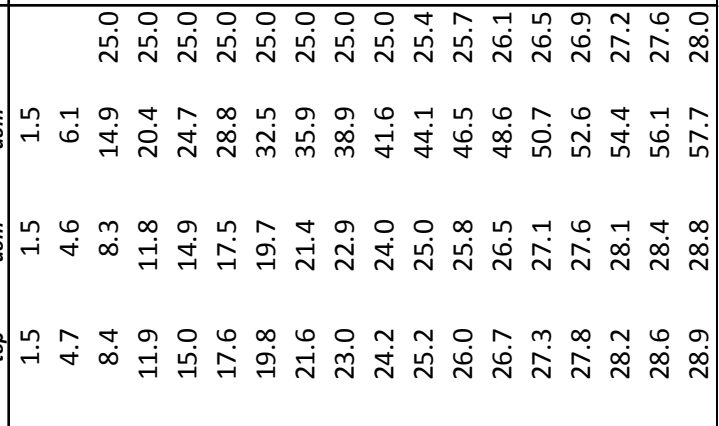 \\
\hline & + & 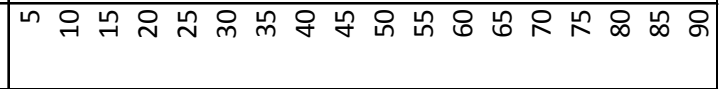 \\
\hline
\end{tabular}




\begin{tabular}{|c|c|c|}
\hline 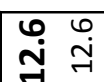 & w & 8 \\
\hline 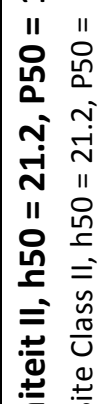 & 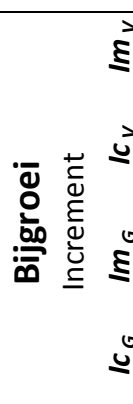 & 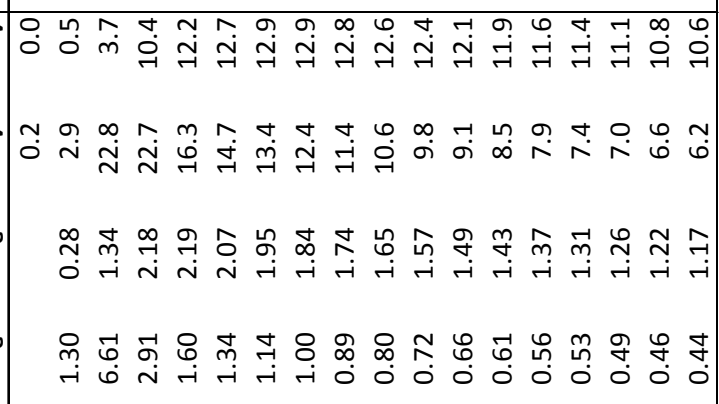 \\
\hline & 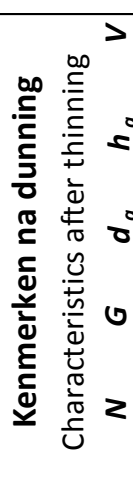 & 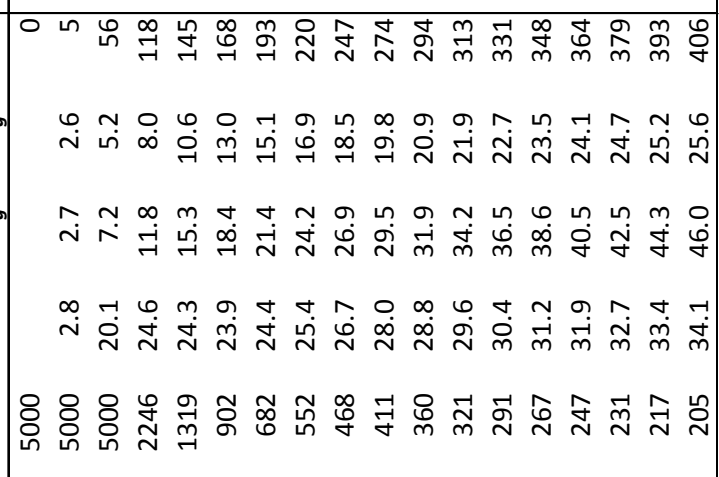 \\
\hline 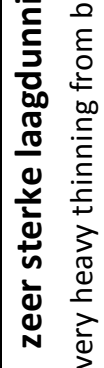 & 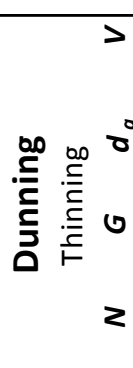 & 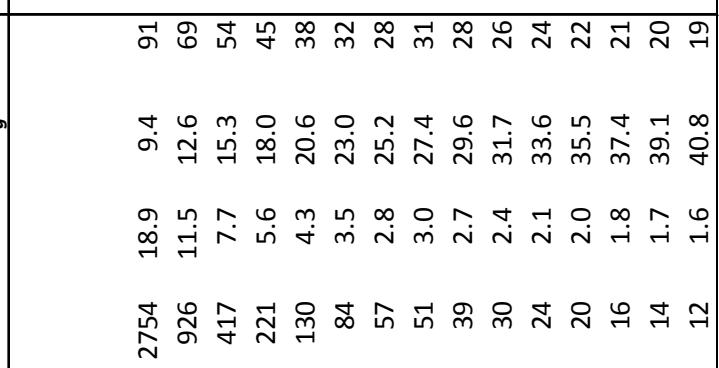 \\
\hline & 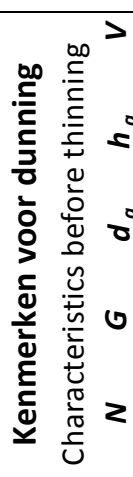 & 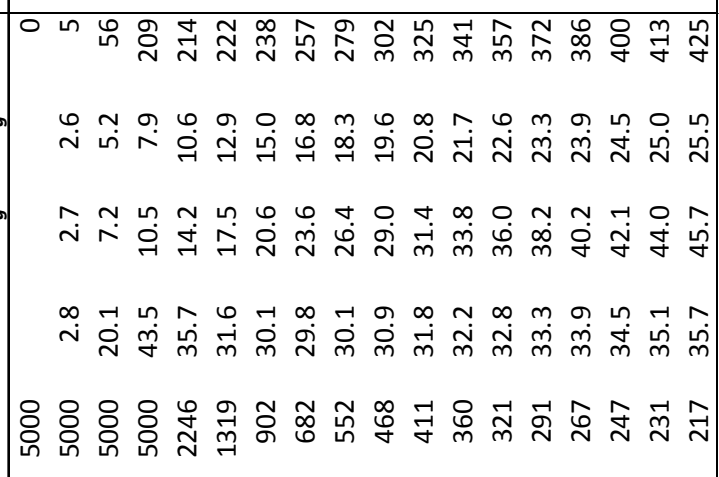 \\
\hline 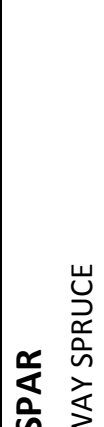 & 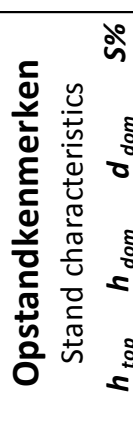 & 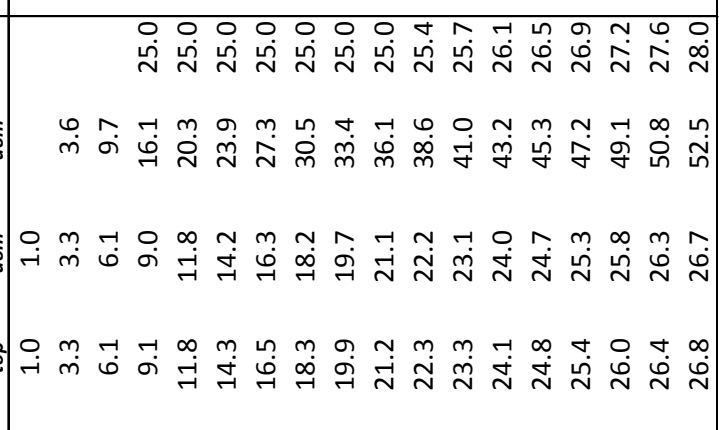 \\
\hline & N & นึ่ 8 ㄴํㅇ \\
\hline
\end{tabular}




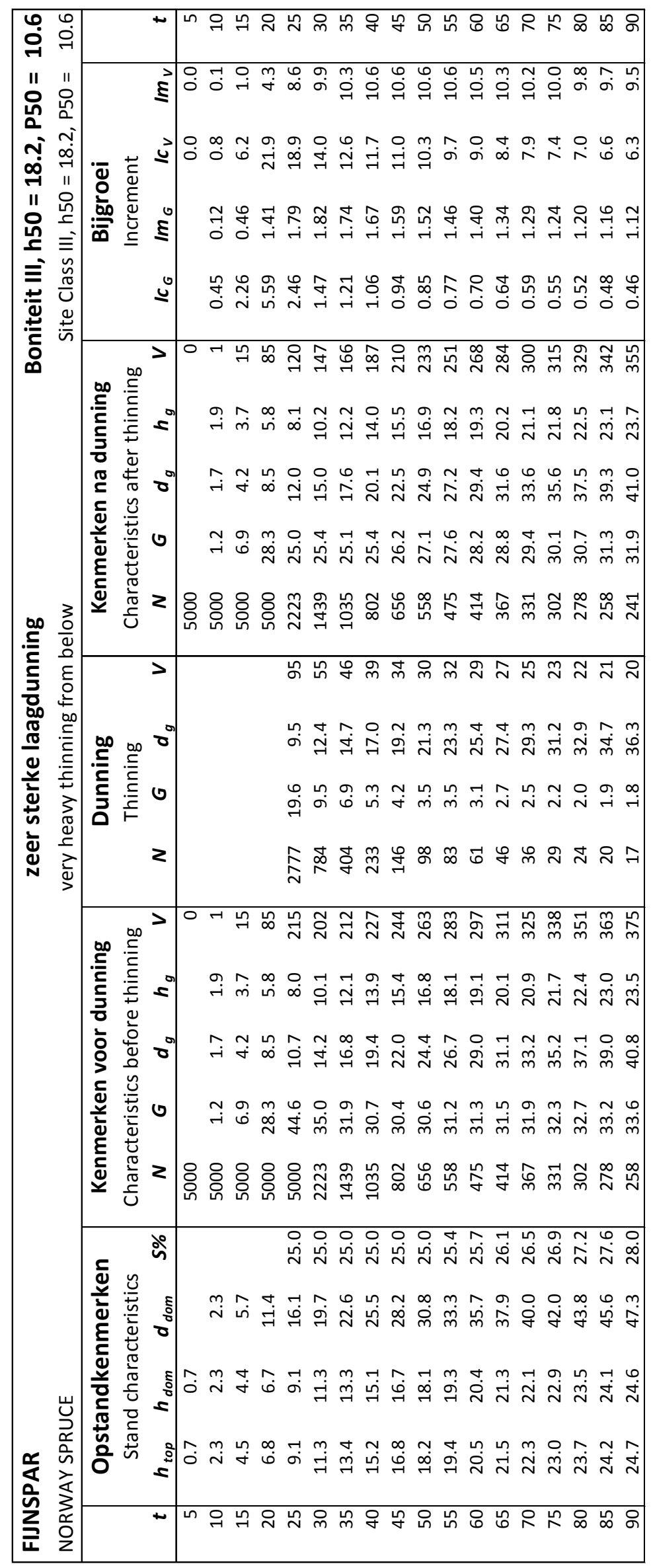




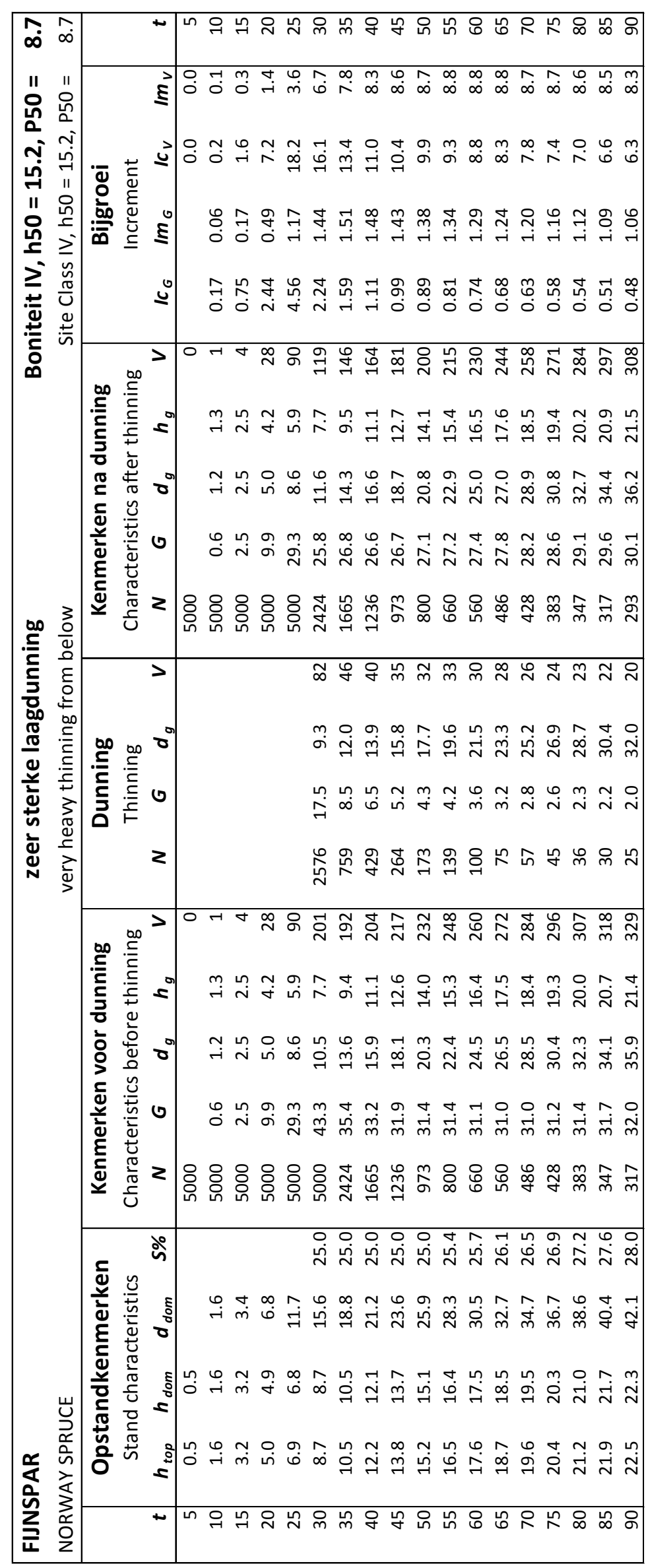




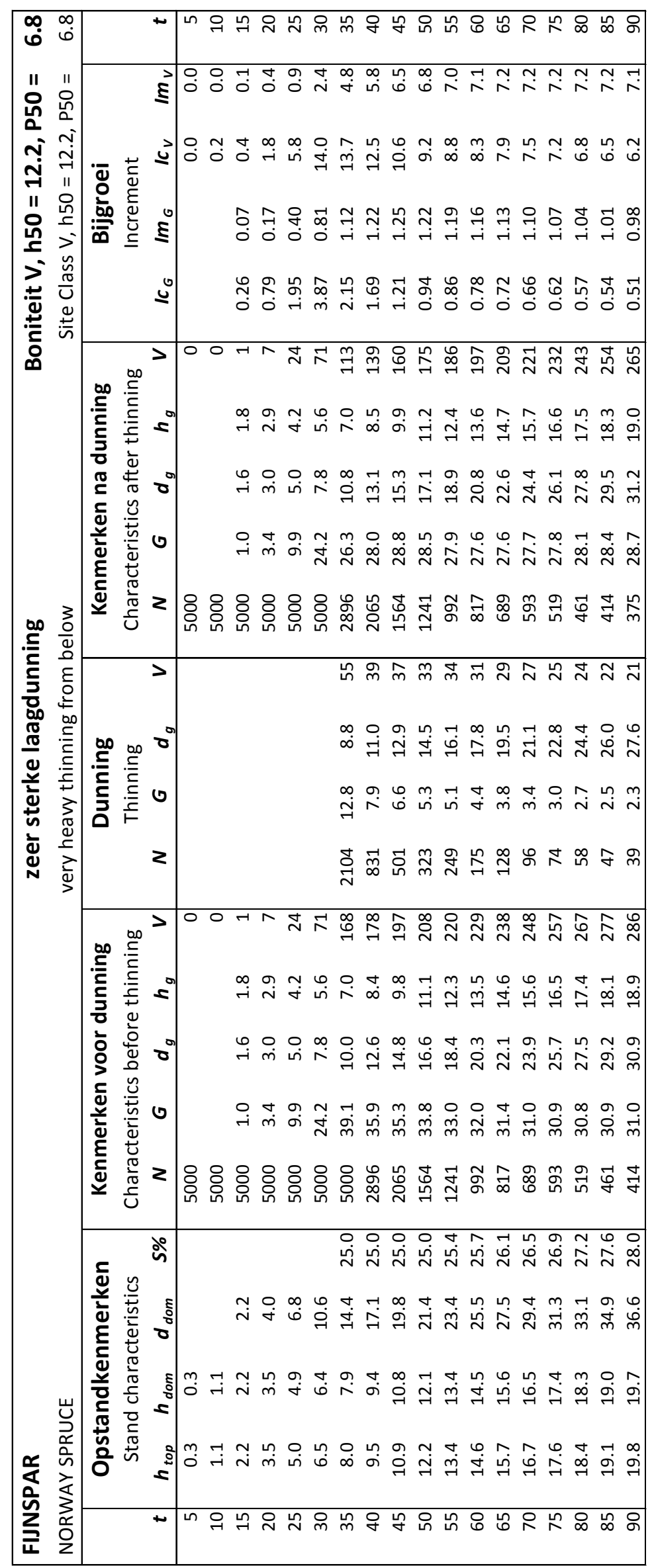




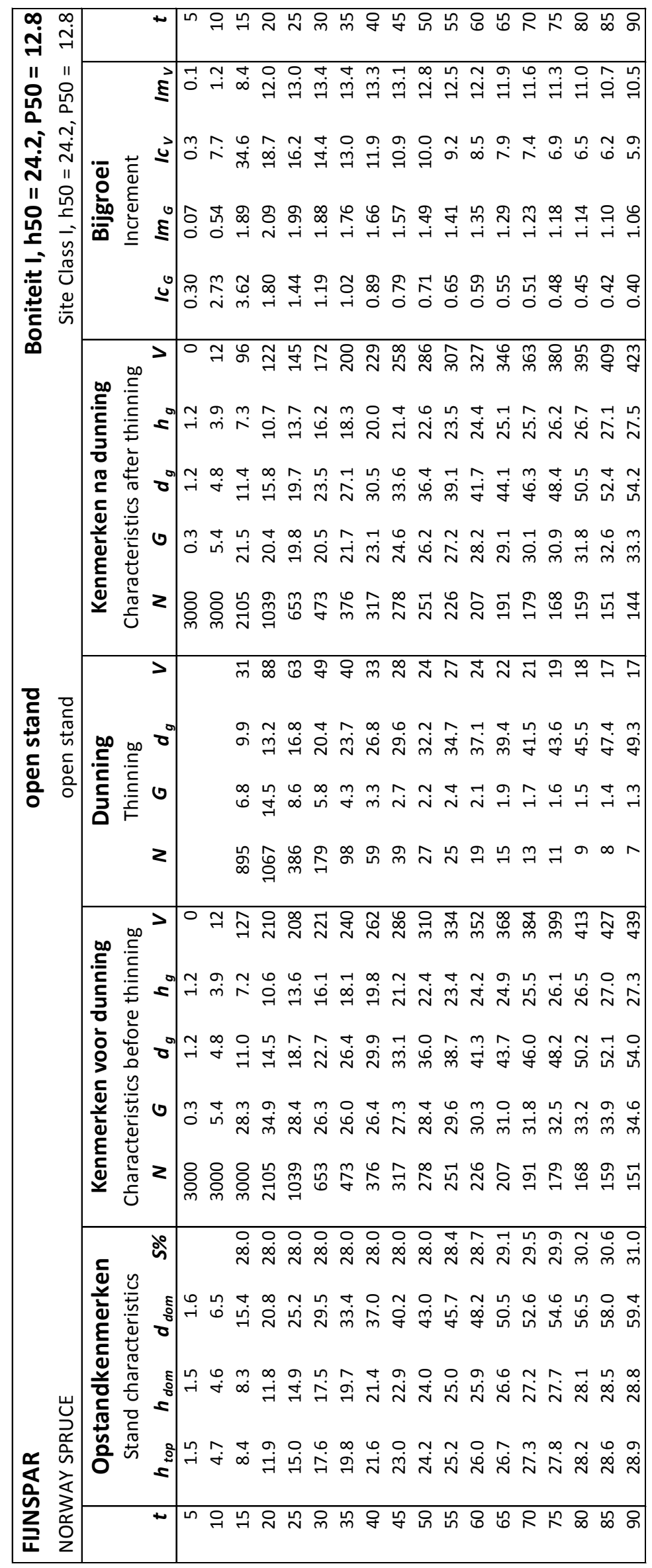




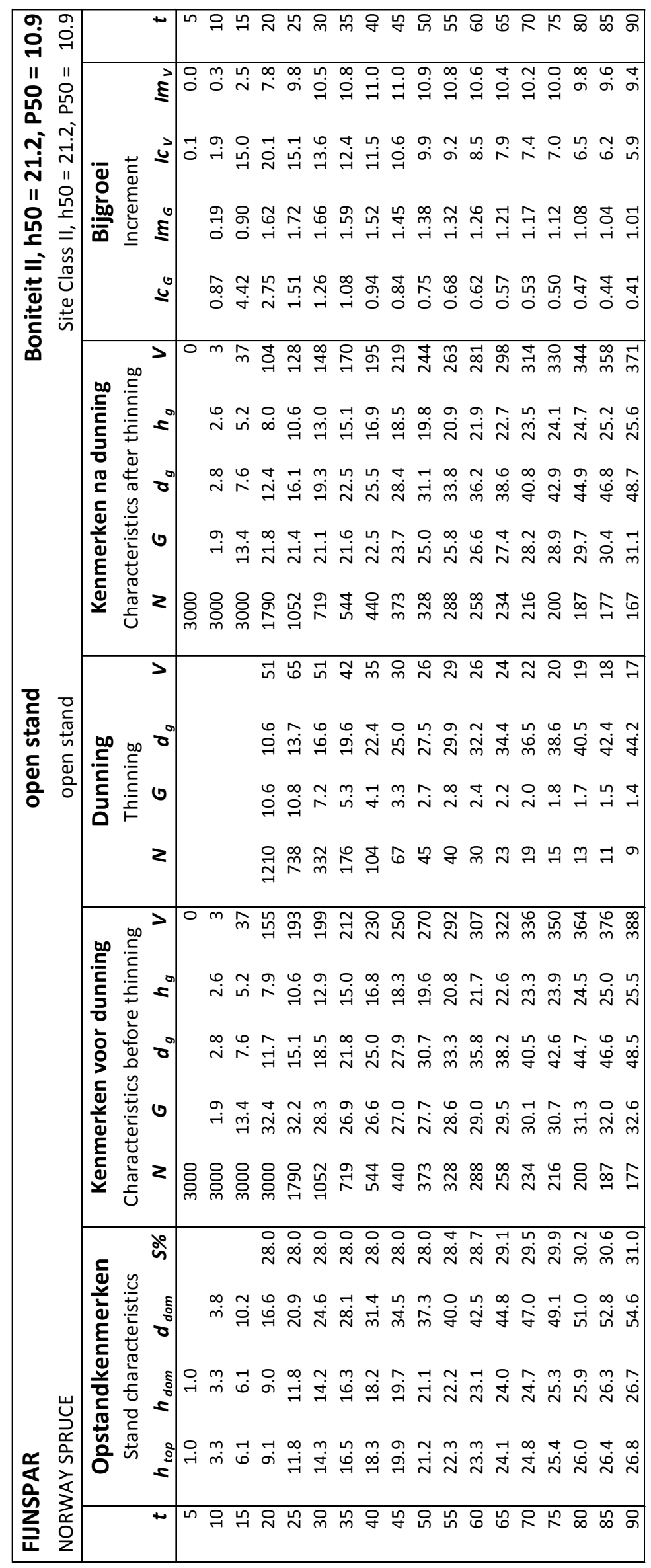




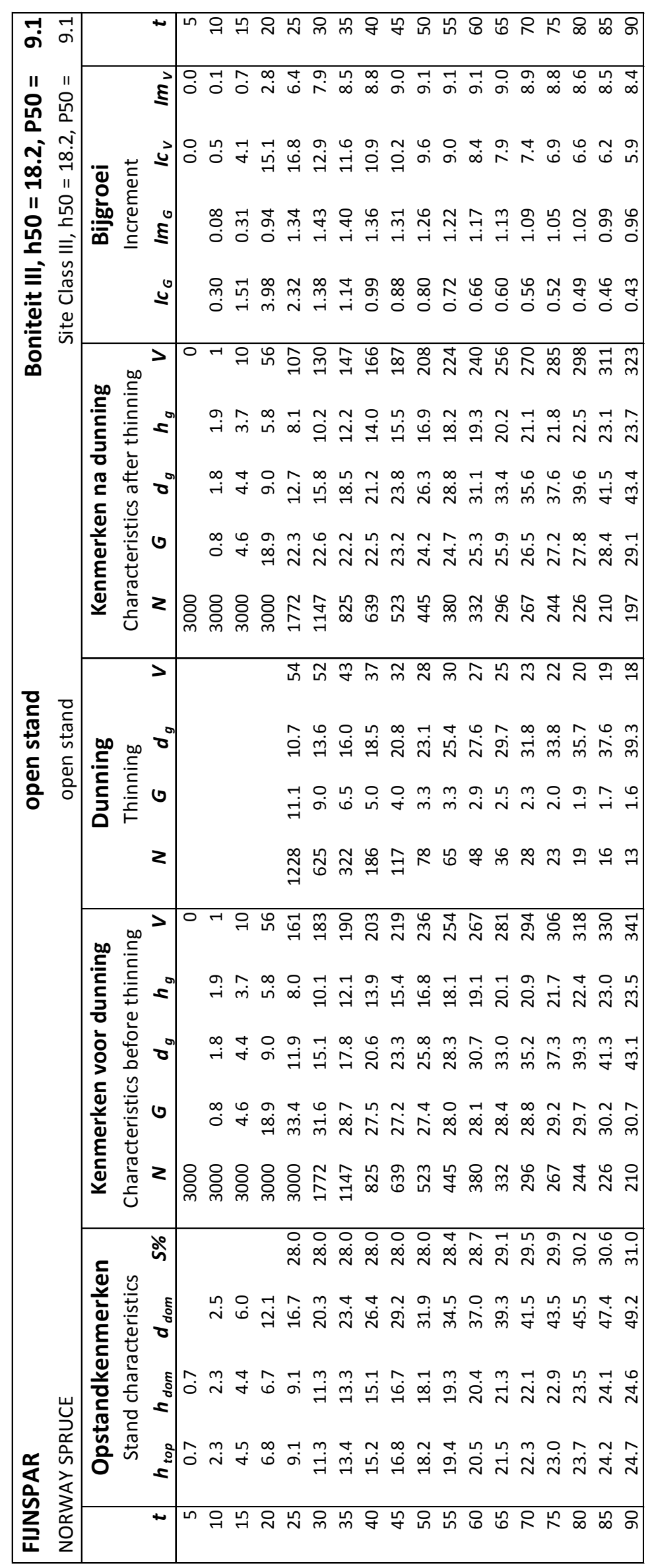




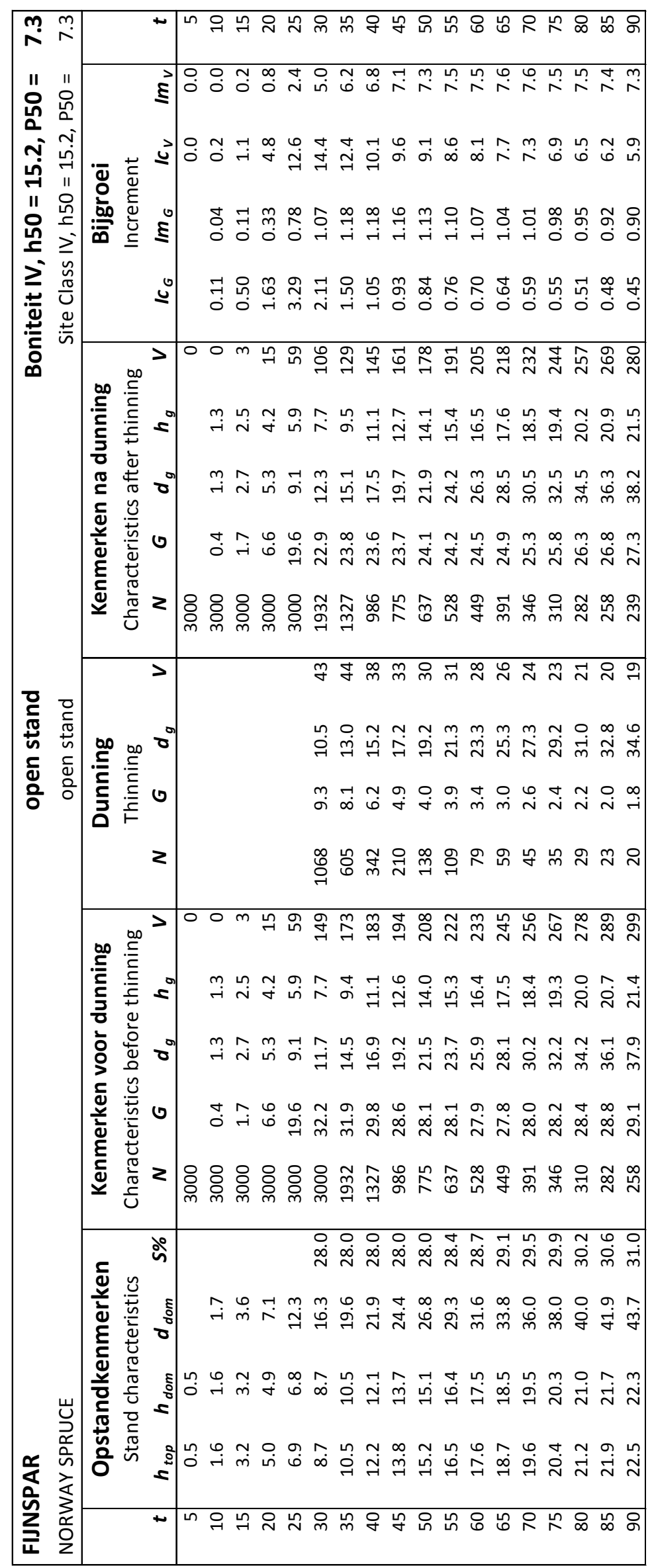




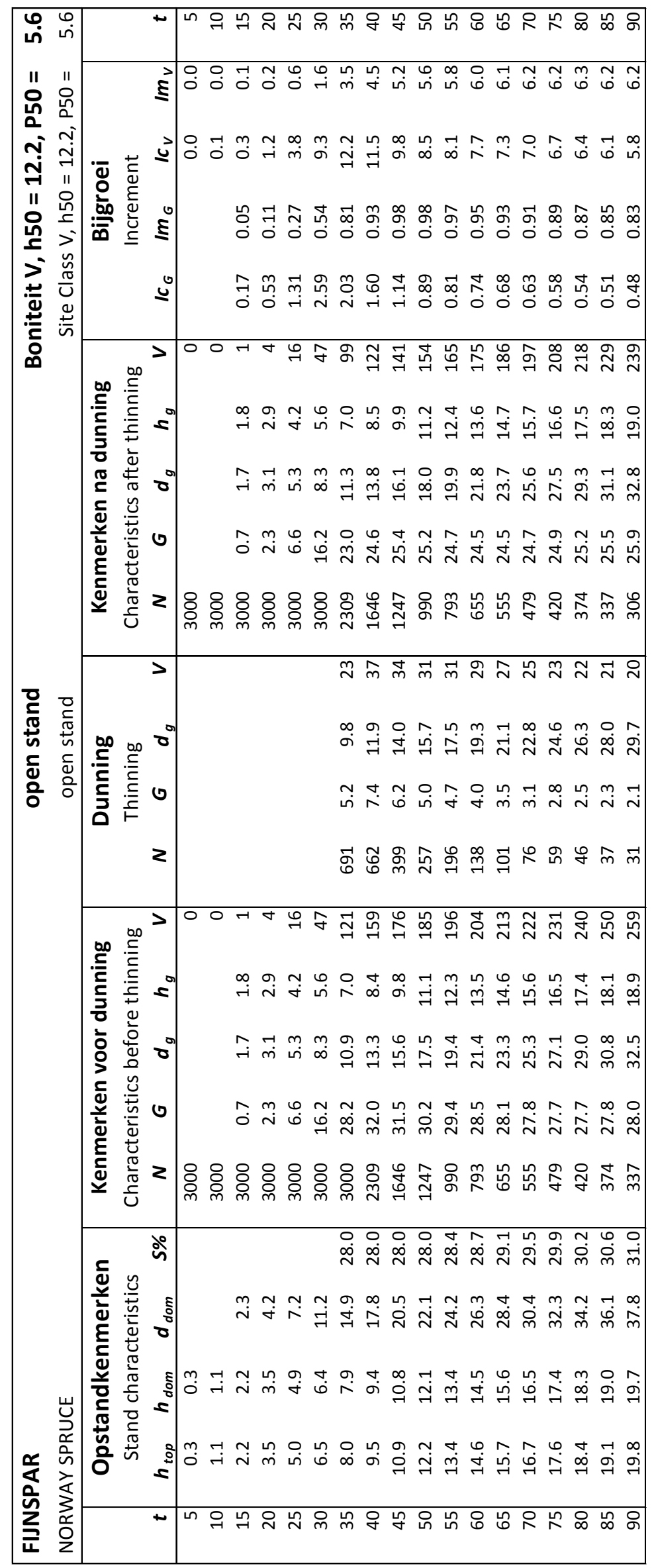

